\author{
Universidade de São Paulo \\ Escola de Engenharia de São Carlos \\ Departamento de Engenharia Elétrica e de Computação
}

ANDRÉ LUÍS DIAS

\title{
Análise de desempenho de redes de comunicação industrial em acionamentos de motores elétricos trifásicos
}

São Carlos

2014 



\section{ANDRÉ LUÍS DIAS}

\section{Análise de desempenho de redes de comunicação industrial em acionamentos de motores elétricos trifásicos}

Dissertação apresentada à Escola de Engenharia de São Carlos da Universidade de São Paulo, como parte dos requisitos para obtenção de título de Mestre em Ciências pelo Programa de Engenharia Elétrica

Área de Concentração: Sistemas Dinâmicos

Orientador: Prof. Dr. Dennis Brandão

Trata-se da versão corrigida da dissertação. A versão original se encontra disponível na EESC/USP que aloja o Programa de Pós-Graduação de Engenharia Elétrica

São Carlos

2014 
AUTORIZO A REPRODUÇÃO TOTAL OU PARCIAL DESTE TRABALHO, POR QUALQUER MEIO CONVENCIONAL OU ELETRO̊NICO, PARA FINS DE ESTUDO E PESQUISA, DESDE QUE CITADA A FONTE.

Dias, André Luís

Análise de desempenho de redes de comunicação industrial em acionamentos de motores elétricos trifásicos / André Luís Dias; orientador Dennis Brandão. São Carlos, 2014.

Dissertação (Mestrado) - Programa de Pós-Graduação em Engenharia Elétrica e Área de Concentração em Sistemas Dinâmicos -- Escola de Engenharia de São Carlos da Universidade de São Paulo, 2014.

1. Redes industriais. 2. Profibus DP. 3. Profinet. 4. Acionamentos elétricos. I. Título. 


\section{FOLHA DE JULGAMENTO}

\section{Candidato: Engenheiro ANDRÉ LUÍS DIAS.}

Título da disserfação: "Análise de desempenho de redes de comunicação industrial em acionamentos de motores elétricos trifásicos".

Data da defesa: 09/12/2014

\section{Comissäo Julgadora:}

Resultado:

Prof. Associado Dennis Brandão (Orientador) aprovado (Escola de Engenharia de São Carlos/EESC)

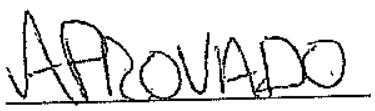

Prof. Associado Ivan Nunes da Silva (Escola de Engenharia de São Carlos/EESC)

Prof. Dr. Edilson Reis Rodrigues Kato

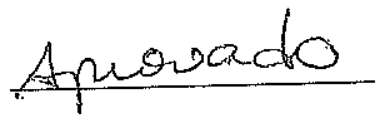

(Universidade Federal de São Carlos/UFSCar)

Coordenador do Programa de Pós-Graduação em Engenhá̛ria Elétrica: Prof. Associado Luís Fernando Costa Alberto

Presidente da Comissão de Pós-Graduação: Prof. Associado Paulo César Lima Segantine 



\section{Dedicatória}

Dedico este trabalho aos meus pais, Libertad e Paulo. Pelo amor, educação e carinho durante toda minha vida. O suporte de vocês foi essencial para minhas conquistas. Muito obrigado! 


\section{Agradecimentos}

À minha noiva Lívia, pelo incentivo e força antes mesmo do início deste trabalho até sua conclusão. Pelo companheirismo e paciência em todos os momentos.

Aos meus pais Libertad e Paulo, e minha irmã Sandra, por todo o carinho e incentivo que sempre me proporcionaram.

Ao amigo Guilherme Serpa Sestito, por sua contribuição no decorrer de todo este trabalho, pela parceria no desenvolvimento de pesquisas científicas, e pelas diversas conversas. Um exemplo de profissional capacitado, responsável e comprometido.

Ao amigo Raphael Eduardo Rowe Menuzzo, pelo suporte na implementação dos experimentos, e principalmente pela amizade desde os tempos de graduação.

Ao orientador e amigo Prof. Dr. Dennis Brandão, primeiramente pela oportunidade, paciência e confiança depositada em mim para fazer parte de sua equipe do Laboratório de Automação Industrial; e pela orientação do trabalho, concedendo liberdade na definição dos temas estudados e horários para realização das atividades.

À Escola de Engenharia de São Carlos e funcionários do Departamento de Engenharia Elétrica que ofereceram todo suporte, em especial a Marisa e Leonardo.

A Siemens Ltda, especialmente aos gerentes Olímpio Correa e Clayton Marcondes pelo incentivo para realização desta pesquisa e liberação para realização das atividades. E ao Eng. Denilson Pegaia, pelo suporte técnico oferecido.

A todos que de alguma maneira contribuíram para que este trabalho fosse possível, das mais simples até as maiores contribuições, todas foram importantes pra mim.

À Deus, por me dar sabedoria e saúde para alcançar meus objetivos profissionais e pessoais. 


\section{RESUMO}

DIAS, A. L. Análise de desempenho de redes de comunicação industrial em acionamentos de motores elétricos trifásicos. 2014. 123f. Dissertação (Mestrado em Engenharia Elétrica) - Escola de Engenharia de São Carlos, Universidade de São Paulo, São Carlos, 2014.

Este trabalho propõe analisar o desempenho de redes de comunicação industrial em aplicações de acionamentos de motores elétricos trifásicos. Compara-se o desempenho da tecnologia Profibus DP em relação à Profinet. $O$ desempenho é verificado a partir de especificações técnicas de ambos protocolos e experimentos práticos para coleta de dados e análise dos seguintes indicadores de desempenho: tempo de ciclo, jitter e ocupação de largura de banda. Adicionalmente, é verificado o desempenho de uma aplicação de controle de posição, utilizando estes protocolos na malha de controle, através do tempo de acomodação do sistema. Conclusões mostram que a rede Profibus DPV0 é a mais rápida quando possui menos dispositivos, porém o Profinet RT consegue manter baixos valores de tempo de ciclo mesmo com grande quantidade de dispositivos e possui maior determinismo na topologia em barramento. No que diz respeito ao controle de posição estudado, as tecnologias apresentam desempenho similar para tempo de acomodação do sistema, porém o Profinet IRT foi o mais determinístico.

Palavras Chaves: Redes industriais, Profibus DP, Profinet, Acionamentos elétricos 



\section{ABSTRACT}

DIAS, A. L. Performance analysis of industrial communication networks in electrical motors drives. 2014. 123f. Dissertation (Master's Degree) - Escola de Engenharia de São Carlos, Universidade de São Paulo, São Carlos, 2014.

This work proposes a performance analysis of industrial communication networks in applications of electric AC motor drives. It compares the performance of Profibus DP technology in relation to Profinet. Performance is verified from technical specifications of both protocols and practical experiments for data collection and analysis of the following performance indicators: cycle time, jitter and bandwidth occupation. Additionally, the performance of a motion control application is verified, by using these protocols in the loop control, through the settling time of the system. Conclusions show that Profibus DPV0 is faster when there is less devices in the network, but Profinet RT manages to maintain low values of cycle time even with large number of devices and has higher determinism when installed in line topology. Regarding the motion control application studied, the technologies have similar settling time for the system performance, but the Profinet IRT was more deterministic.

Keywords: Industrial networks, Profibus DP, Profinet, Electrical drives 



\section{Índice de Figuras}

Figura 1 - Partes de um motor elétrico trifásico ......................................... 23

Figura 2 - Desenvolvimento da partida direta. Adaptado de: SIEMENS LTDA (2003)

Figura 3 - Diagramas de partida direta convencional. Adaptado de: ABNT, 2011 25

Figura 4 - Diagramas de chave de partida reversora. Adaptado de: ABNT, 2011 27

Figura 5 - Princípio de funcionamento de soft starter. Adaptado de: SIEMENS LTDA (2003) 28

Figura 6 - Conjugado de partida e correntes de partida utilizando soft starters. Adaptado de: SIEMENS LTDA (2003) 29

Figura 7 - Diagramas de partida suave convencional. Adaptado de: ABNT, 2011

Figura 8 - Princípio de funcionamento de inversor de frequência. Adaptado de: FRANCHI (2008) 31

Figura 9 - Formas de onda em um inversor de frequência (a) Entrada do retificar (b) após filtro (c) aplicada aos enrolamentos do motor 31 Figura 10 - Gráficos da relação V/f e Torque em motores elétricos acionados por conversores de frequência 32

Figura 11 - Diagrama de partida direta: (a)Convencional (b)Inteligente. Adaptado de: ABNT, 2011 34

Figura 12 - Diagrama de partida suave: (a) Convencional (b) Inteligente. Adaptado de: ABNT, 2011 35

Figura 13 - Diagrama Inversor de Frequência: (a) Convencional (b) Inteligente 35

Figura 14 - Relação entre camadas da rede OSI e Profibus DP. Adaptado de PROFIBUS, 2010 42

Figura 15 - Modelo Mestre/Escravo utilizado no Profbus DP. Adaptadode PROFIBUS, 2010. 43

Figura 16 - Parâmetros na configuração da rede DPV0 via STEP7 45

Figura 17 - Parâmetros na configuração da rede DPV2 via STEP7 46 
Figura 18 - Configuração de uma rede Profibus DP para acionamento de

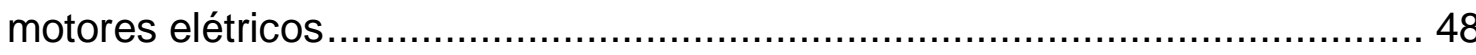

Figura 19 - Possíveis estruturas para Ethernet Real Time. Adaptado de: FELSER (2005) 51

Figura 20 - Base instalada de nós de protocolos RTE 2010-2015. Adaptado de: IMSResearch (2011) 53

Figura 21- Modelo de comunicação Profinet. Adaptado de : KLEINES et al. (2008) 55

Figura 22 - Configuração de uma rede Profibus DP para acionamento de motoes elétricos 56

Figura 23 - Velocidade de transmissão para aplicações de exigência de tempo

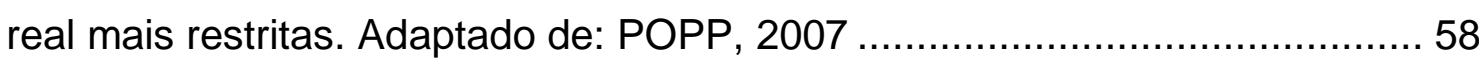

Figura 24 - Parâmetros na configuração da rede Profinet via STEP7 ............ 58 Figura 25 - Ciclo de comunicação Profinet. Adaptado de: Ferrari et al. (2007b)

Figura 26 - Exemplo de conector e cabo Tipo A Profinet. Adaptado de: POPP, 2007 60

Figura 27 - Topologia Profinet em estrela para acionamentos de motores elétricos 61

Figura 28 - Topologia Profinet em Barramento/Linha para acionamentos de motores elétricos 62 Figura 29 - Topologia em anel Profinet para acionamentos de motores elétricos 63

Figura 30 - Modelo apresentado por Ferrari et al. (2006) para medição do tempo de reação de evento e jitter .................................................. 68

Figura 31 - Curva de distribuição normal para tempo de ciclo ....................... 73

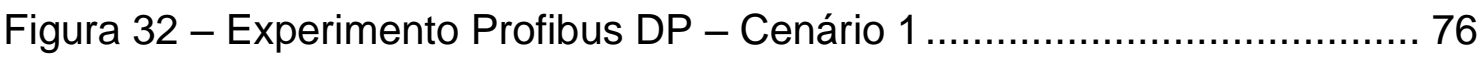

Figura 33 - Dados coletados pelo software Wireshark em conjunto com TAP Kunbus

Figura 34 - Utilização de estampa de tempo. Adaptado de: Depari et al. (2008) 79

Figura 35 - Experimento Profinet topologia estrela - Cenário 1 ....................79

Figura 36 - Experimento Profinet topologia barramento - Cenário 1 ............... 80

Figura 37 - Experimentos - Cenário 2 (a) Profibus DP (b) Profinet ................. 83 
Figura 38 - Mecanismo de coleta de dados para o controle de posição - Cenário

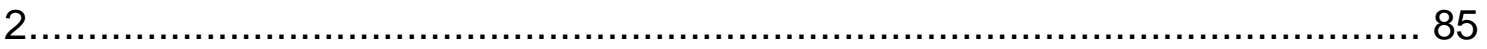

Figura 39 - Experimentos - Resultados do cenário 1 - DPV0 .......................... 86

Figura 40 - Experimentos - Resultados do cenário 1 - DPV0 com tempo de

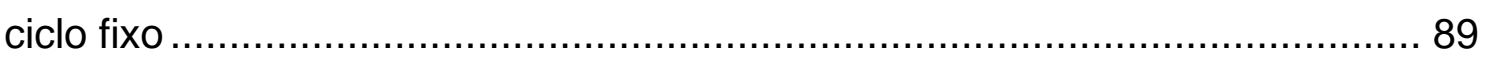

Figura 41 - Resultados do cenário 1 - Profinet RT topologia estrela................ 91

Figura 42 - Resultados do cenário 1 - Profinet RT topologia barramento ....... 94

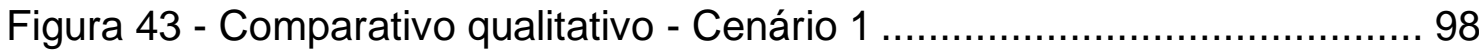

Figura 44 - Comparativo de tempo de acomodação para as tecnologias estudas

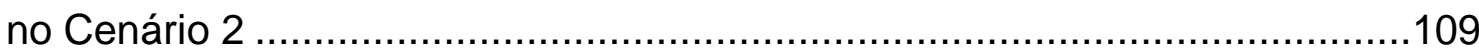




\section{Índice de Tabelas}

Tabela 1 - Componentes utilizados em partidas direta e reversora ................ 26

Tabela 2 - Componentes utilizados em partida suave ................................... 29

Tabela 3 - Comparação de dados fornecidos por partidas de motores

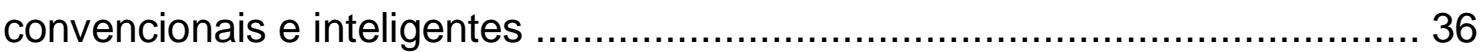

Tabela 4 - Distância entre nós utilizando meio físico elétrico (RS 485) de acordo com velocidades de transmissão....................................................... 47

Tabela 5 - Protocolos industriais baseados em Ethernet segundo IEC61784-2

Tabela 6 - Mercado mundial de protocolos industriais baseados em Ethernet por nível de hierarquia de rede ........................................................... 52

Tabela 7- Novos nós de protocolos industriais baseados em Ethernet........... 54 Tabela 8 - Comparação de especificações técnicas Profibus DP e Profinet para acionamentos de motores elétricos 64

Tabela 9 - Equipamentos utilizados para experimento Profibus DP - Cenário 1 75

Tabela 10 - Especificação das redes Profibus DP do Cenário 1 .................... 76

Tabela 11 - Adição de equipamentos nos experimentos do Cenário 1 ............ 77

Tabela 12 - Equipamentos utilizados para experimento Profinet - Cenário 1. 77

Tabela 13 - Especificação das redes Profinet do Cenário 1 ............................. 80

Tabela 14 - Equipamentos utilizados para Cenário 2 ................................... 81

Tabela 15 - Especificação das redes para Cenário 2 ................................... 82

Tabela 16 - Lista de equipamentos e parâmetros para acionamento do motor

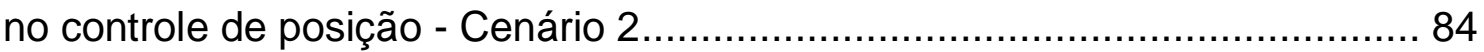

Tabela 17 - Tempo de ciclo e desvio da rede DPV0 - Cenário 1 ..................... 88

Tabela 18 - Tempo de ciclo e desvio da rede DPV0 com tempo de ciclo fixo Cenário 1 90

Tabela 19 - Jitter da rede DPV0 com tempo de ciclo fixo - Cenário 1 1............. 90 Tabela 20 - Tempo de ciclo médio - Cenário 1 - Profinet RT Topologia Estrela 92

Tabela 21 - Jitter da rede PNRT Topologia Estrela - Cenário 1 93 Tabela 22 - Tempo de Ciclo da rede PN RT Topologia Barramento/Linha Cenário 1 95 
Tabela 23 - Jitter da rede PN RT Topologia Barramento/Linha - Cenário 1..... 96 Tabela 24 - Extrapolação de quantidade de dispositivos na rede e tempo de ciclo 97

Tabela 25 - Gráficos de curva normal da tecnologia Profibus DPV0- Cenário 2 100

Tabela 26 - Tempo de acomodação, tempo de ciclo e desvio padrão para rede DPV0 - Cenário 2 101

Tabela 27 - Tempo de ciclo e desvio padrão do jitter para rede DPV2 - Cenário 2 . 102

Tabela 28 - Gráficos de curva normal da tecnologia Profibus DPV2- Cenário 2 103

Tabela 29 - Tempo de acomodação para rede DPV2 - Cenário 2 103

Tabela 30 - Tempo de ciclo e desvio padrão do jitter para rede PN RT - Cenário 2 . 104

Tabela 31 - Gráficos de curva normal da tecnologia Profinet RT - Cenário 2.105 Tabela 32 - Tempo de acomodação para rede PN RT - Cenário 2 105

Tabela 33 - Tempo de ciclo e desvio padrão do jitter para rede PN IRT Cenário 2 106

Tabela 34 - Gráficos de curva normal da tecnologia Profinet IRT - Cenário 2106 Tabela 35 - Tempo de acomodação para rede PN IRT 107 



\section{Sumário}

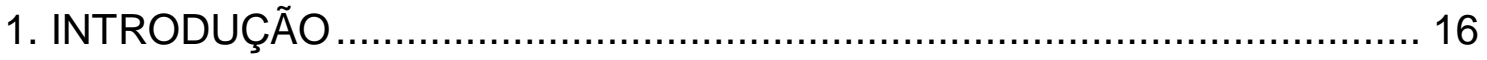

1.1. Objetivos e trabalhos publicados .................................................... 17

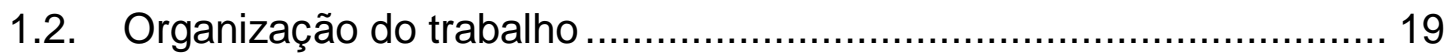

2. ACIONAMENTOS DE MOTORES ELÉTRICOS AC ................................. 22

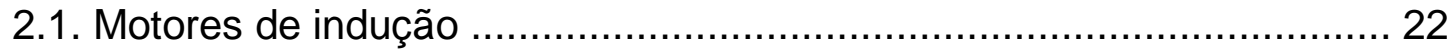

2.2. Métodos de acionamento de motores trifásicos .................................. 23

2.3. Integração de acionamentos elétricos ao sistema de automação .......... 33

3. REDES DE COMUNICAÇÃO INDUSTRIAL............................................ 40

3.1. Conceitos Básicos sobre o protocolo Profibus DP ……….................. 40

3.2. Utilização de Ethernet em ambientes industriais .................................. 48

3.3. Conceitos Básicos sobre o protocolo Profinet ...................................... 54

3.4. Considerações finais sobre conceitos dos protocolos ........................... 63

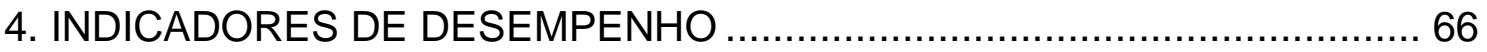

4.1. Indicadores de desempenho da norma IEC 61784-2 …......................66

4.2. Pesquisas correlatas sobre indicadores de desempenho na literatura .. 67

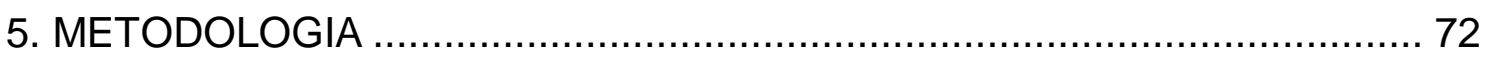

5.1. Experimentos para coleta de dados ................................................. 74

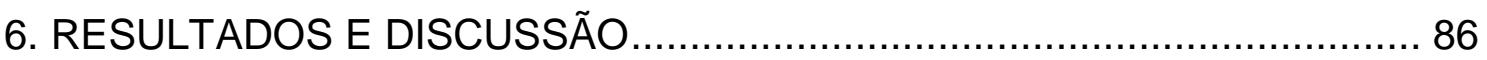

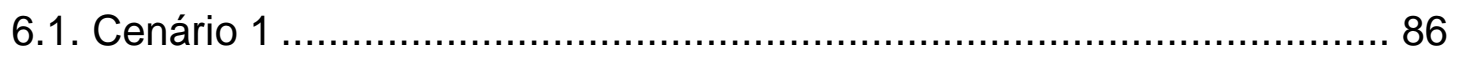

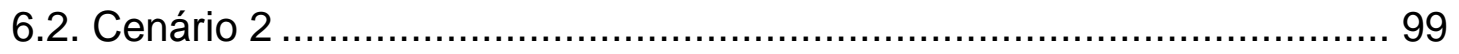

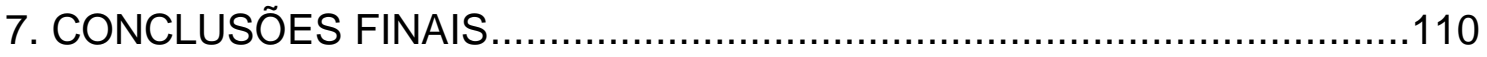

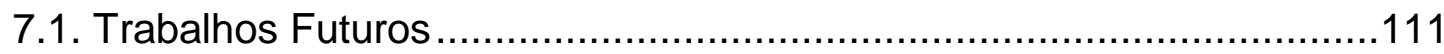

8. REFERÊNCIAS BIBLIOGRÁFICAS .....................................................114

APÊNDICE A - CONFIGURAÇÃO DO CLP VIA STEP7 ............................118 


\section{INTRODUÇÃO}

Motores elétricos trifásicos $A C$ são os responsáveis pela transmissão de movimento em máquinas dos mais diversos segmentos de mercado. Atualmente é o tipo de motor mais utilizado em todo o mundo devido a sua simplicidade, robustez de construção e operação; e adicionalmente por vantagens econômicas para compra e manutenção (AGUIAR, 2012). De acordo com a funcionalidade requerida pela carga a ser acionada o motor é dimensionado e são disponíveis diversos métodos para seu acionamento.

A necessidade de integração de processos industriais ao sistema de automação para gerenciamento dos motores elétricos, gerou a necessidade de utilizar redes de comunicação para troca desse grande volume de dados. Assim, ocorreu desenvolvimento significativo nos equipamentos de comunicação de fábrica, que passou de ponto-a-ponto (sinais digitais e analógicos), para uma estrutura de redes de comunicação industrial, que oferecem capacidade para operar em aplicações de tempo real possuindo determinismo compatível.

Um painel de acionamentos de motores elétricos com esta característica é comumente chamado de Centro de Controle de Motores Inteligentes (CCMi). Este possui diversas funcionalidades que garantem ganhos aos usuários em relação a engenharia, instalação, operação e manutenção de suas plantas, como redução de custos de cabeamento, redução do tempo de parada da máquina, entre outros.

As tecnologias de rede de automação industrial utilizadas foram se desenvolvendo, e o protocolo Profibus DP surgiu como destaque, possuindo maior participação atual no mercado (YU et al., 2012). Porém, em aplicações de acionamentos de motores elétricos, possui restrições de topologias e apresentam certa sensibilidade a qualidade de suas instalações o que pode influenciar seu desempenho.

Neste contexto as redes Ethernet, geralmente utilizadas em escritórios, foram ganhando destaque em ambientes industriais devido a sua robustez, baixo custo e alta taxa de comunicação. As características de tempo real e determinismo, originalmente inexistentes no padrão Ethernet original, puderam ser alcançadas com o desenvolvimento de equipamentos adequados (switches, cabos conectores, dispositivos inteligentes, etc) e protocolos que operam em 
modo full-duplex. Assim, surgiram as redes Real Time Ethernet (RTE) definidas pela norma IEC 61784-2, onde o Profinet se destaca por ser um dos protocolos mais promissores para os próximos anos segundo Ferrari (2007a).

\subsection{Objetivos e trabalhos publicados}

O trabalho tem por objetivo dissertar sobre a aplicação do protocolo Profibus DP e Profinet na integração de motores elétricos trifásicos ao sistema de automação, verificando seu desempenho. Assim, o trabalho contribui para comunidade científica explorando a utilização e desempenho das tecnologias estudadas. Também suporta o usuário final da tecnologia na escolha da rede mais apropriada para atendimento de suas necessidades e utilização de funcionalidades.

Adicionalmente é verificado se as redes RTE (Profinet) são capazes de substituir as redes fieldbus (Profibus DP) em sua integridade, verificando limites de operação e requisitos necessários para esta mudança de tecnologia

Para este fim, são utilizados alguns indicadores para verificar o desempenho das redes, são eles:

- tempo de ciclo: tempo necessário para troca de dados entre os dispositivos em um ciclo da rede;

- jitter: definido como variações de pequenas durações não acumulativas nos instantes significativos de um sinal digital da sua posição ideal no tempo (INTERNATIONAL TELECOMMUNICATION UNION, 1993);

- ocupação de largura de banda: relação entre a quantidade de dados transmitidos e a largura de banda disponível.

Além disso, utiliza-se o indicador tempo de acomodação em um sistema de controle de posição, verificando o desempenho no ponto de vista da aplicação.

Dois cenários são criados, o primeiro em condições voltadas a indústrias de processo onde há necessidade de grande quantidade de acionamentos de motores elétricos em um CCMi e o segundo voltado à aplicação de indústrias de manufatura, com utilização de uma aplicação de motion control simples, sem sincronismo de eixos. 
A metodologia desenvolvida também contribui para a comunidade científica como metodologia de engenharia para análise de redes de comunicação industrial.

Em relação ao tema proposto foram publicados os seguintes artigos:

- DIAS, A. L. e BRANDÃO, D. "Funcionalidades da Integração de Acionamentos Elétricos ao Sistema de Automação" In: Simpósio Brasileiro de Automação Inteligente (SBAI), 2011.

- DIAS, A. L. e BRANDÃO, D. "Funcionalidades da integração de ccms inteligentes ao sistema de automação através de redes de comunicação industrial" In: Revista C\&l Controle \& Instrumentação Ano 14 - n. 172 - 2011

- DIAS, A. L., SESTito, G. S., TURCATO, A. C., SOUZA, P. H. T. O. e BRANDÃO, D. "Um estudo sobre a tecnologia Profinet" In: I Congresso de Automação e Inovação Tecnológica Sucroenergética, Sertãozinho, 2013.

- SEstito, G. S., DiAS, A. L., TURCATO, A. C., SOUZA, P. H. T. O. e BRANDÃO, D. "Análise comparativa de redes Profibus e

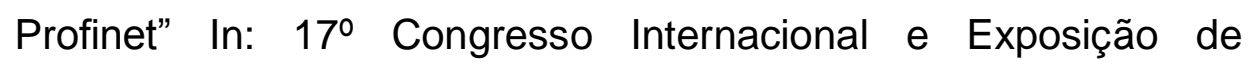
Automação, Sistemas E Instrumentação, 2013, São Paulo. Brazil Automation - ISA, 2013.

- DIAS, A. L ., SESTITO, G. S., MOSSIN, E. A., FERNANDES, R. e BRANDÃO, D. "Análise Comparativa de Desempenho de Redes Profibus DP e Profinet". In: XX Congresso Brasileiro de Automática (CBA), Belo Horizonte, 2014.

Os artigos "Funcionalidades da Integração de Acionamentos Elétricos ao Sistema de Automação" no SBAI 2011 (Simpósio Brasileiro de Automação Inteligente 2011) e "Funcionalidades da integração de ccms inteligentes ao sistema de automação através de redes de comunicação industrial" mostram a importância da utilização de CCMs Inteligentes em geral e um estudo sobre o aproveitamento desta tecnologia no segmento de açúcar e etanol. Verificou-se que este tipo de indústria deve usufruir mais das funcionalidades oferecidas pelo CCMi, e para isso deve ser investido em qualificação dos usuários e em 
horas de engenharia para disponibilizar as informações no nível supervisório para operação e manutenção da planta.

No artigo intitulado "Um estudo sobre a tecnologia Profinet", publicado no I Congresso de Automação e Inovação Tecnológica Sucroenergética 2013, apresentam-se as atuais linhas de pesquisa sobre a tecnologia Profinet categorizadas através de temas.

O trabalho "Análise comparativa de redes Profibus e Profinet" apresentado no congresso ISA Show 2013, de maneira similar ao trabalho atual, analisa o desempenho de redes Profibus DP e Profinet, porém considerando uma rede pequena, isto é, com um único dispositivo (escravo ou IO-Device) além do controlador (mestre classe 1 ou IO-Controller). Este trabalho conclui que Profinet apresentou significativa vantagem em relação ao protocolo Profibus em relação a ocupação de banda da rede, e adicionalmente apresentou importantes contribuições em relação a metodologia utilizada na coleta de dados.

O artigo "Análise Comparativa de Desempenho de Redes Profibus DP e Profinet" também se baseia na dissertação apresentada, comparando as redes com maior quantidade de dispositivos em relação ao trabalho anterior, porém limitado a versão DPV0 no Profibus DP e RT do Profinet.

Por fim, o artigo indicado abaixo não tem como tema principal o foco dessa dissertação. Todavia, foi elaborado em paralelo ao desenvolvimento deste trabalho .

- $\quad$ SESTITO, G. S. ; MOSSIN, E. A. ; DIAS, A. L. ; SOUZA, P. H. T. O. ; BRANDAO, D. Artificial Neural Networks and Signal Clipping for PROFIBUS DP diagnostics. In: INDIN 2014 - IEEE International Conference on Industrial Informatics, 2014, Porto Alegre. Proceedings of the 12th IEEE International Conference on Industrial Informatics. New York: IEEE, 2014. v. 1.

\subsection{Organização do trabalho}

O trabalho atual é composto pelos seguintes capítulos:

- Capítulo 2 - apresenta a utilização de motores elétricos de indução e seus principais métodos de acionamento. Adicionalmente, as funcionalidades da 
integração desses acionamentos com sistema de automação são apresentadas e como essa infraestrutura pode ser usufruída pelos usuários.

- Capítulo 3 - disserta-se sobre conceitos dos protocolos Profibus DP e Profinet, importantes para o entendimento da proposta de trabalho, focando tipos de dispositivos utilizados, topologias, temporização na comunicação e diagnósticos;

- Capítulo 4 - introduz conceitos de indicadores de desempenho e trabalhos correlatos nas principais bases de dados de pesquisa científica da área;

- Capítulo 5 - se expõe a metodologia utilizada para análise de desempenho entre as redes Profibus DP e Profinet, explicitando experimentos práticos para coleta de dados;

- Capítulo 6 - apresenta resultados, discussão e conclusões dos experimentos realizados;

- Capítulo 7 - apresenta conclusões finais da dissertação;

- Capítulo 8 - mostra as referências bibliográficas utilizadas;

- Apêndice A - configuração do controlador lógico programável utilizado nos experimentos, via software STEP7. 


\section{ACIONAMENTOS DE MOTORES ELÉTRICOS AC}

Neste capítulo, são apresentadas informações a respeito da utilização de motores elétricos trifásicos de indução e seus principais métodos de acionamento com detalhamento de componentes utilizados, vantagens e desvantagens.

Posteriormente se explana sobre integração desses acionamentos com sistema de automação e como essa infraestrutura pode ser usufruída pelos usuários.

\subsection{Motores de indução}

O motor de indução, também conhecido como motor elétrico de corrente alternada (AC) possui grande destaque no mercado industrial. É o tipo de motor mais utilizado e difundido nas mais variadas aplicações em todo 0 mundo, devido ao princípio de alimentação através de energia elétrica em corrente alternada. Ele alcançou e manteve essa posição pois trata-se de um motor robusto em termos de construção e operação, além de proporcionar consideráveis vantagens econômicas em relação a aquisição e manutenção (AGUIAR, 2012).

Outros tipos de motores elétricos, como os motores de corrente contínua (CC) que possuem relativa complexidade construtiva, não serão abordados no escopo deste trabalho.

A Figura 1 mostra os principais componentes de um motor trifásico de indução AC, mais detalhes sobre princípio de funcionamento podem ser encontrados em Aguiar (2012). 


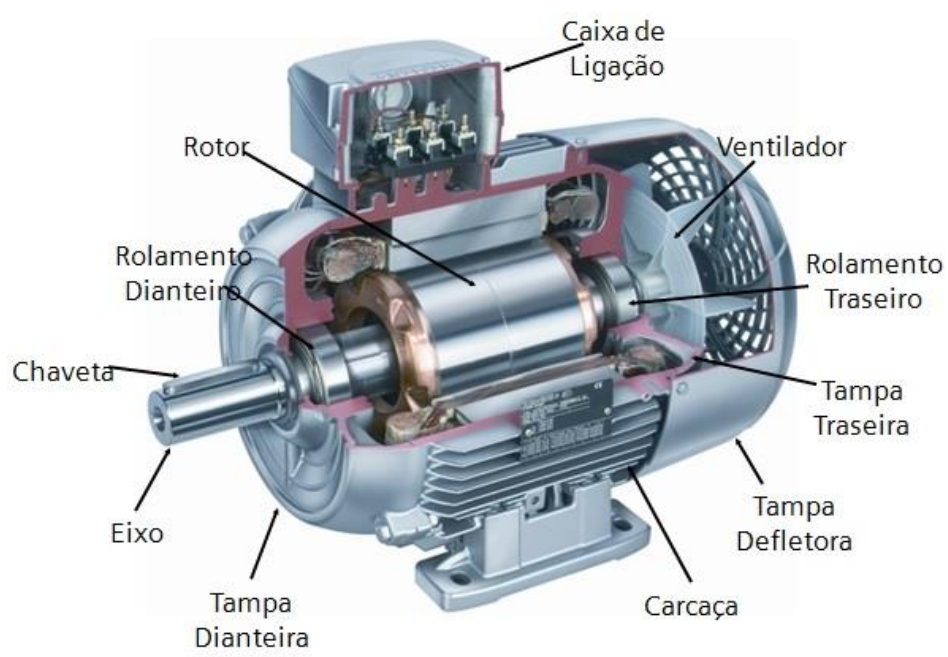

Figura 1 - Partes de um motor elétrico trifásico

Segundo o relatório do Ministério de Minas e Energia sobre balanço energético nacional de $2014,40,7 \%$ do total de energia elétrica produzida no Brasil é consumida pelo setor industrial (EMPRESA DE PESQUISA ENERGÉTICA, 2014). Em uma indústria de processo, por exemplo, o consumo de energia elétrica representa o segundo maior custo, sendo inferior apenas da matéria-prima. Aproximadamente $64 \%$ do valor de eletricidade alimentam motores elétricos (SHAIKH, 2006). Desta maneira se verifica a importância de utilizar corretamente estes equipamentos, tendo a possibilidade de gerenciar todo seu ciclo de vida, desde o projeto, passando pela operação e manutenção.

\subsection{Métodos de acionamento de motores trifásicos}

Existem diversos métodos de partida para os motores elétricos trifásicos, segue abaixo os principais critérios para se considerar na escolha do mais apropriado para cada aplicação:

- Características da máquina a ser acionada (CARGA): deve-se atentar para o momento de inércia e torque resistente da carga, que implica no valor de corrente e tempo de partida;

- Circunstâncias da disponibilidade de potência de alimentação: deve limitar as perturbações da rede elétrica, principalmente na partida dos motores, por exemplo: quedas de tensão, sobrecarga do sistema de alimentação (geradores, transformadores, redes UPS (uninterruptible power supply - fonte de alimentação ininterrupta), etc); 
- Confiabilidade do serviço: verificar a necessidade de controle de velocidade, posição ou torque, inversão de rotação, entre outros;

- Distância da fonte de alimentação, devido a queda de tensão em regime normal de operação.

Em seguida se apresenta a descrição dos principais métodos de partida de motores elétricos, focando principais típicos de circuitos de potência e suas principais vantagens e limitações.

\subsubsection{Partida direta}

O método de partida de motor conhecido como partida direta, se baseia alimentando-se o motor com sua tensão nominal, assim saindo de zero a sua tensão de operação em um intervalo de tempo muito pequeno.

Ao acionar o motor desta maneira, solicita-se da fonte de alimentação corrente elétrica de 6 a 7 vezes o valor da corrente nominal do motor. Isto pode causar queda de tensão na alimentação, seja para a rede ou para outros consumidores da mesma instalação e também oferece um alto torque de partida, normalmente maior do que o necessário para maior parte das aplicações (GOH; LOOI; KOK, 2003). Por outro lado, o motor elétrico aplica um alto torque no eixo do motor que está acionando, fazendo com que a partida seja bastante robusta.

Dependendo da carga a ser acionada, esse pico de corrente pode se estender por mais ou menos tempo durante a partida, assim, quanto maior 0 valor do conjugado resistente da carga, maior será o tempo de partida, mantendo-se a corrente elétrica que flui no motor elevada.

A Figura 2 mostra esta relação entre corrente e conjugado do motor, em relação ao conjugado resistente da carga a ser acionada. 


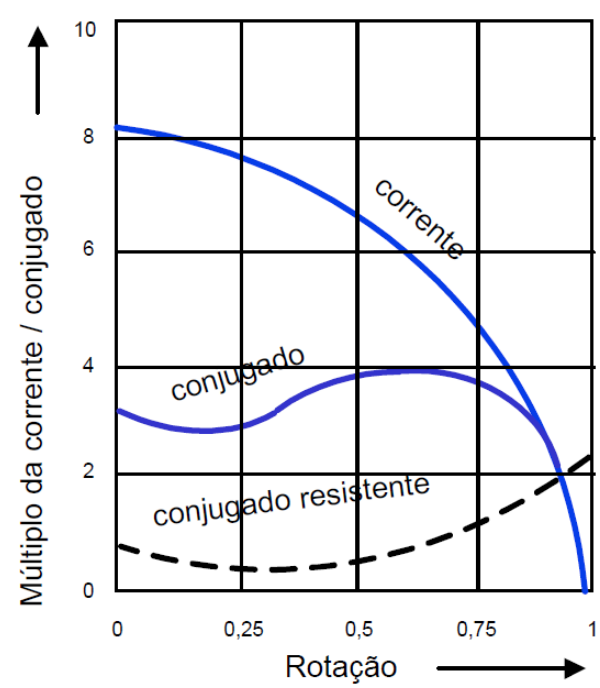

Figura 2 - Desenvolvimento da partida direta. Adaptado de: SIEMENS LTDA (2003)

Existem diversos típicos de partidas diretas de motores elétricos, os mais utilizados estão ilustrados através de seus circuitos de potência na Figura 3.

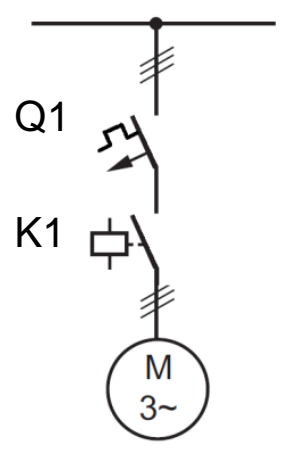

(a)

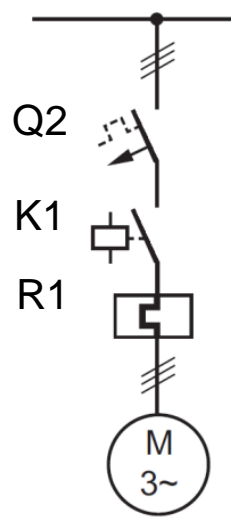

(b)

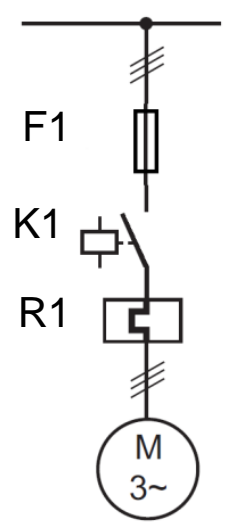

(c)

Figura 3 - Diagramas de partida direta convencional. Adaptado de: ABNT, 2011

A norma NBR-5410 estabelece como limite para partida direta a potência de $5 \mathrm{cv}$ caso a alimentação seja fornecida por concessionária de energia que não defina limites. A Tabela 1 mostra os equipamentos utilizados. 
Tabela 1 - Componentes utilizados em partidas direta e reversora

\begin{tabular}{|c|l|l|l|}
\hline $\begin{array}{c}\text { Referência } \\
\text { K1 }\end{array}$ & Descrição & Tipo de Componente & Norma Técnica \\
\hline Q1 & Disjuntor Motor & $\begin{array}{l}\text { Proteção (Curto-circuito) } \\
\text { Proteção (Sobrecarga) }\end{array}$ & NBR EC 60947-4 \\
\hline Q2 & $\begin{array}{l}\text { Disjuntor Motor } \\
\text { (magnético) }\end{array}$ & Proteção (Curto-circuito) & NBR IEC 60947-2 \\
\hline F1 & $\begin{array}{l}\text { Fusível Retardado } \\
\text { (Categoria gG) }\end{array}$ & Proteção (Curto-circuito) & NBR IEC 60269-2 \\
\hline R1 & Relé de sobrecarga & Proteção (Sobrecarga) & NBR IEC 60947-2 \\
\hline
\end{tabular}

Observações:

1. O disjuntor motor também realiza função de seccionamento do circuito elétrico

2. O fusível retardado apesar de possuir função de proteção contra sobrecarga, é utilizado na combinação de partida apenas em falhas de curto-circuito.

Este tipo de partida se aplica a máquinas com qualquer tipo de carga, que permitam suportar o conjugado (torque) de aceleração, disponibilidade de potência da fonte de alimentação e que exijam confiabilidade de serviço pela composição e comando simples (SIEMENS LTDA, 2003).

Vantagens de sua utilização são:

- simplicidade e fácil instalação: são utilizados componentes simples

- dimensões compactas: a montagem de uma partida direta ocupa pouco espaço no painel elétrico quando comparada a outros tipos de partida - robustez e confiabilidade: por seus componentes serem eletromecânicos (contator), a probabilidade de falha é muito baixa;

- baixo custo: componentes de baixo valor quando comparados a outros tipos de acionamentos.

Desvantagens de sua utilização:

- corrente de partida elevada: a corrente de partida em uma partida direta chega a valores de 6 a 7 vezes a corrente nominal do motor; - alto toque de partida resultando em solavancos, podendo haver danos a mecânica das máquinas que estão acopladas ao eixo do motor. 
A partida direta é a forma mais simples de partir um motor elétrico. Deve ser usada sempre que possível, em aplicações onde o motor possui baixa potência, a carga não necessita de aceleração progressiva e o conjugado de partida seja elevado (FRANCHI, 2008).

\subsubsection{Chave de partida reversora}

Para chaves de partida reversora, as mesmas considerações apresentadas para partida direta devem ser consideradas, porém adicionalmente para este método de partida é adicionado um contator no circuito de potência, responsável pela inversão do sentido de rotação do motor. Os contatores são intertravados mecanicamente e/ou eletricamente para evitar que sejam acionados no mesmo instante, provocando curto-circuito. Estão ilustrados na Figura 4 os circuitos de potência mais utilizados. A Tabela 1 mostra os equipamentos que os compõem.

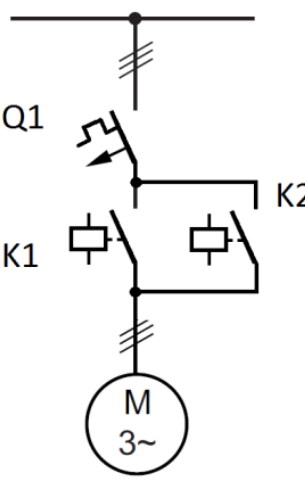

(a)

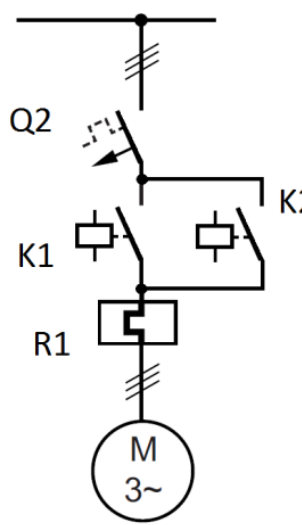

(b)

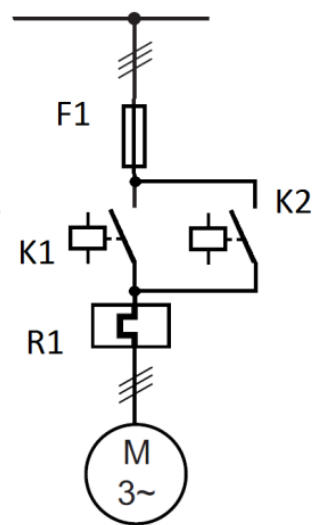

(c)

Figura 4 - Diagramas de chave de partida reversora. Adaptado de: ABNT, 2011

\subsubsection{Partida Suave (Soft Starter)}

Para as cargas acopladas em motores elétricos que exijam acionamentos suaves, principalmente em motores de grande porte emprega-se atualmente a partida suave com eletrônica de potência, ou conhecida como soft starter. Trata-se de um dispositivo de manobra, adequado para partida e parada suave de motores trifásicos, onde deseja-se eliminar os altos conjugados de aceleração do motor e picos de corrente na partida 
(SOLVESON; MIRAFZAL; DEMERDASH, 2006), ou seja, ela se adequa onde se apresentam as desvantagens da partida direta.

A partida de motores utilizando soft starters se baseia na aplicação de um valor de tensão de partida reduzido aos enrolamentos do motor, através do controle do ângulo da fase da tensão de alimentação, e realizando uma rampa de tensão e/ou uma rampa de corrente, que pode incluir aceleração controlada, até a tensão plena de acordo com parâmetros pré-configurados (SOLVESON; MIRAFZAL; DEMERDASH, 2006 e ASSOCIAÇÃO BRASILEIRA DE NORMAS TÉCNICAS, 2011). O acionamento através do controle do ângulo de fase é realizado normalmente por um SCR (silicon-controlled rectifiers) comandada por placa de controle embarcada no equipamento.

Com esse procedimento, tem-se possibilidade de partir do estado de repouso e chegar ao de rotação nominal ("Aceleração" na Figura 5), através do controle da aceleração, cuja variação atende plenamente a própria curva da carga. Também é possível realizar a parada suave da carga ("Desaceleração" na Figura 5), principalmente utilizada em bombas hidráulicas, evitando 0 fenômeno chamado de golpe de aríete. A Figura 5 mostra seu princípio de funcionamento.
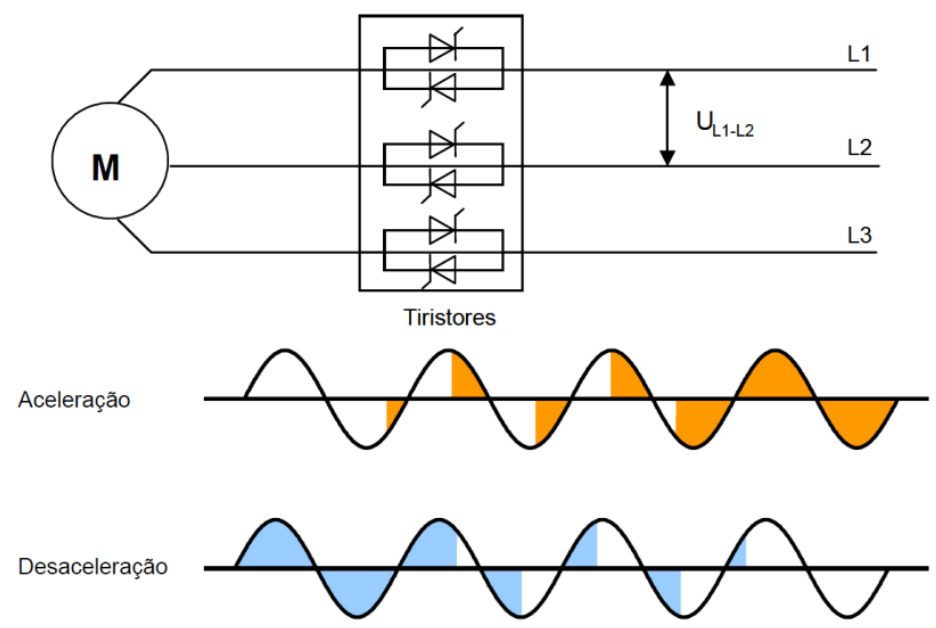

Figura 5 - Princípio de funcionamento de soft starter. Adaptado de: SIEMENS LTDA (2003)

Na Figura 6, verifica-se que devido a redução da tensão de partida, o conjugado de partida também diminui, resultando em um conjugado de aceleração menor quando comparada a partida direta e corrente de partida também menor. Observa-se que durante a partida do motor, deve ser aplicado 
um valor de tensão suficiente para que o rotor gere um conjugado de partida maior do que o conjugado resistente da carga.
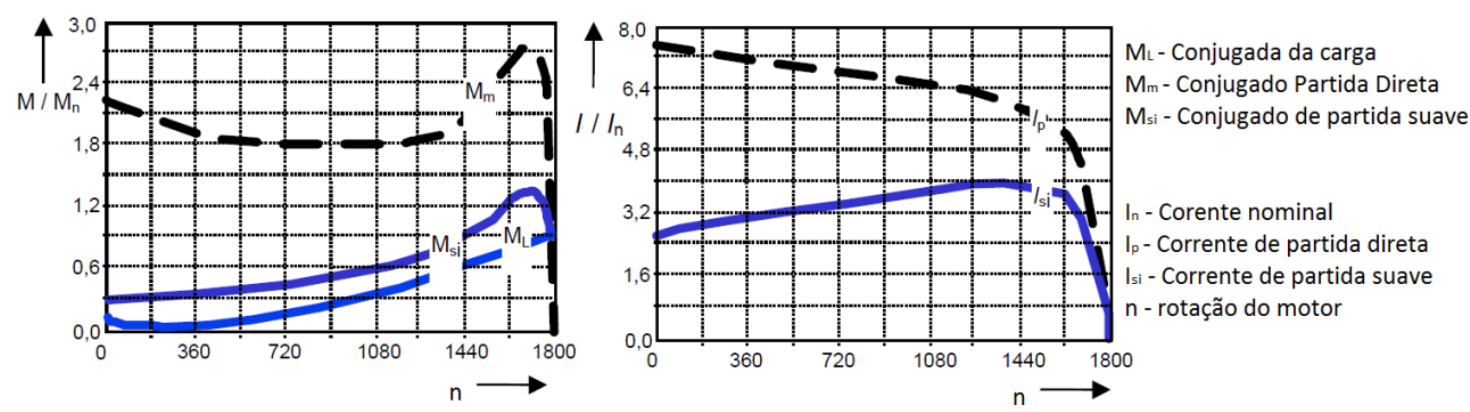

Figura 6 - Conjugado de partida e correntes de partida utilizando soft starters. Adaptado de: SIEMENS LTDA (2003)

A Figura 7 mostra os diagramas unifilares de partida suave mais utilizados, e a

Tabela 2 mostra os equipamentos utilizados.

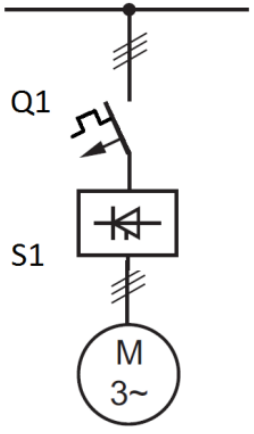

(a)

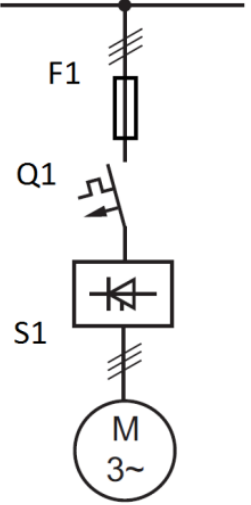

(b)

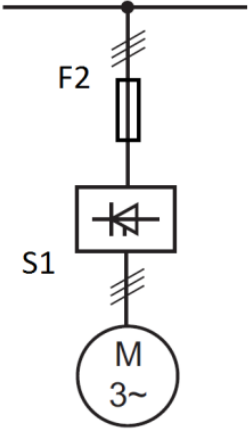

(c)

Figura 7 - Diagramas de partida suave convencional. Adaptado de: ABNT, 2011

Tabela 2 - Componentes utilizados em partida suave

\begin{tabular}{|c|l|l|l|}
\hline Referência & Descrição & Tipo de Componente & Norma Técnica \\
\hline S1 & Soft Starter & $\begin{array}{l}\text { Manobra } \\
\text { Proteção (sobrecarga) } \\
\text { Outras proteções }\end{array}$ & NBR IEC 60947-4-2 \\
\hline Q1 & Disjuntor Motor & Proteção (Curto-circuito) & NBR IEC 60947-2 \\
\hline F1 & $\begin{array}{l}\text { Fusível Ultra-rápido } \\
\text { (Categoria aR) }\end{array}$ & $\begin{array}{l}\text { Proteção (Curto-circuito) para } \\
\text { soft starter }\end{array}$ & NBR IEC 60269-2 \\
\hline F2 & $\begin{array}{l}\text { Fusível Combinado } \\
\text { (Categoria gR) }\end{array}$ & $\begin{array}{l}\text { Proteção (Curto-circuito) para } \\
\text { soft starter e motor }\end{array}$ & NBR IEC 60269-2 \\
\hline \multicolumn{3}{|l}{} \\
\multicolumn{2}{|l}{}
\end{tabular}


Vantagens da utilização de partidas suaves:

- simplicidade e fácil instalação: são utilizados componentes de baixa complexidade;

- permite parametrização da partida, permitindo sua adequação a necessidade da carga a ser acionada, assim evita-se solavancos exigindo menos do sistema mecânico e evitam grandes picos de corrente na partida, exigindo menos do sistema elétrico;

- geração de harmônicas na rede elétrica desprezível e dissipação de energia reduzida, quando comparados a conversores de frequência.

Limitações e necessidades de sua utilização:

- utilização de fusíveis ultrarrápidos e combinados para maior proteção;

- devido a tensão de partida reduzida, o torque de partida do motor também fica reduzido;

- não possuem funcionalidade de controle de velocidade e/ou posição.

\subsubsection{Partida por inversor de frequência}

O método mais eficiente de controle de velocidade de motores de indução trifásicos, com menos perdas no dispositivo responsável pela variação da velocidade, consiste na variação da frequência da fonte alimentadora através de conversores de frequência, também conhecidos como inversores de frequência. Neste método de acionamento o motor pode ser controlado de modo a prover um ajuste contínuo de velocidade e conjugado com relação a carga mecânica (FRANCHI, 2008).

Podemos dividir seu funcionamento em três estágios, como mostra a Figura 8. Inicialmente, a corrente alternada que oscila na frequência nominal da rede é transformada em corrente contínua pelo bloco "Retificador" e posteriormente pelo "Filtro". Normalmente o bloco "Retificador" é constituído por ponte de diodos e o bloco "Filtro", é constituído por banco de capacitores.

No bloco "Inversor", constituído por ponte de IGBTs (Insulated Gate Bipolar Transistor), é alimentado pela tensão contínua, e através de um circuito de comando chaveia a potência para o motor de maneira a obter um sistema de tensão alternada em que as frequências estão defasadas em 120 graus. Assim, o princípio de funcionamento se baseia em uma tensão contínua no 
circuito intermediário, transformando em tensão alternada para acionar um motor trifásico (FRANCHI, 2008).

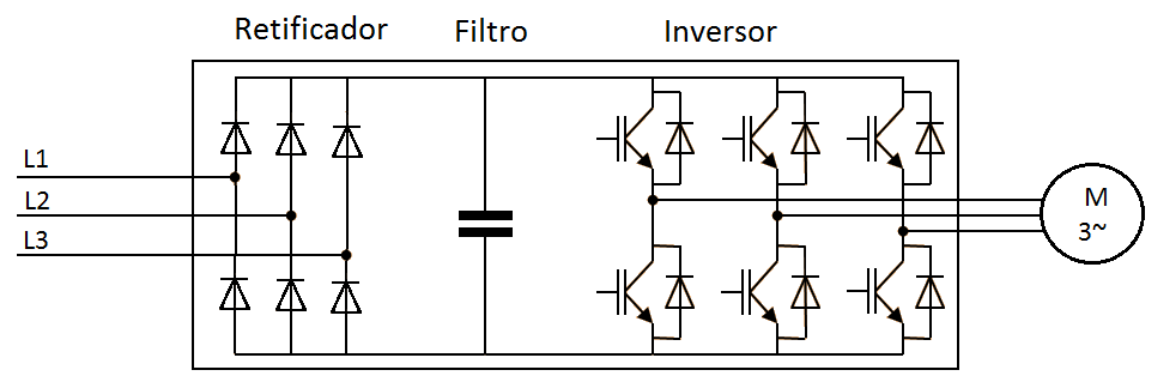

Figura 8 - Princípio de funcionamento de inversor de frequência. Adaptado de: FRANCHI (2008)

O método de modulação mais utilizado que transforma a corrente contínua em corrente alternada aplicada aos enrolamentos do motor é conhecido como PWM (Pulse Width Modulation).

A Figura 9 mostra exemplos de curvas de tensão nas diversas etapas de um acionamento com conversor de frequência.

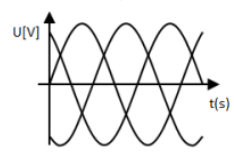

(a)

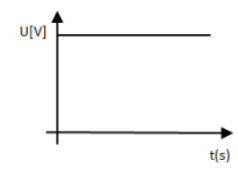

(b)

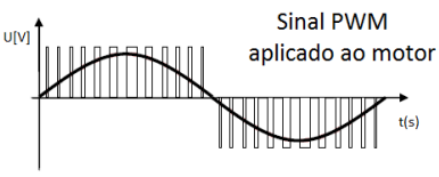

(c)

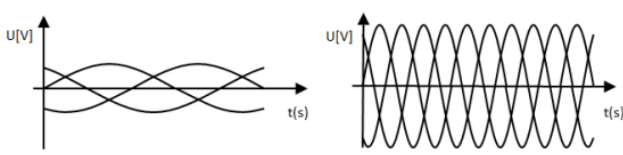

Figura 9 - Formas de onda em um inversor de frequência (a) Entrada do retificar (b) após filtro (c) aplicada aos enrolamentos do motor

A equação de rotação de um motor assíncrono segue na Equação 1.

$$
n=\frac{120 \cdot f \cdot(1-s)}{p}
$$

Onde: $n$ : rotação [rpm]

$f$ :frequência da rede de alimentação[Hz]

$p$ : número de pólos do motor

$s$ :escorregamento do motor 
Assim, a melhor maneira de se variar a velocidade de um motor de indução é por meio da variação de sua frequência de alimentação. No entanto, para que o motor possa trabalhar em uma faixa de velocidades, não basta variar apenas a frequência, mas também a amplitude de maneira proporcional. Assim, o fluxo e por conseguinte o torque do motor permanecem constante. Pela teoria de motor de indução e desprezando a queda de tensão na impedância do enrolamento estatórico, as equações 2 e 3 descrevem torque e fluxo no motor (WEG, 2009).

$$
\begin{aligned}
& T=K_{1} \cdot \Phi_{m} \cdot I \\
& \Phi_{m}=K_{2} \cdot \frac{V}{f}
\end{aligned}
$$

onde:

$T$ : torque ou conjugado disponível no eixo do motor [n.m]

$\Phi_{m}$ : fluxo de magnetização [Wb]

I: corrente do rotor $[\mathrm{A}]$

$V$ : tensão do estator [V]

$K 1$ e K2: constantes dependem do material e projeto

$A$ variação da relação $V / f$ é feita linearmente até a frequência nominal do motor, e acima disto a tensão (amplitude permanece constante havendo apenas variação da frequência causando o chamado enfraquecimento de campo, onde o fluxo diminui com o aumento da frequência provocando redução do torque no eixo do motor. A Figura 10 mostra estas relações.
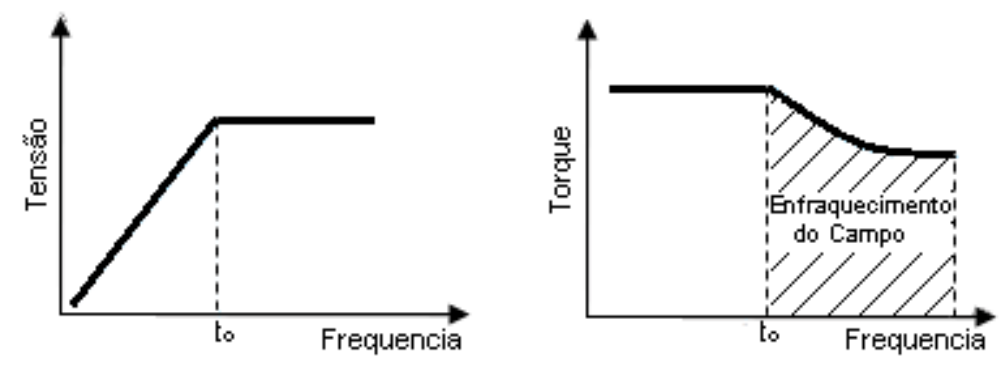

Figura 10 - Gráficos da relação V/f e Torque em motores elétricos acionados por conversores de frequência 
Vantagens da utilização de conversores de frequência:

- controle de posição simples e sincronismo de diversos motores de indução trifásicos (motion contro);

- manter o torque do motor constante mesmo em baixas rotações;

- maior eficiência energética na utilização de motores;

Desvantagens:

- grande energia dissipada nos painéis elétricos por aquecimento;

- gera harmônicas no sistema elétrico.

\subsubsection{Outros métodos de partida}

Ainda existem outros métodos de partida que apesar de possuírem grande base instalada, são cada vez menos utilizados em acionamentos de motores atualmente, seja em ampliações ou novas plantas nos mais diversos segmentos de mercado. Dentre eles podemos destacar a partida estrelatriângulo, a partida compensadora (com autotransformador) e a partida série paralela, que não iremos abordar neste trabalho.

\subsection{Integração de acionamentos elétricos ao sistema de automação}

A ampla integração de processos industriais, necessitando maior volume de dados a serem transmitidos, produziu desenvolvimento significativo nos equipamentos de comunicação de fábrica, que passou de ponto-a-ponto (sinais digitais e analógicos), para barramentos de transmissão digital de dados, conhecido como fieldbuses (BENZI; BUJA; FELSER, 2005). Estas redes também chamadas de redes de campo ou redes de comunicação industrial, são utilizadas para interconectar dispositivos de campo, como controladores lógico programáveis (CLP) de processo, sensores, atuadores, interface homem-máquina entre outros (THOMESSE, 2005).

\subsubsection{Diagramas de acionamentos de motores elétricos de baixa tensão integrados ao sistema de automação}

Os acionamentos dos motores elétricos em uma indústria normalmente são instalados de maneira centralizada em painéis elétricos, e são comumente chamados de Centro de Controle de Motores (CCM). 
As redes de comunicação industrial dão a infraestrutura necessária para equipamentos inteligentes de acionamentos de motores enviarem mais informações sobre o funcionamento e status dos motores elétricos, possibilitando seu gerenciamento e controle no sistema produtivo. Um painel de acionamentos de motores elétricos com esta funcionalidade é comumente chamado de Centro de Controle de Motores Inteligentes (CCMi).

Através de sua utilização há possibilidade de integração entre esses acionamentos e o sistema de automação. Em CCMis os diagramas unifilares chaves de partidas diretas e reversoras podem ser vistos na Figura 11 e contemplam:

- Contatores - Componentes de manobra

- Relés inteligentes - Componentes de proteção, comando e supervisão (via rede de comunicação industrial)

- Disjuntor motor - Componentes de proteção (específico para proteção contra curto-circuito).

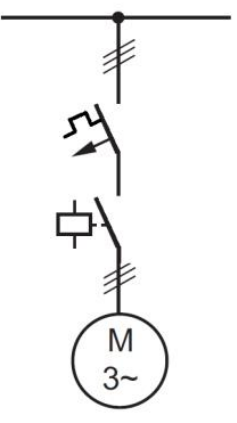

(a)

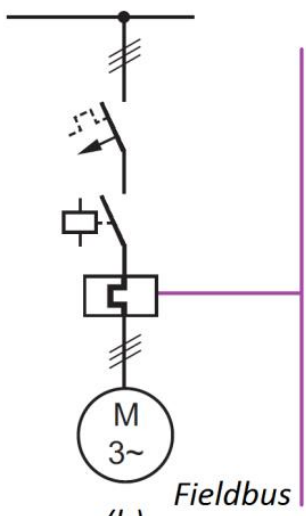

(b)

Figura 11 - Diagrama de partida direta: (a)Convencional (b)Inteligente. Adaptado de: ABNT, 2011

O típico de partida suave é exibido na Figura 12 e contempla:

- Soft Starter - Componentes de manobra, proteção, comando e supervisão (via rede de comunicação industrial)

- Fusíveis/disjuntores - Componente de proteção (específico para proteção contra curto-circuito). 


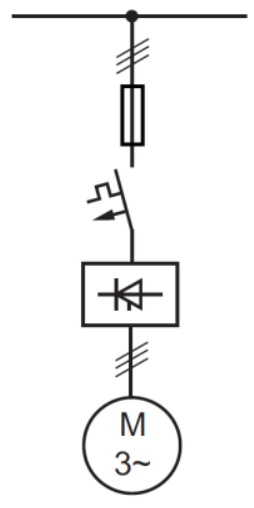

(a)

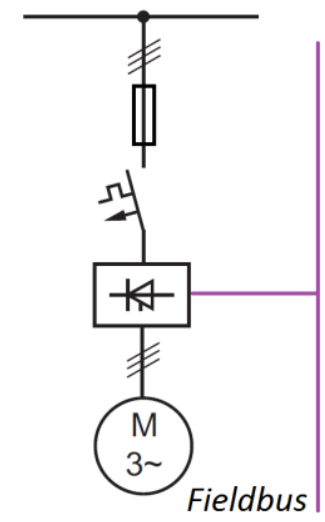

(b)

Figura 12 - Diagrama de partida suave: (a) Convencional (b) Inteligente. Adaptado de: ABNT, 2011

Em CCMis os diagramas unifilares de partida utilizando conversores de frequência, mostrado na Figura 13, contemplam:

- Conversor de frequência - Componentes de manobra/acionamento, proteção, comando e supervisão (via rede de comunicação industrial)

- Fusíveis/disjuntores - Componente de proteção (específico para proteção contra curto-circuito)

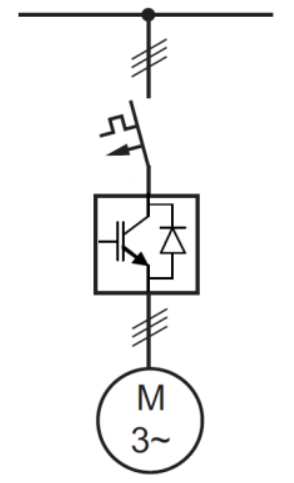

(a)

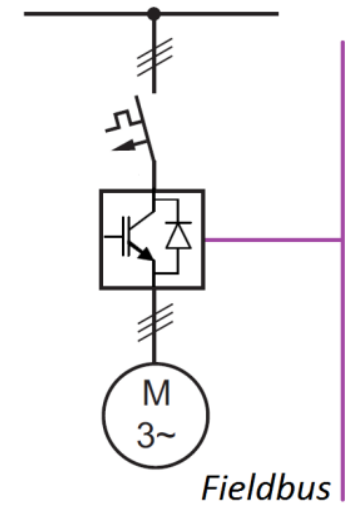

(b)

Figura 13 - Diagrama Inversor de Frequência: (a) Convencional (b) Inteligente

\subsubsection{Funcionalidades da utilização de CCMs Inteligentes}

A utilização de redes de comunicação industrial rende diversas vantagens sobre as soluções convencionais, utilizando entradas e saídas digitais e analógicas de CLPs que governaram há décadas o cenário de sistemas de controle industriais (FALDELLA; TUCCI, 2009). 
A partir desta estrutura, os dispositivos inteligentes disponibilizarão maior quantidade de informações ao sistema de automação, como mostra o comparativo de dados fornecidos pelos típicos de partida na Tabela $\mathbf{3}$, possibilitando alcançar os ganhos listados nas próximas páginas.

Tabela 3 - Comparação de dados fornecidos por partidas de motores convencionais e inteligentes

\begin{tabular}{|c|c|c|c|}
\hline Típico & Convencional & Inteligente & \\
\hline \multirow{2}{*}{$\begin{array}{c}\text { Partida } \\
\text { Direta/Reversora }\end{array}$} & 4 bits & 10 bytes & Enviados \\
\hline & 2 bits & 4 bytes & Recebidos \\
\hline \multirow{2}{*}{$\begin{array}{l}\text { Partida Soft } \\
\text { Starter }\end{array}$} & $\begin{array}{c}4 \text { bits } \\
1 \text { analógico }\end{array}$ & 2 bytes & Enviados \\
\hline & 2 bits & 2 bytes & Recebidos \\
\hline \multirow{2}{*}{$\begin{array}{l}\text { Partida } \\
\text { Conversor de } \\
\text { Frequência }\end{array}$} & $\begin{array}{c}2 \text { bits } \\
1 \text { analógico }\end{array}$ & 24 bytes & Enviados \\
\hline & $\begin{array}{c}4 \text { bits } \\
1 \text { analógico }\end{array}$ & 24 bytes & Recebidos \\
\hline
\end{tabular}

Obs.: Baseado em partidas inteligentes utilizando Simocode pro V, soft starter 3RW44 e conversores de frequência Sinamics da SIEMENS

\section{Redução dos custos de cabeamento}

Devido a utilização de redes de campo, as informações coletadas dos dispositivos inteligentes são transmitidas para o sistema de automação de maneira econômica e confiável, não sendo necessário alto custo de cabeamento para envio de sinais discretos (SHAIKH, 2006). Para cada compartimento inteligente, um cabo de rede único pode ser utilizado para transferir dados que necessitariam de 6 a 12 pares de fios ligados a várias entradas e saídos digitais e analógicas do CLP. Faldella e Tucci (2009) referem sobre a verificação da instalação, que pode ser mais problemática quando são utilizados sinais digitais e analógicos para cada dispositivo, em comparação a utilização de dispositivos conectados via fieldbus, e sobre sua maior resistência a ruídos.

Dados de projetos atuais apontam para redução no custo de engenharia, instalação e manutenção em 30\% não são incomuns (SHAIKH, 2006). Exemplo: para a integração do CCMi ao sistema de automação não será necessário a utilização de estações remotas com cartões de entrada e saída digital, tampouco régua de bornes para sua interligação com comando de cada partida. Toda a integração é realizada apenas interconectando os dispositivos através de um cabo como meio físico de uma rede de comunicação industrial. 


\section{Redução do tempo de parada de máquinas}

Os dispositivos inteligentes além de realizar a proteção do motor, podem informar ao sistema de automação a causa e localização da falha (sobrecarga, falta de fase, flutuações de tensão, entre outras). Também podem enviar alarmes, prevendo as falhas antes de acontecerem (rebaixamento de tensão na rede, consumo excessivo de corrente, tempo para disparo do motor entre outras).

Também é possível contabilizar as horas de operação da máquina, evitando manutenções que não sejam necessárias, o próprio CCMi informa ao supervisório quando determinada máquina deverá receber manutenção preventiva, isto é, quanto tempo a máquina operou.

Estima-se que $38 \%$ das paradas não programadas são causadas em falhas em equipamentos que poderiam ter sido evitadas (SHAIKH, 2006).

Também é possível fornecer histórico de falhas de cada carga acionada registrados nos dispositivos inteligentes, tornando a tomada de decisões sobre reparos mais assertiva.

Exemplo: Caso haja quebra de um dos mancais da máquina, causando neste momento um aumento na corrente nominal do motor. Os dispositivos inteligentes recebem esta informação, e envia ao supervisório que há algo de errado com o acionamento, sem antes ter desligado a máquina. Neste momento toda a manutenção toma conhecimento, e o problema pode ser resolvido antes de uma parada não programada. 


\section{Monitoração de dados para ações em relação a eficiência energética e otimização do processo}

Motores elétricos não dimensionados corretamente, operam em condições distintas a suas nominais, e consequentemente geram maior custo de aquisição, operação e podem também apresentar falhas prematuras (SHAIKH, 2006).

Através de históricos de consumo de energia enviado pelo CCMi e armazenados no sistema de automação, há possibilidade de analisar 0 desempenho e tendências do processo (identificação de problemas de carga acionada, substituição de motores em função da sua resposta às mudanças nas condições do processo ou instalação, analisar resultados de desempenho do processo após modificações de parâmetros no sistema de controle).

Assim, com a disponibilização de dados pelo CCMi é possível reconhecer pontos de otimização de maneira a alcançar melhorias na produtividade do processo.

\section{Gerenciamento de ativos}

Utilizando uma ferramenta de gerenciamento de ativos, o usuário pode executar a configuração, diagnóstico e manutenção de dispositivos de campo inteligentes, concentrando as informações em um único banco de dados (SIEMENS, 2008).

Algumas funções são a definição e modificação de parâmetros, identificação e teste dos dispositivos, comissionamento, calibração, entre outras funções que podem ser realizadas de um único ponto através de uma estação de engenharia.

\section{Gerenciamento de energia}

Através de um supervisório com banco de dados conectados via redes de campo com os CCMis, é possível coletar o consumo de energia de cada área da planta, e mesmo de cada carga em específico. Desta maneira fica possível gerar relatórios de rateio de energia, e mesmo controlar demanda da planta evitando multas com a concessionária. Normalmente se utiliza multimedidores de grandezas elétricas na alimentação de cada CCMi.

Além dos pontos apresentados acima é possível ainda utilizar a estrutura de CCMi para outros fins devido a utilização de dispositivos 
inteligentes, como integração de sensores de proteção específicos de máquinas aos acionamentos elétricos inteligentes e aumento de segurança dos operados com indicação de acionamentos elétricos em manutenção, por exemplo.

Deve se apresentar também, que a utilização dos CCMi em contrapartida, requerem algumas condições especiais para que o usuário possa usufruir de suas funcionalidades. Essas condições são mais exigentes comparadas aos CCMs convencionais, tais como:

- investimento inicial superior por parte de hardware, principalmente devido a utilização de equipamentos inteligentes, e também de softwares para parametrização destes dispositivos, software de gerenciamentos de ativos, entre outros;

- mão de obra mais especializada tanto na integração com o sistema de automação, quanto na operação e manutenção dos equipamentos;

- conectores e cabos de comunicação com blindagem específicos são recomendados e devem ser instalados de maneira adequada pois normalmente trabalham em ambientes hostis. Estes itens influenciam no desempenho da rede de comunicação, podendo prejudicar o controle do processo. A perda de comunicação irá desabilitar o controle remoto realizado pelo sistema de automação.

Por todas as funcionalidades apresentadas, os CCMi tendem a serem instalados também em novas indústrias e ampliações de plantas existentes, sendo necessário trabalho tanto nas empresas integradoras de sistemas quanto nos usuários, conduzindo o projeto de implementação de CCMi com disponibilização de suas funcionalidades (DIAS; BRANDÃO, 2011).

Assim, serão necessários investimentos em horas de engenharia para disponibilizar estas funcionalidades no supervisório e investimento em capacitação de funcionários para operação e manutenção dos sistemas que utilizam esta infraestrutura de integração de acionamentos elétricos com 0 sistema de automação via rede de comunicação industrial.

Em seguida algumas tecnologias de rede de automação industrial são introduzidas pois serão utilizadas posteriormente no trabalho para verificar seu desempenho nas aplicações de integração de acionamentos elétricos ao sistema de automação. 


\section{REDES DE COMUNICAÇÃO INDUSTRIAL}

Existem diversas tecnologias de redes de comunicação industrial desenvolvidas atualmente. $O$ desempenho de uma rede pode ser influenciado por sua topologia, pelo protocolo de comunicação, pelo meio físico, pela velocidade de transmissão de dados, dentre outros fatores.

Este capítulo apresenta conceitos dos protocolos Profibus DP e Profinet que serão importantes para o entendimento da proposta deste trabalho, focando tipos de dispositivos, temporização na comunicação e diagnósticos.

\subsection{Conceitos Básicos sobre o protocolo Profibus DP}

O protocolo Profibus é suportado pela Profibus International (PI), uma associação de empresas do segmento de automação industrial, sendo a maior organização de automação do mundo, atualmente conta com mais de 1.400 empresas membros e 50 Centros de Competência responsáveis pelo suporte técnico à tecnologia (PROFIBUS, 2013). A PI também é responsável pela tecnologia Profinet.

O Profibus possuia até o final de 2012, 43,8 milhões de nós instalados (PROFIBUS, 2013), o que confere a este protocolo a maior participação no mercado atual e êxito entre todos protocolos de comunicação no domínio industrial (YU, 2012).

Há duas perspectivas:

- Profibus DP (Decentralized Periphery)

- Profibus PA (Procces Automation)

Nesta proposta de trabalho será estudado o protocolo Profibus DP, que é a perspectiva adequada e utilizada para acionamento de motores elétricos trifásicos, conforme SHAIKH (2006). Este protocolo possibilita a comunicação entre controladores e diversos dispositivos de campo, como sensores, atuadores e drives. Também possibilita troca de dados entre níveis de comunicação mais elevados.

A norma IEC 61784 (International Electrotechnical Commission) define os subconjuntos de serviço e protocolo indicados na IEC 61158, que são usados por um determinado fieldbus. Eles são definidos como Communication 
Profile Families (CPF).

Este protocolo possui três versões (PROFIBUS, 2010):

- DPV0: suporta funções básicas, como comunicação cíclica entre dispositivos e diagnósticos para fácil localização de falhas;

- DPV1: suporta as funções DPV0 e adicionalmente comunicação acíclica entre dispositivos, como funções de parametrização, operação, monitoramento e tratamento de alarmes. Possibilita acesso online aos nós via uma estação de engenharia.

- DPV2: possui funções adicionais ao DPV1 como controle de drives, possibilitando comunicação entre escravos, sincronização e estampa de tempo, próprias para aplicação de motion control.

Existem três tipos de dispositivos nesta tecnologia (PROFIBUS, 2010):

- Mestre Classe 1: representa a estação central, como um controlador de um sistema de controle. Responsável pela comunicação cíclica de troca de dados de processo com seus escravos associados.

- Mestre Classe 2: inicialmente definido como um mestre usado como uma ferramenta de comissionamento. Para comunicação DPV1 e DPV2, é definido como um mestre, que pode ser usada para definir os parâmetros do dispositivo através de comunicação acíclica. Dispositivos deste tipo são geralmente parte de uma estação de engenharia utilizada para configuração de dispositivos. Um mestre classe 2 não precisa estar permanentemente conectado a uma rede Profibus DP.

- Escravo: representa um nó de comunicação passivo que reage a instruções do mestre, enviando uma mensagem de resposta. São geralmente dispositivos de campo (Remotas $1 / 0$, drives, relés inteligentes para acionamento de motores, válvulas, transdutores, entre outros) que adquirem dados do processo ou atuam no processo, por meio de variáveis manipuladas.

A Figura 14 apresenta relação de referências entre camadas da rede OSI e suas perspectivas no protocolo Profibus DP. 


\begin{tabular}{|c|c|c|}
\hline & Programa de Usuário & Aplicação \\
\hline 7 & Aplicação & PROFIBUS DP (DP-V0, DP-V1, DP-V2) \\
\hline 6 & Apresentação & \multirow{4}{*}{ Não Utilizado } \\
\hline 5 & Sessão & \\
\hline 4 & Transporte & \\
\hline 3 & Rede & \\
\hline 2 & Dados & Fieldbus Data Link (FDL)Mestre Escravo \\
\hline \multirow[t]{2}{*}{1} & Física & Tecnologia de Transmissão \\
\hline & Modelo OSI & Modelo OSI p/ Profibus \\
\hline
\end{tabular}

\subsubsection{Troca de dados no Profibus DP}

O Profibus DP utiliza modelo de comunicação Mestre-Escravo, sendo que um mestre pode controlar um ou mais escravos. O método de acesso ao meio é o modelo Token Passing, de modo que o mestre que possui o token controle o acesso ao meio físico, e também possibilite a aplicação de múltiplos mestres em uma mesma rede compartilhando o acesso.

Durante a fase de inicialização da rede, o mestre transfere parâmetros de configuração para os escravos (endereço de mestre, watchdog time que garante comunicação segura do sistema no caso de falha do mestre ou cabos; e número de identificação) e depois os checa. A comunicação cíclica só ocorre se o número de identificação coincide com o número de identificação salvo no escravo.

Em seguida a informação sobre os módulos configurados são transferidas para os escravos e checadas. Os escravos fisicamente presentes devem coincidir com os parâmetros configurados ou se adaptar a configuração recebida.

O estabelecimento bem sucedido da comunicação é verificado via requisição de dados de diagnóstico. Caso parâmetros e dados forem válidos, o mestre inicia a comunicação cíclica com os escravos associados. Cada escravo pode realizar troca de dados com um único mestre classe 1 , evitando dados inconsistentes (PROFIBUS, 2010). 
A troca de dados baseia-se no princípio de requisições individuais do mestre classe 1 (normalmente são controladores lógico programáveis, computadores industriais, sistema controles, etc) para os escravos distribuídos em campo (remotas, relés inteligentes, drives, instrumentação, etc) que o respondem com as informações solicitadas. Essa troca de dados é feita ciclicamente, normalmente utilizada para dados do processo, com exigência de tempo real.

Também é possível comunicação acíclica ente o mestre classe 2 e os escravos, onde o mestre classe 2 inicia uma requisição e verifica se a estação possui a resposta no próximo ciclo. Normalmente são utilizados para supervisão e parametrização das estações. A comunicação cíclica possui prioridade em relação a comunicações acíclicas (YU et al., 2012; MOSSIN, 2012).

É importante ressaltar que somente os mestres trocam o token, esta prática dá origem ao anel de token. De forma que, a comunicação mestreescravo e mestre-mestre compõe o que é chamado de comunicação híbrida.

A Figura 15 representa graficamente o tempo de ciclo de uma rede Profibus DP, representando pacotes de comunicação cíclica e acíclica.

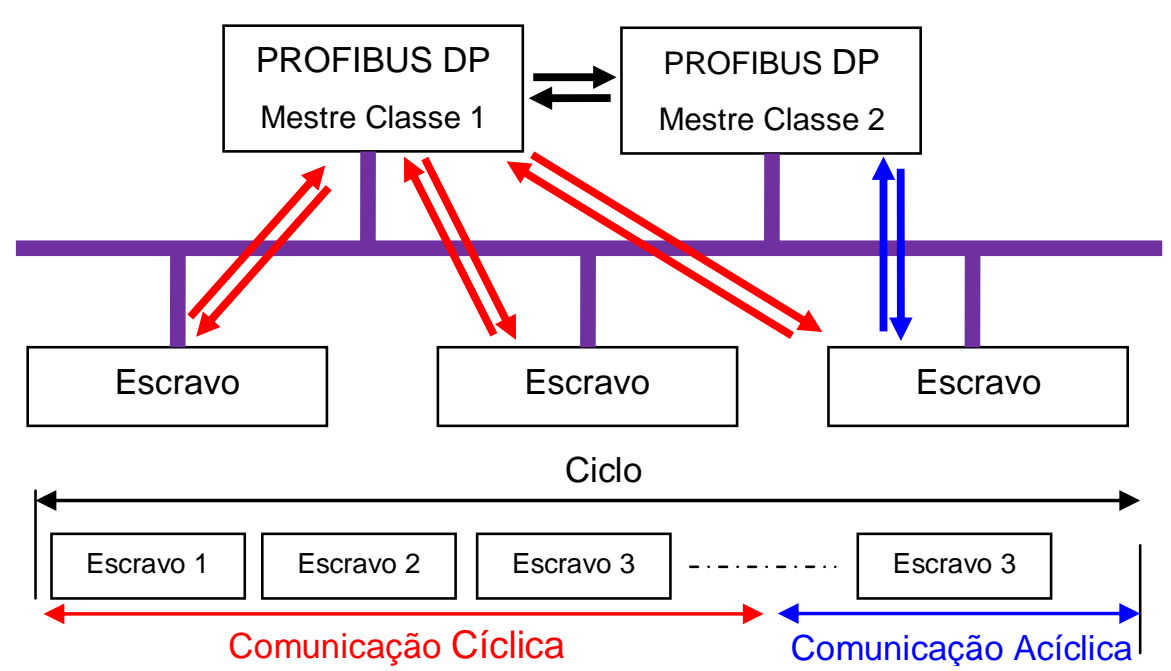

Figura 15 - Modelo Mestre/Escravo utilizado no Profbus DP. Adaptadode PROFIBUS, 2010

O volume de dados por mensagem que o protocolo possibilita é de 244 bytes de entrada e 244 bytes de saída. Este trabalho estuda as aplicações com 
experimentos que utizam comunicação cíclica, com nível de desempenho DPV0 para uma aplicação que simula um CCMi com grande quantidade de escravos, que é aumentada gradativamente.

Diversos parâmetros são utilizados na configuração de temporização da rede, conforme mostra a Figura 16. Devido a grande quantidade de parâmetros, somente os mais relevantes serão discutidos. Eles são apresentados normalmente na forma de $T_{\text {bit }}$ que é o tempo decorrido para se transmitir um bit na rede em função da taxa de transmissão configurada.

Segundo Torres (2013), Target Rotation Time ( TTR) é o parâmetro que indica o tempo de ciclo previsto para a rede Profibus DP, ele deve levar em consideração os diversos parâmetros, já que alguns problemas podem ocorrer durante a transmissão dos pacotes, podendo fazer com que este tempo previsto varie. Geralmente o software configurador do CLP calcula este valor automaticamente baseado na taxa de transmissão, quantidades de escravos e quantidade de dados a serem trocados. Porém é possível configurar um tempo de ciclo fixo, que deve ser sempre superior ao tempo de rotação típico para a rede em questão. Ao final de cada ciclo o mestre calcula o Real Rotation Time $\left(T_{R R}\right)$, que é o tempo real do ciclo e verifica se este valor foi inferior ao $T_{T R}$.

O SlotTime ( $\mathrm{T}_{\text {slot }}$ ) é o limite de tempo que o mestre aguarda a resposta de um escravo, antes de tentar novamente requisição. O Tqui é o tempo de vazio, que deve ser considerado quando se utiliza um dispositivo que insira atraso na rede, como um repetidor ou conversor de fibra óptica por exemplo. $O$ Idle Time ( $T_{\mathrm{id} 1}$ e $T_{\mathrm{id} 2}$ ) é o tempo de espera do mestre entre receber o último bit da última resposta e iniciar o envio do primeiro bit da próxima requisição (TORRES, 2013).

Os mínimos e máximos atrasos de todas estações (Min. $T_{\text {sdr }}$ e Max. $T_{\text {sdr }}$ ) já que cada estação leva um tempo para responder uma requisição, que varia de acordo com o fabricante do equipamentos.

O parâmetro Watchdog é o tempo que o escravo deve aguardar por uma atualização do mestre, e caso não ocorra o escravo vai para modo de falha segura. 


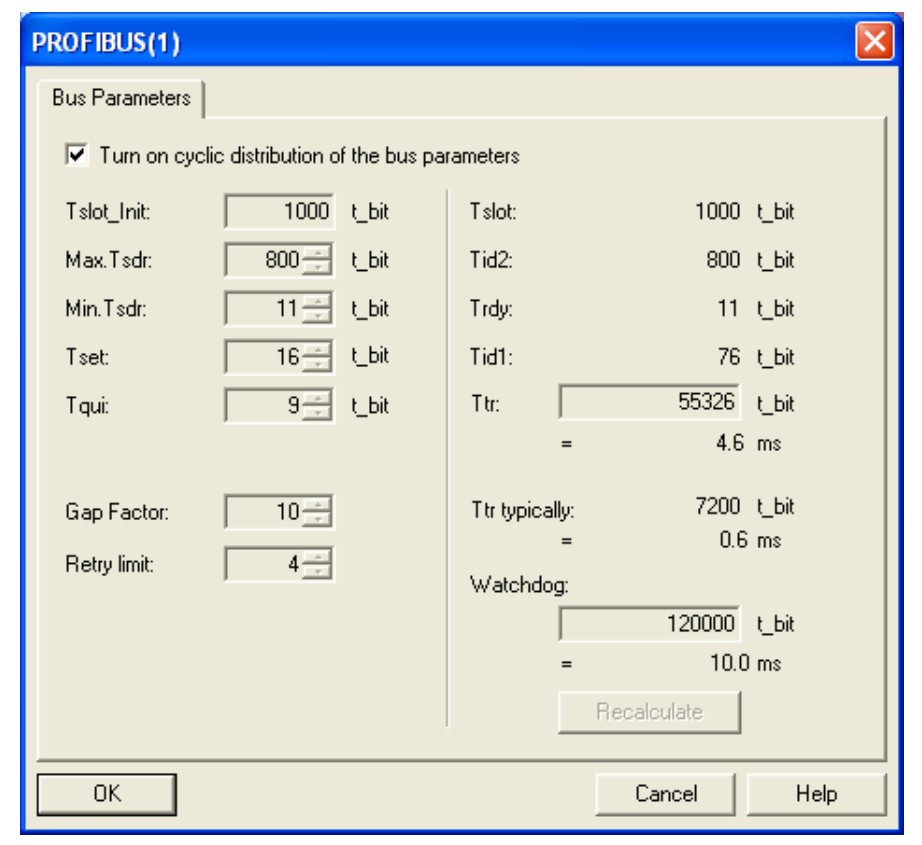

Figura 16 - Parâmetros na configuração da rede DPV0 via STEP7

A equação 4 define o cálculo aproximando do tempo de ciclo de mensagens.

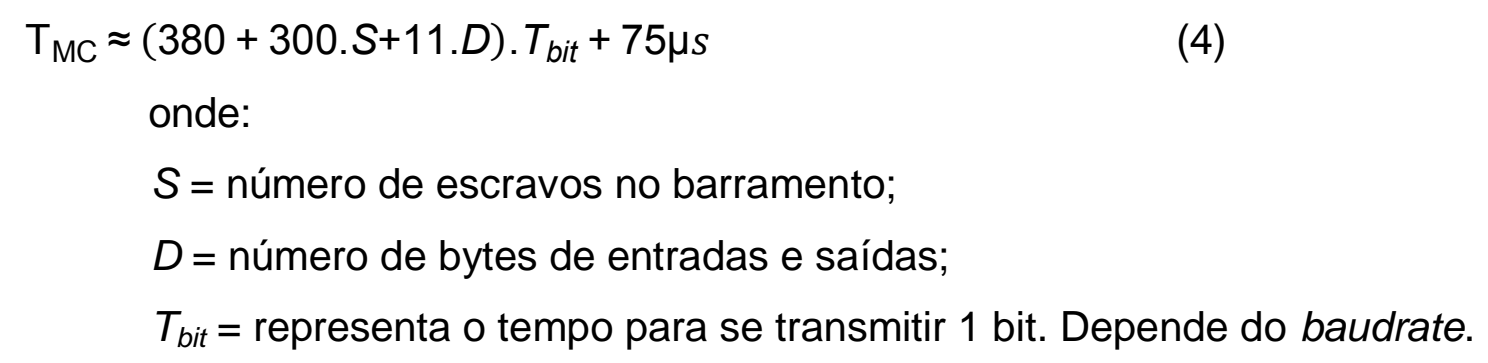

As constantes utilizadas na equação referem-se aos valores aproximados de espera entre receber o último bit de uma mensagem e enviar o primeiro bit de outra ( $\mathrm{T}_{\text {Iddle }}$ ) e o tempo que um dispositivo leva para responder a uma mensagem (TSRR (MOSSIN, 2012).

Este trabalho também aborda a versão DPV2, em uma aplicação de controle de posição simples. Neste caso alguns parâmetros adicionais são realizados no software de configuração, conforme mostra a Figura 17. 


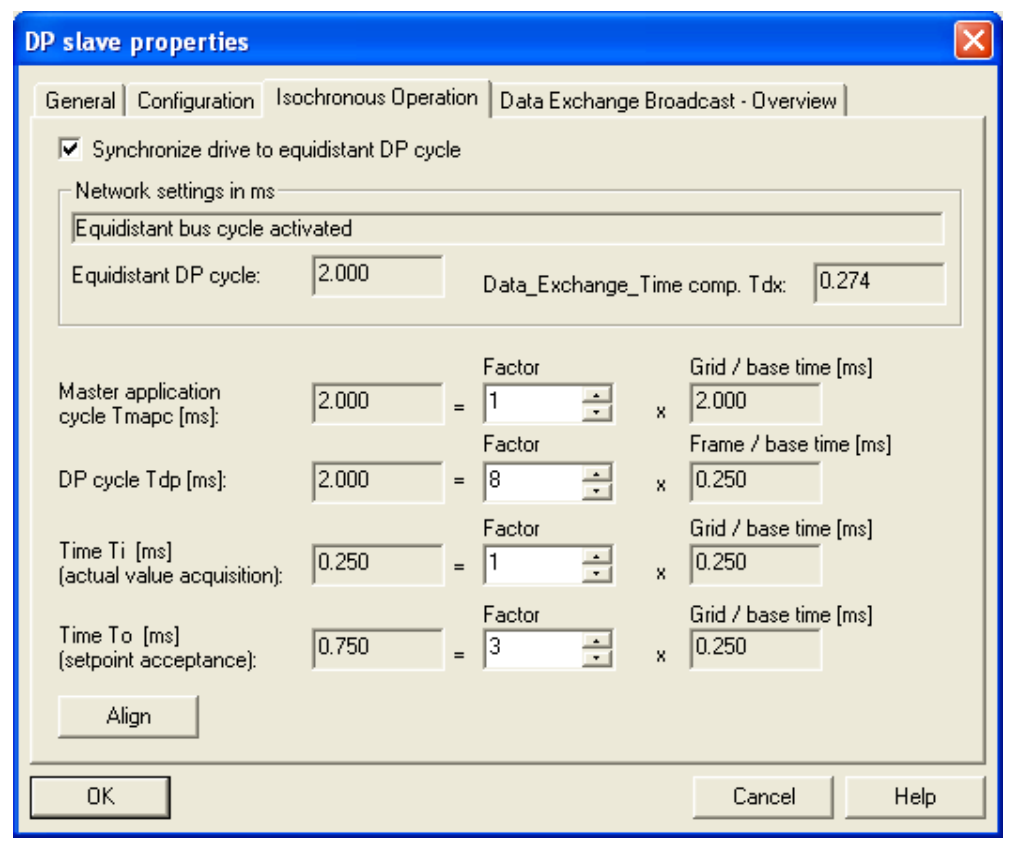

Figura 17 - Parâmetros na configuração da rede DPV2 via STEP7

Os parâmetros mais importantes nesta configuração são o "Master application cycle $T_{\text {mapc }}$ que é o tempo de ciclo do mestre, que deve ser múltiplo do "DP cycle $T_{d p}$ " que é o tempo de ciclo da rede para troca de dados de todos os escravos. $\mathrm{O} \mathrm{T}_{\mathrm{i}}$ e $\mathrm{T}_{0}$ tem relação com os tempos de ciclo locais dos escravos da rede, e se referem ao tempo para aquisição do valor atual que ocorre antes do início do ciclo, e tempo de transferir os dados na rede a partir do início do tempo de ciclo respectivamente.

\subsubsection{Camada Física do protocolo Profibus DP}

Na camada física, o transporte de dados ocorre via cabo elétrico RS485 ou fibra ótica, com sentido de transmissão half duplex. Este trabalho focará a utilização do meio RS485, por ser o meio mais utilizado, apresentar taxas de transmissão suficientes, instalação simples e barata. Ademais, é o meio físico comumente utilizado em aplicações de acionamentos de motores elétricos trifásicos. O padrão RS485, atualmente conhecido como EIA-485 (Eletronic Industry Association) utiliza um cabo par trançado e blindado, permitindo que até 32 estações sejam ligadas em um segmento, podendo se estender até 126 estações com utilização de repetidores (PROFIBUS, 2010), que é o limite da tecnologia. Outras limitações são o tamanho do cabeamento de cada segmento 
da rede e a velocidade de transmissão, que estão relacionadas como mostra a Tabela 4.

Tabela 4 - Distância entre nós utilizando meio físico elétrico (RS 485) de acordo com velocidades de transmissão

\begin{tabular}{|c|c|}
\hline $\begin{array}{c}\text { Taxa de transmissão } \\
{[\mathrm{Kbps}]}\end{array}$ & $\begin{array}{c}\text { Distância de } \\
\text { transmissão por } \\
\text { segmento }[\mathrm{m}]\end{array}$ \\
\hline $9.6 ; 19.2 ; 45.45 ; 93.75$ & 1000 \\
\hline 187.5 & 1000 \\
\hline 500 & 400 \\
\hline 1500 & 200 \\
\hline $3000 ; 6000 ; 12000$ & 100 \\
\hline
\end{tabular}

Fonte: PROFIBUS, 2010

A topologia física de uma rede de comunicação define a forma como as estações estão fisicamente interligadas, levando-se em consideração a alocação do canal de comunicação. Para o meio físico RS485, a topologia de rede utilizada é a barramento/linha. Atualmente existem alguns tipos de repetidores de múltiplos canais, podendo assim utilizar a rede Profibus na topologia estrela, porém estes equipamentos não são comumente aplicados em CCMi.

Há necessidade de utilização de um terminador ativo no início e final de cada segmento de rede a fim de evitar reflexões de sinais. Geralmente cada conector Profibus que interliga um escravo na rede possui este terminador integrado que pode ser ativado ou não de acordo com sua posição física no barramento de rede. A Figura 18 apresenta uma configuração básica para redes de comunicação Profibus DP na aplicação de acionamentos de motores elétricos. 


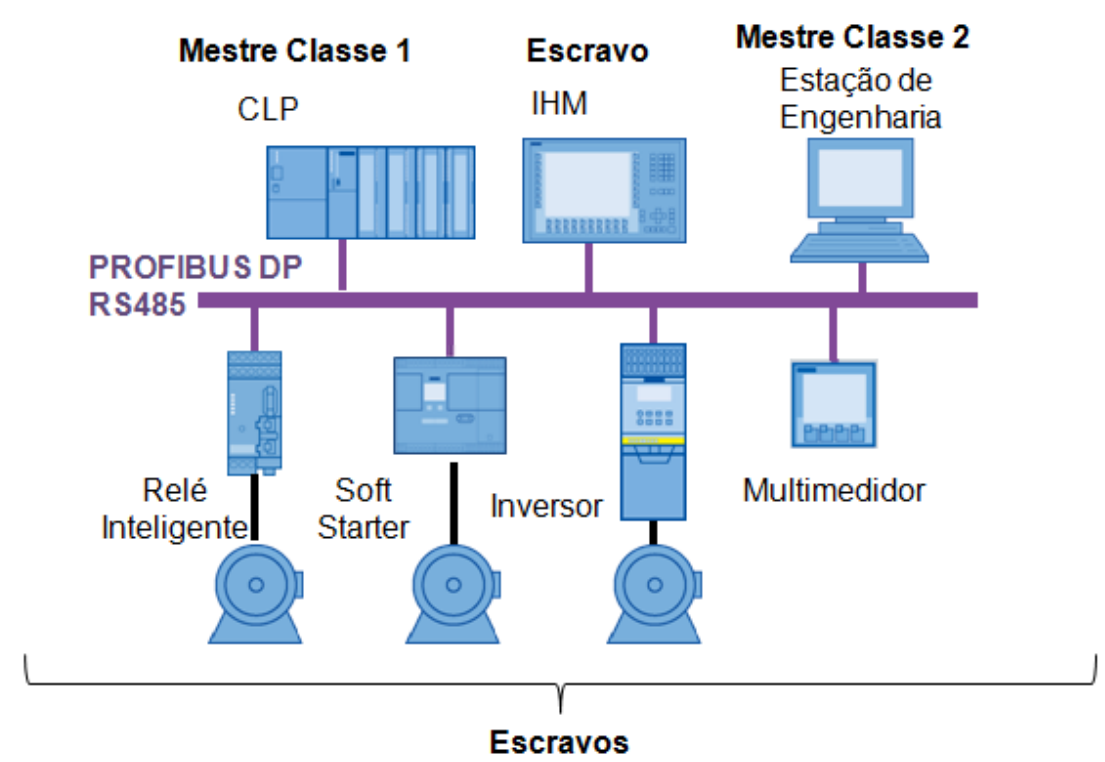

Figura 18 - Configuração de uma rede Profibus DP para acionamento de motores elétricos

As redes tipo fieldbus, que tiveram desenvolvimento iniciado na década de 1980 (THOMESSE, 2005), apresentam sensibilidade relacionada a qualidade de suas instalações que alteram as características elétricas da rede e consequentemente degradam o sinal transmitido até o ponto de provocar falhas na comunicação, além de poderem afetar os pacotes transmitidos pelo protocolo (MOSSIN, 2012). Neste contexto, por volta do ano 2000 grandes empresas iniciaram pesquisas sobre adequação de protocolos baseada no padrão Ethernet para o ambiente industrial, que é descrito na próxima seção.

\subsection{Utilização de Ethernet em ambientes industriais}

Publicado em 1983 no padrão IEEE 802.3, o Ethernet foi inicialmente destinado para o uso em escritórios, no entanto é bastante atrativo também para a área de automação, devido ao seu alto desempenho e amplas possibilidades de diagnóstico (DOLEJS; SMOLIK; HANZALEK, 2004; WARREN, 2009 e GIORGETTI et al., 2013). Esta tecnologia não foi utilizada de imediato em processos industriais, que se caracterizam por apresentar ambientes hostis, umidade, poeira e temperaturas elevadas. Além destas características do ambiente, necessitam de comunicação em tempo real, determinismo e outros critérios de desempenho (KLEINES et al., 2008). 
O padrão Ethernet define apenas a camada física e de enlace do modelo ISO/OSI, assim é necessário sua integração com camadas superiores (LIU; LI, 2006). Para aplicações industriais, a utilização desta tecnologia teve que adequar suas características, como comunicação em tempo determinístico, sincronismos entre os dispositivos de campo, e troca de pequenos dados de maneira eficiente e frequente (FELSER, 2005).

Após investimentos em pesquisas, ocorreram aprimoramentos que possibilitaram o surgimento de soluções baseadas em Ethernet para automação industrial. Tais melhorias consolidaram estes protocolos industriais, houve modificações em hardware como: conectores, cabos e switches e em software como determinismo na troca de dados, amplas possibilidades de diagnóstico, e ademais, a utilização de tecnologias Web aos usuários. Essas características possibilitaram aprimoramento de desempenho nos sistemas de comunicação industriais baseados em Ethernet, denominados Real Time Ethernet (RTE).

Atualmente a tecnologia RTE é amplamente aceita e utilizada em ambientes industriais, suas aplicações estão se expandindo e seu uso está em ascensão (FERRARI, 2006). Esses sistemas são implementados tanto em nível de supervisório, como nos níveis de controle e campo da hierarquia de redes.

Diversos fabricantes aprimoraram protocolos e atualmente 14 padrões de comunicação baseados em RTE foram normatizados pela IEC 61784-2. São eles: o Profinet, EthernetIP, EtherCAT, ModbusTCP, P-NET, Vnet/IP, TCnet, Ethernet Powerlink, EPA e SERCOS III, todos baseados no padrão IEEE 802. A Tabela 5 apresenta a lista de protocolos RTE definido pela IEC 61784-2, e indicação de seus profiles. 
Tabela 5 - Protocolos industriais baseados em Ethernet segundo IEC61784-2

\begin{tabular}{|c|c|c|}
\hline $\begin{array}{c}\text { Profile } \\
\text { (IEC61784) }\end{array}$ & $\begin{array}{c}\text { Camada de } \\
\text { Enlace } \\
\text { (IEC61158) }\end{array}$ & Descrição \\
\hline Profile 2/2 & TCP/UDP/IP & Ethernet/IP \\
\hline $\begin{array}{c}\text { Profile 3/4 } \\
\text { Profile 3/5 } \\
\text { Profile 3/6 }\end{array}$ & Type 10 & Profinet IO \\
\hline Profile 4/3 & Type 4 & P-NET \\
\hline Profile 10/1 & UDP/IP & Vnet/IP \\
\hline Profile 11/1 & Type 11 & TCnet \\
\hline $\begin{array}{c}\text { Profile 12/1 } \\
\text { Profile 12/2 }\end{array}$ & Type 12 & EtherCAT \\
\hline Profile 13/1 & Type 13 & Ethernet Powerlink \\
\hline $\begin{array}{c}\text { Profile14/1 } \\
\text { Profile 14/2 }\end{array}$ & $\begin{array}{c}\text { UDP/TCP/IP } \\
\text { Type 14 }\end{array}$ & EPA \\
\hline Profile 15/1 & TCP/IP & ModbusTCP \\
\hline Profile 16/3 & Type 16 & SERCOS III \\
\hline
\end{tabular}

A atual existência de vários protocolos para uma diversidade de aplicações leva a uma fragmentação do mercado. Como consequência natural deste cenário, alguns deles têm maior relevância no mercado enquanto outros protocolos permanecem como soluções proprietárias de fabricantes (com pouca disponibilidade de equipamentos para as diversas aplicações e necessidades do mercado) (KLEINES et al., 2008). Neste cenário, o Profinet com significativa variedade de dispositivos no mercado e parque instalado, tem apresentado destaque.

\subsubsection{Abordagens de RTE}

Os protocolos industriais definidos pela IEC61158 são estruturados de acordo com as camadas OSI e a IEC61784-2 lista profiles baseados na ISO/IEC 8802.3 para aplicações em tempo real. Três diferentes abordagens podem ser utilizadas para implementação dos protocolos de comunicação industrial baseado em Ethernet:

(i) Abordagem "Sobre TCP/UDP/IP", onde se mantêm os protocolos TCP/UDP/IP sem alterações e se concentram todas as alterações de tempo real na camada superior, o hardware Ethernet também não é modificado;

(ii) Abordagem "Sobre o Ethernet", onde o hardware do Ethernet não é modificado, porém há especificação de um protocolo especial que acessa a 
funcionalidade Ethernet diretamente; assim o protocolo TCP/UDP/IP é ignorado para os dados de tempo real;

(iii) Abordagem "Ethernet modificada", onde para alcançar requisitos de tempo real restritos, além de utilizar um protocolo que acessa diretamente a funcionalidade Ethernet, há alterações em seu hardware, assim o mecanismo Ethernet e infraestrutura são modificados para assegurar alto desempenho em tempo real. Essas modificações são mandatórias para todos os dispositivos dentro do segmento de tempo real (FELSER, 2005).

A Figura 19 mostra os diferentes tipos de abordagens graficamente.

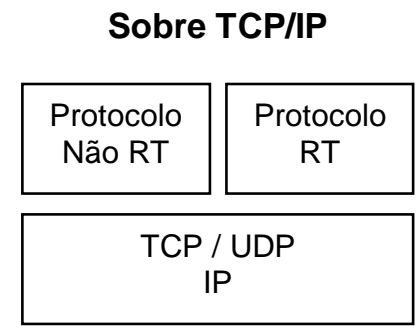

Ethernet
Sobre Ethernet

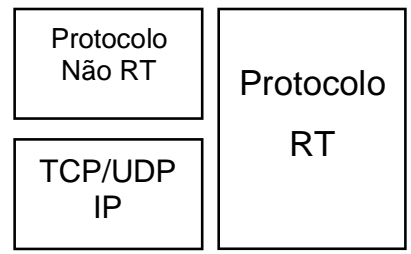

Ethernet
Ethernet Modificada

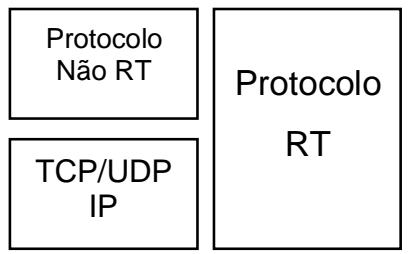

Ethernet Modificada

Figura 19 - Possíveis estruturas para Ethernet Real Time. Adaptado de: FELSER (2005)

Os protocolos Ethernet também podem ser classificados em três categorias (WARREN, 2009):

(i) Non-real-time (NRT): promove conectividade sobre o padrão Ethernet, não necessitando de dispositivos especiais, porém com um pior tempo de resposta.

(ii) Real-time (RT): utiliza configurações e funcionalidades para minimizar os tempos de ciclo e técnicas de priorização de pacotes para reduzir jitter.

(iii) Isochronous real-time (IRT): utilizam dispositivos customizados e requerem switches especiais, possibilitando tempos de resposta muito pequenos e precisos para aplicações como motion control.

\subsubsection{Mercado RTE no Mundo}

O IMS Research publica informações de mercado sobre indústria de eletrônicos. Segundo seu relatório sobre o mercado mundial para Ethernet 
Industrial de dezembro de 2011, são estimados que 26,3 milhões de nós estavam instalados em aplicações de automação até o final de 2010, e é estimado que este número seja de 73,3 milhões até o final de 2015.

Componentes utilizados em níveis de campo indicam um forte crescimento, como mostra a Tabela 6, o que é explicado pela tendência da utilização de redes industriais baseados em Ethernet nos níveis mais baixos da hierarquia de redes. Existe a necessidade destes produtos em diversas aplicações específicas, como instrumentação, válvulas e equipamentos para acionamentos de motores como drives, relés inteligentes, disjuntores, multimedidores de grandezas elétricas entre outros. Estes dados reafirmam a tendência da utilização de redes RTE para integração de acionamentos elétricos ao sistema de automação.

Tabela 6 - Mercado mundial de protocolos industriais baseados em Ethernet por nível de hierarquia de rede

$\begin{array}{lllllll}2010 & 2011 & 2012 & 2013 & 2014 & 2015 & \begin{array}{c}\text { Taxa de } \\ \text { Crescimento }\end{array}\end{array}$

2010-2015

\begin{tabular}{lccccccc}
\hline Nível de & 6032,6 & 6811,3 & 7667,8 & 8583,9 & 9749,0 & 10941,7 & $12,6 \%$ \\
$\begin{array}{l}\text { Supervisório } \\
\text { Nível de Controle }\end{array}$ & 355,5 & 401,6 & 472,4 & 533,4 & 669,3 & 797,8 & $17,5 \%$ \\
Nível de Campo & 18,8 & 52,0 & 61,6 & 70,5 & 81,3 & 88,2 & $36,3 \%$ \\
\hline & & & & & & Unidade em milhares de nós \\
& & & & & & & \\
& & & & & & &
\end{tabular}

A Figura 20 apresenta a base instalada de procotolos de comunicação industrial baseado em Ethernet de 2010 e a previsão para o ano de 2015. Observa-se que o Profinet e o Ethernet/IP são as tecnologias com maior base instalada prevista. 


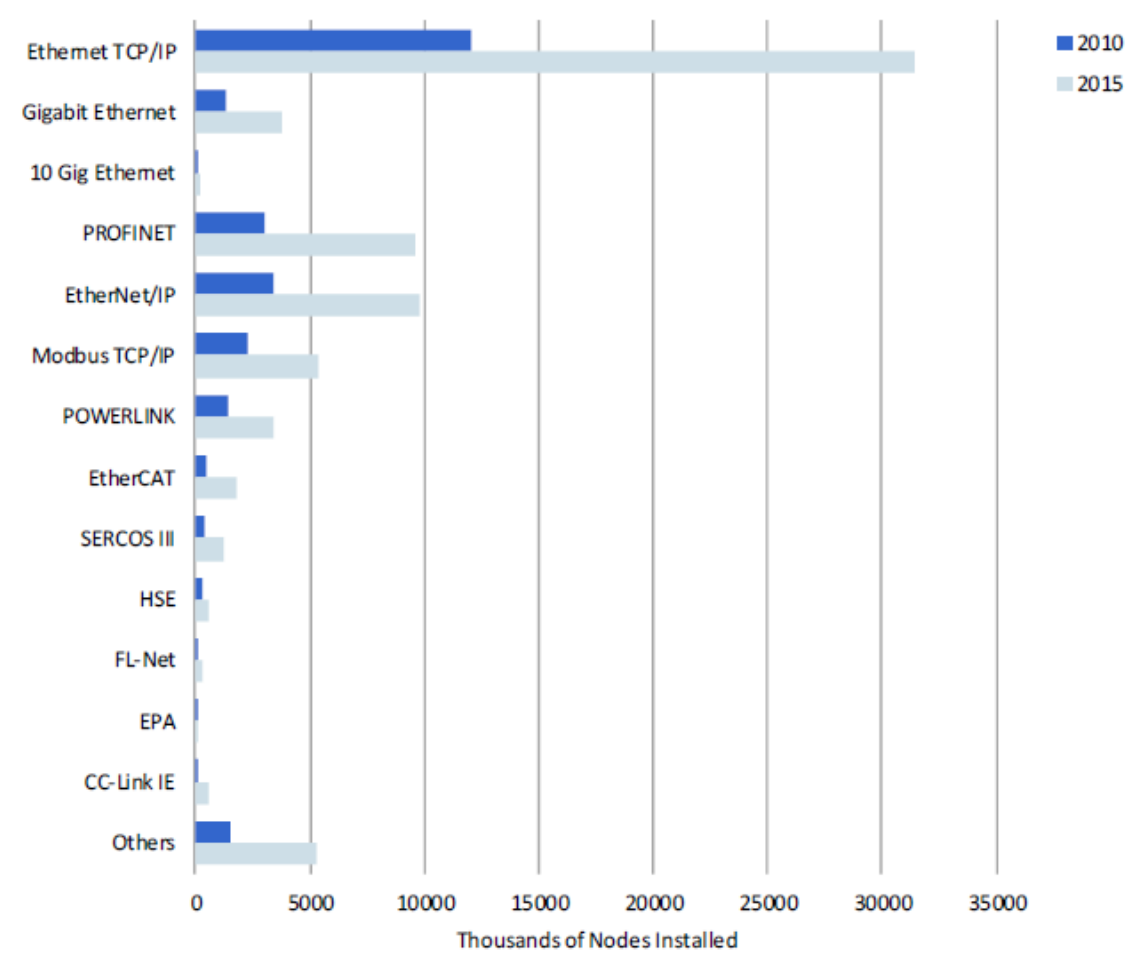

Figura 20 - Base instalada de nós de protocolos RTE 2010-2015. Adaptado de:

IMSResearch (2011)

A tecnologia Profinet adicionalmente possui taxa de crescimento elevada entre os protocolos RTE, possuindo crescimento em número de nós na ordem de 1,491 e 1,712 milhões de nós para os anos de 2014 e 2015 respectivamente, o maior entre as tecnologias RTE. A Tabela 7 mostra 0 número de novos nós instalados em redes de comunicação industrial para os próximos anos.

Devido a sua importância e pelo Profinet tratar-se de uma tecnologia baseada no Profibus DP, suportada pela mesma organização (Profibus Internationa), este trabalho utilizará o Profinet, como protocolo RTE, e o Profibus DP, como tecnologia fieldbus consolidada, em uma análise comparativa de desempenho de redes de comunicação industrial em acionamentos de motores elétricos trifásicos. 
Tabela 7- Novos nós de protocolos industriais baseados em Ethernet

\begin{tabular}{cccccccc}
\hline & $\mathbf{2 0 1 0}$ & $\mathbf{2 0 1 1}$ & $\mathbf{2 0 1 2}$ & $\mathbf{2 0 1 3}$ & $\mathbf{2 0 1 4}$ & $\mathbf{2 0 1 5}$ & $\begin{array}{c}\text { Taxa de } \\
\text { cresc. } \\
\mathbf{2 0 1 0 - 2 0 1 5}\end{array}$ \\
\hline $\begin{array}{c}\text { Fieldbus } \\
\text { (TodosProtcolos) }\end{array}$ & 21,33 & 24,04 & 26,38 & 28,65 & 30,82 & 33,23 & $9.3 \%$ \\
Ethernet TCP/IP & 2,752 & 3,083 & 3,425 & 3,789 & 4,306 & 4,752 & $11.5 \%$ \\
Gigabit Ethernet & 310 & 360 & 414 & 472 & 542 & 619 & $14.8 \%$ \\
10Gig Ethernet & 17 & 20 & 23 & 26 & 29 & 33 & $13.5 \%$ \\
PROFINET & 835 & 975 & 1,133 & 1,298 & 1,491 & 1,712 & $15.4 \%$ \\
Ethernet/IP & 854 & 979 & 1,108 & 1,256 & 1,433 & 1,639 & $13.9 \%$ \\
Modbus TCP/IP & 454 & 506 & 563 & 617 & 681 & 752 & $10.6 \%$ \\
POWERLINK & 277 & 318 & 359 & 401 & 449 & 499 & $12.5 \%$ \\
EtherCAT & 136 & 166 & 203 & 244 & 300 & 362 & $21.7 \%$ \\
SERCOS III & 95 & 117 & 142 & 172 & 206 & 243 & $20.8 \%$ \\
HSE & 46 & 54 & 61 & 69 & 78 & 88 & $13.8 \%$ \\
FL-NET & 14 & 15 & 19 & 22 & 28 & 34 & $18.8 \%$ \\
EPA & 2 & 2 & 2 & 3 & 4 & 5 & $23.3 \%$ \\
CC-Link IE & 40 & 47 & 64 & 89 & 129 & 189 & $36.3 \%$ \\
Outros & 574 & 625 & 686 & 749 & 823 & 902 & $9.4 \%$ \\
\hline & & & & & & Unidade em milhares de nós \\
& & & & & & Fonte: IMSResearch, 2011
\end{tabular}

\subsection{Conceitos Básicos sobre o protocolo Profinet}

O protocolo de comunicação Profinet é definido pelas normas IEC61158 e IEC61784 nos profiles 3/4, 3/5 e 3/6. Esta tecnologia possuía duas versões: O PROFINET CBA (Component Based Network) e o PROFINET IO.

Atualmente o PROFINET CBA não é utilizado no mercado industrial, por este motivo não será abordado em detalhes neste trabalho. A versão PROFINET IO é tida como padrão desta tecnologia e será denominada apenas de Profinet no decorrer do trabalho (PROFINET...,2011).

O protocolo utiliza modelo Provider/Consumer na comunicação entre uma estação central e dispositivos descentralizados, onde um dispositivo Provider disponibiliza os dados para o Consumer. É utilizado no controle e supervisão em aplicações de acionamento de motores elétricos nos mais diversos segmentos de mercado.

São definidos os seguintes tipos de dispositivos, os quais não possuem hierarquia entre si: 
- IO-Controller: representa a estação central de inteligência, como um controlador lógico programável (CLP) ou um PC Industrial. Responsável pela configuração e parametrização de seus respectivos dispositivos associados e controla a transferência de dados do processo.

- IO-Device: representa os dispositivos de campo. Ele transmite ciclicamente os dados de processo coletados ao IO-Controller. Também disponibiliza diagnósticos.

- IO-Supervisor: representa a estação de engenharia para programação, configuração ou diagnóstico, como um computador com a ferramenta de configuração do CLP ou um monitor de rede (PROFINET..., 2011).

A Figura 21 apresenta uma arquitetura básica de uma rede Profinet.

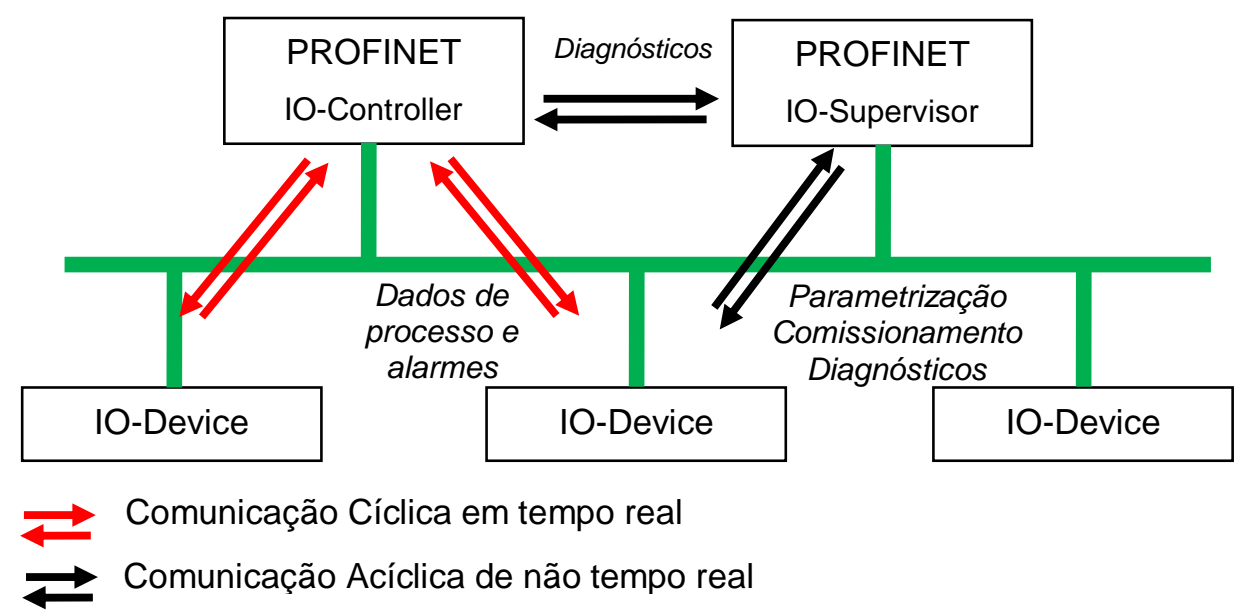

Figura 21- Modelo de comunicação Profinet. Adaptado de : KLEINES et al. (2008)

Uma rede Profinet exige pelo menos um IO-Controller (podendo também utilizar múltiplos IO-Controllers) e um ou mais IO-Devices. A existência do IOSupervisor é opcional, sendo utilizado apenas temporariamente como ferramenta de comissionamento e parametrização.

A Figura 22 mostra um exemplo de rede Profinet com seus dispositivos de campo de acionamento de motores elétricos. 


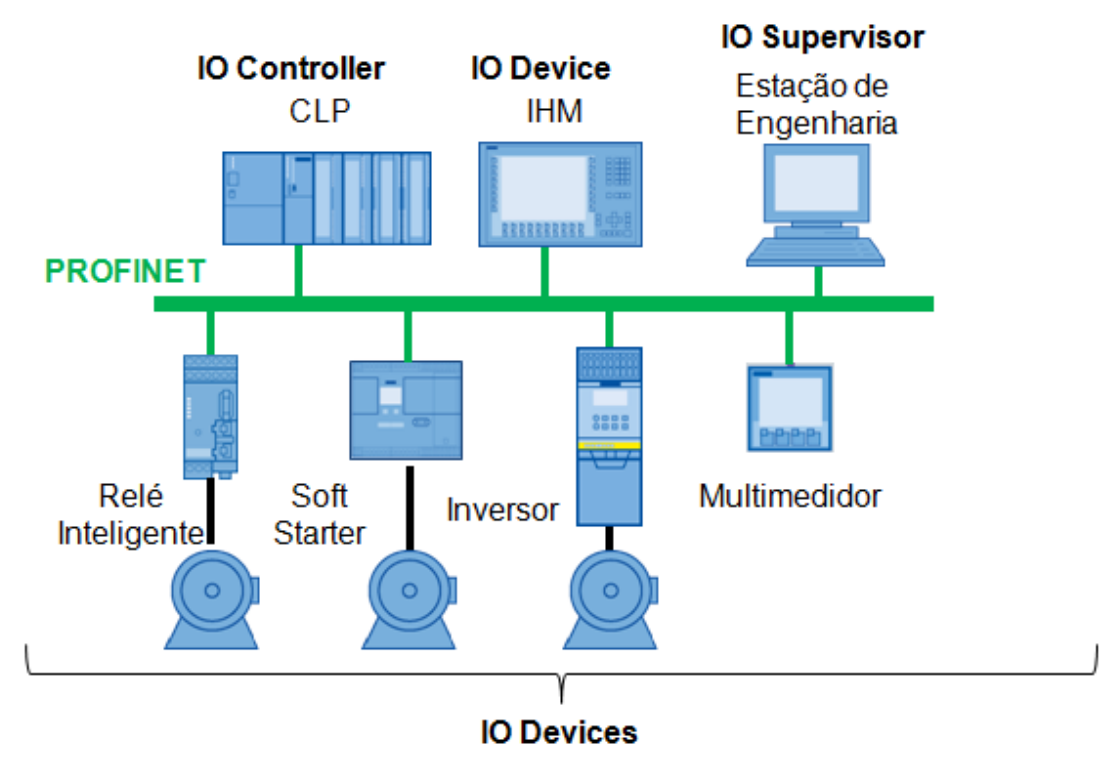

Figura 22 - Configuração de uma rede Profibus DP para acionamento de motoes elétricos

\subsubsection{Troca de dados no Profinet}

Quando um sistema Profinet é inciado, relações lógicas entre 1Ocontroller e os IO-Devices são estabelecidas. Esta tarefa é realizada pelo IOController baseadas nas configurações parametrizadas na estação de engenharia, esta relação chama-se Application Relationship (AR). Posteriormente, são estabelecidos canais de comunicação para troca de dados de processo e alarmes, estes são chamados de Communication Relationship (CR). Esta etapa é realizada através de um canal de comunicação non-real time (nRT), onde são utilizados os protocolos UDP, TCP e IP. Adicionalmente este canais nRT também podem enviar dados de diagnóstico, troca de parâmetros, entre outros.

Depois deste procedimento inicial, existe uma troca de dados contínua e bidirecional entre estes dispositivos, através de pacotes contendo informações de processo, alarmes, etc. Cada dispositivo envia um quadro Profinet para o controlador com valores recebidos no campo, enquanto o controlador envia pacotes para os dispositivos com valores de saída para o campo (FERRARI et al., 2012). O tempo de ciclo de cada relação de comunicação entre IOController e IO-Device pode ser especificado individualmente, e assim adaptado as necessidades da aplicação, os tempo de ciclo podem ser de 
250 as até 512ms (PROFINET..., 2011). Esta funcionalidade não é disponiblizada na rede Profibus DP.

A troca de dados cíclica é feita por canais de comunicação denominados real time (RT). Adicionalmente existe a comunicação isochronous real time (IRT), que permite transferênia de dados sincronizados, utilizado normalmente em aplicações de sincronismo de eixos

Os quadros destes tipos de comunicação (RT e IRT) podem ser classificados de acordo com seu grau de determinismo, como mostra Ferrari et al. (2007a) e PROFINET (2011):

- RT Class 1 (PN RT)- utilizado em aplicações que necessitam tempo de ciclo de até 10 milisegundos. Esta classe não necessita de hardwares especiais, ou seja, switches padrões podem ser utilizados, o que implica no aumento do jitter.

- RT Class 2 - utilizado em aplicações que necessitam de tempo de ciclo menores que 10 milisegundos, ainda não exigindo hardware especial e configuração prévia da rede. Por este motivo, apresenta jitter maiores que o RT Class 3 , apresentado em seguida. Foi descontinuado.

- RT Class 3 (PN IRT)- também chamado de tempo real isócrono ou isochronous real time (IRT) é utilizado em aplicações que requerem isocronocidade e tempo de ciclos na ordem de 1 milisegundo. Este é a classe de desempenho mais alta, com jitter extremamente baixo, porém exige uma rígida topologia de rede configurada previamente, e hardware específico (normalmente possui switches integrados nos dispositivos de campo).

Neste escopo de trabalho será utilizado o tipo de comunicação RT (RT Class 1) para uma aplicação que simula um CCMi com grande quantidade de escravos, e comunicação RT e IRT para uma aplicação de controle de posição de motor elétrico.

A Figura 23 mostra as aplicações para os tipos de comunicação nRT, RT e IRT. 

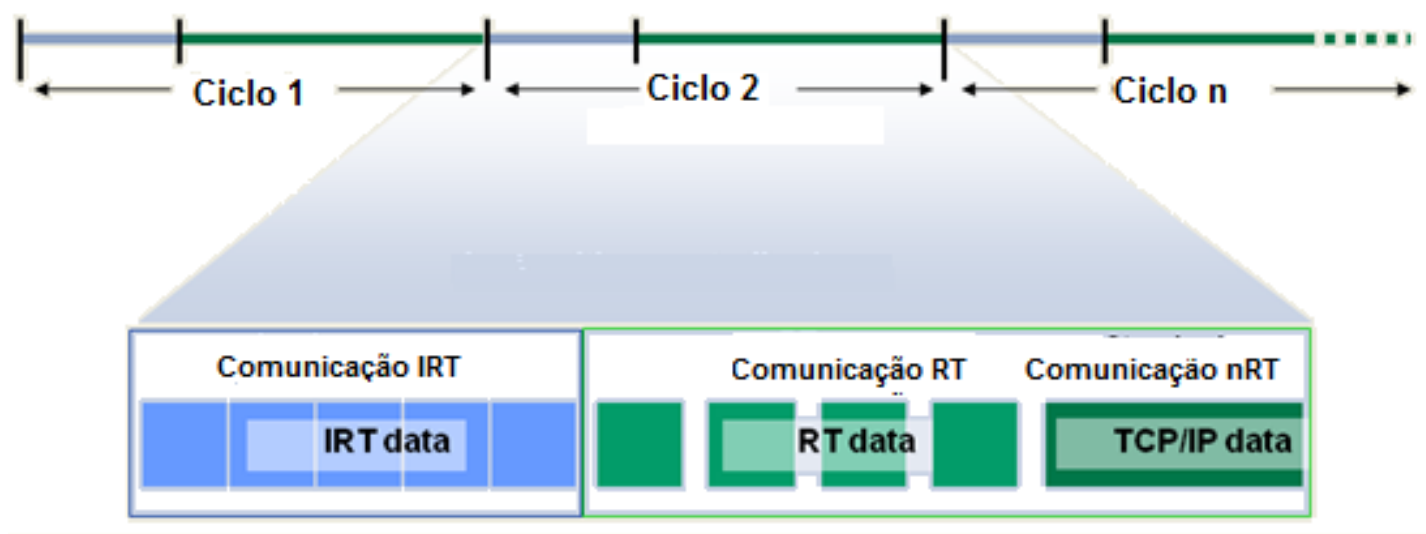

Figura 23 - Velocidade de transmissão para aplicações de exigência de tempo real mais restritas. Adaptado de: POPP, 2007

Em relação a temporização, denomina-se sendclock o intervalo de tempo comum em um tempo de ciclo, e o Reduction Ratio, que indica a quantidade de intervalos de sendclock o dispositivo deve esperar para enviar seus dados ciclicamente, assim é possível definir as taxas de atualização distintas para cada IO-Device. O usuário também pode definir tempo de ciclo fixo para troca de dados de cada IO-Device. A Figura 24 mostra exemplo de parametrização da rede Profinet no software de configuração de CLP.

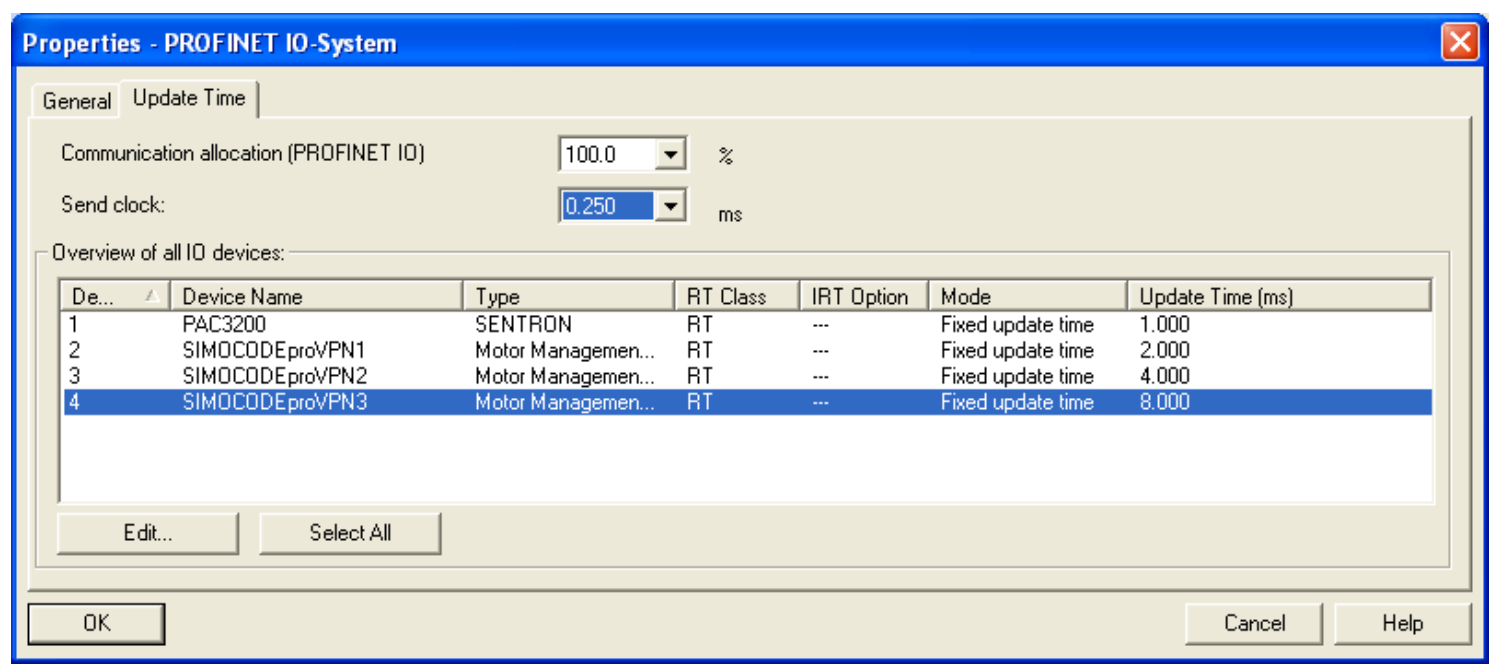

Figura 24 - Parâmetros na configuração da rede Profinet via STEP7

Desta maneira o tempo de ciclo na tecnologia Profinet utiliza um método de divisão do tempo por multiplexação, baseado em um alto ciclo de repetição descrito na IEC 61158-5-10, transportando dados Non-RT, RT e IRT. A Figura 25 apresenta um diagrama sobre o ciclo de comunicação, dividido em diversas fases (FERRARI et al., 2007b). 


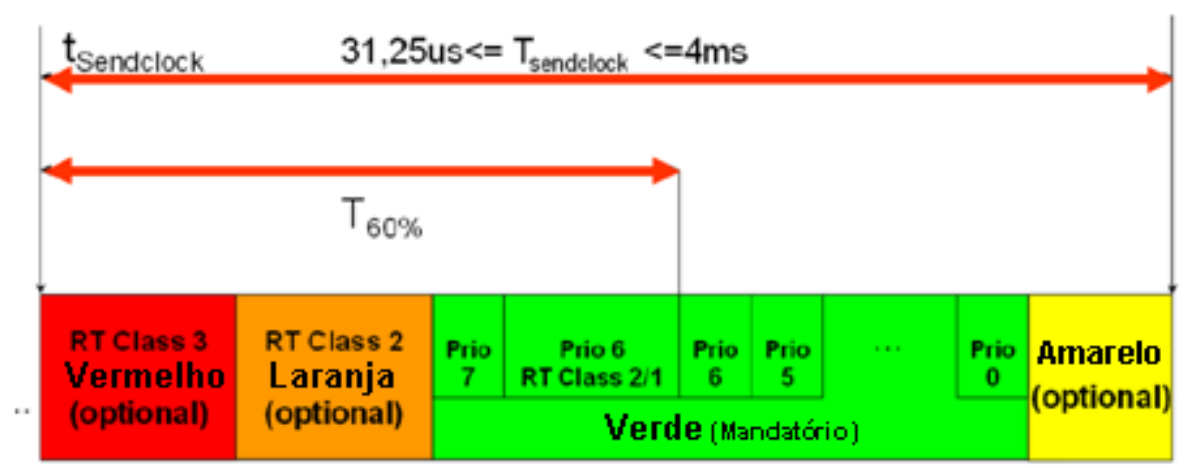

Figura 25 - Ciclo de comunicação Profinet. Adaptado de: Ferrari et al. (2007b)

Fase vermelha: apenas os quadros RT Class 3 ou IRT são enviados, todos os dispositivos Profinet RT Classe 3 sabem quando e qual porta física irão acessar.

Fase Laranja: apenas quadros RT Classe 2 são enviados, porém os dispositivos não são configurados sobre quais portas físicas e dispostivos haverá troca de dados.

Fase Verde: é composta por gerenciamento de mensagem Ethernet por prioridades. São enviados quadros RT Classe 2, RT Class 1 e todo restante dos frames NRT, como frames TCP/IP e UDP/IP (estes possuem baixa prioridade). Estes tipos de pacotes são enviados em grandes quantidades de dados, assim deve ver deixado livre no mínimo $40 \%$ da banda para a parcela NRT.

Fase amarela: nesta fase apenas os quadros que podem ser transmitidos completamente até o final desta fase são enviados.

\subsubsection{Topologias de rede Profinet}

O meio físico utilizado em uma rede Profinet pode ser o cabo elétrico (padrão 100BASE-TX, cabo blindado tipo par trançado com dois pares de cabo Categoria 5) ou fibra óptica. Sentido de transmissão é full duplex, ou seja que atua com comunicação simultânea nas duas direções. Existe adicionalmente a possibilidade de comunicação wireless.

Este trabalho focará a utilização de um cabo elétrico Profinet, que é o meio físico similar ao utilizado para a tecnologia Profibus, além de ser o meio físico mais utilizado nas aplicações de acionamentos de motores elétricos. $O$ 
cabo elétrico Profinet é constituído de 4 fios de cobre (4 núcleos de cobre tipo par trançado) com blindagem. Existem diversos tipos de cabos que variam de acordo com a estrutura dos fios e o tipo de material de revestimento e construção física. O cabo Tipo A utilizado para instalações estáticas, normalmente atinge os requisitos para projetos de automação e são os mais frequentemente utilizados (PROFINET..., 2010).

Da mesma maneira, existem diversos tipos de conectores onde o mais utilizado é o padrão RJ45 devido a sua maneabilidade e ser um padrão consolidado em redes Ethernet, possibilitando ser rapidamente conectado a um notebook ou computador (por exemplo, como função de estação de engenharia)(PROFINET ..., 2010).

A Figura 26 mostra exemplo de conector RJ45 e cabo Profinet.
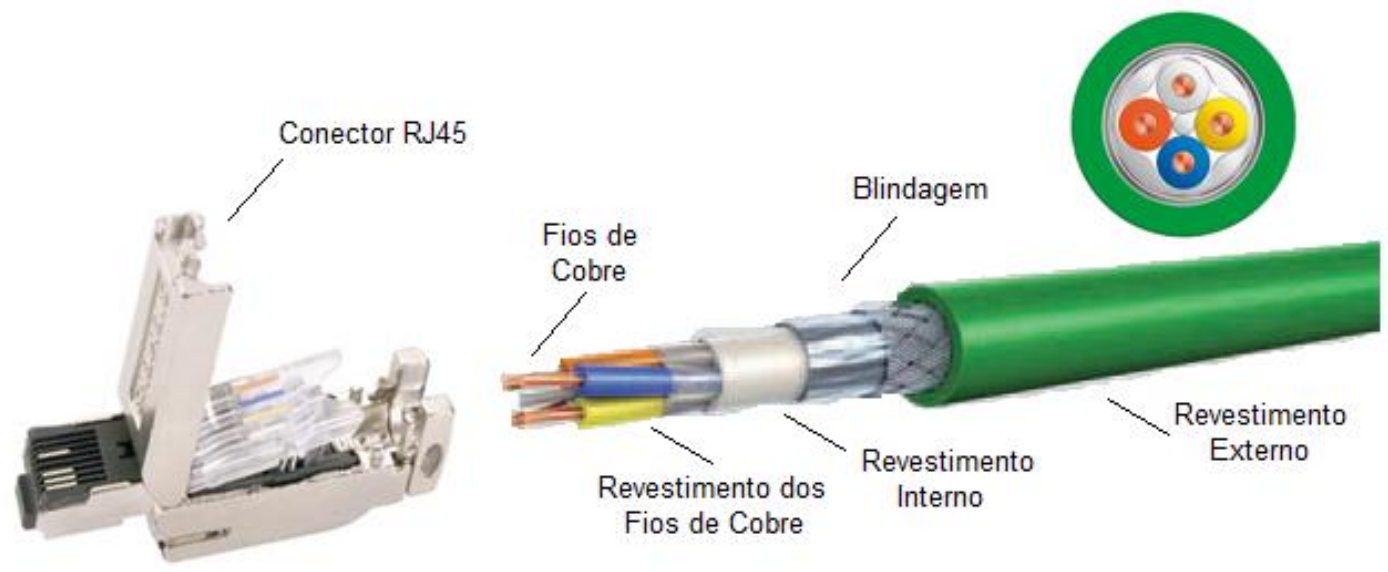

Figura 26 - Exemplo de conector e cabo Tipo A Profinet. Adaptado de: POPP, 2007

O número máximo de IO-Devices por IO-Controller é 256 dispositivos (dependendo do equipamento utilizado pode ser inferior) não sendo necessário utilização de terminadores de rede. A taxa de transmissão de dados é de $100 \mathrm{Mbps}$. Como em uma rede Ethernet padrão, a distância de cabeamento entre cada segmento da rede de ponto a ponto utilizando cabo tipo par trançado é de 100 metros. Porém a distância de uma rede Profinet pode aumentar com utilização de switches e outros dispositivos (POPP, 2007).

A topologia de rede utilizada na tecnologia é bem versátil, sendo possíveis topologia estrela, árvore, barramento ou linha, anel e as combinações entres elas. Um dispositivo bastante utilizado na estrutura da rede é o switch.

O switch modelo "cut-trought" é mais utilizado em aplicações de tempo real restritas, pois insere menos atrasos nas mensagens transmitidas quando 
comparado ao modelo "store-and-foward". Caracteriza-se pela checagem dos seis primeiros bytes da mensagem, correspondentes ao MAC address de destino. Deste modo, há o direcionamento da mensagem para seu destino sem praticamente atrasos, não há a colisão de mensagens, e em contrapartida não há a checagem de erros em toda a mensagem.

\subsubsection{Topologia em Estrela}

Consiste de várias estações (IO-Controller, IO-Devices, IO-Supervisor) interconectadas através de um switch. Trata-se de uma topologia bastante comum em redes Profinet, e consequentemente vem sendo muito utilizada para acionamentos de motores elétricos, pois é adequada para redes que possuem limitação geográfica, como um CCMi que possui seus dispositivos instalados em um único painel.

Nesta topologia, todas as mensagens passam pelo switch, caso um IODevice falhe, a comunicação permanece, porém caso o switch falhe não haverá comunicação.

A Figura 27 mostra um exemplo de topologia em estrela aplicada a acionamentos de motores elétricos.

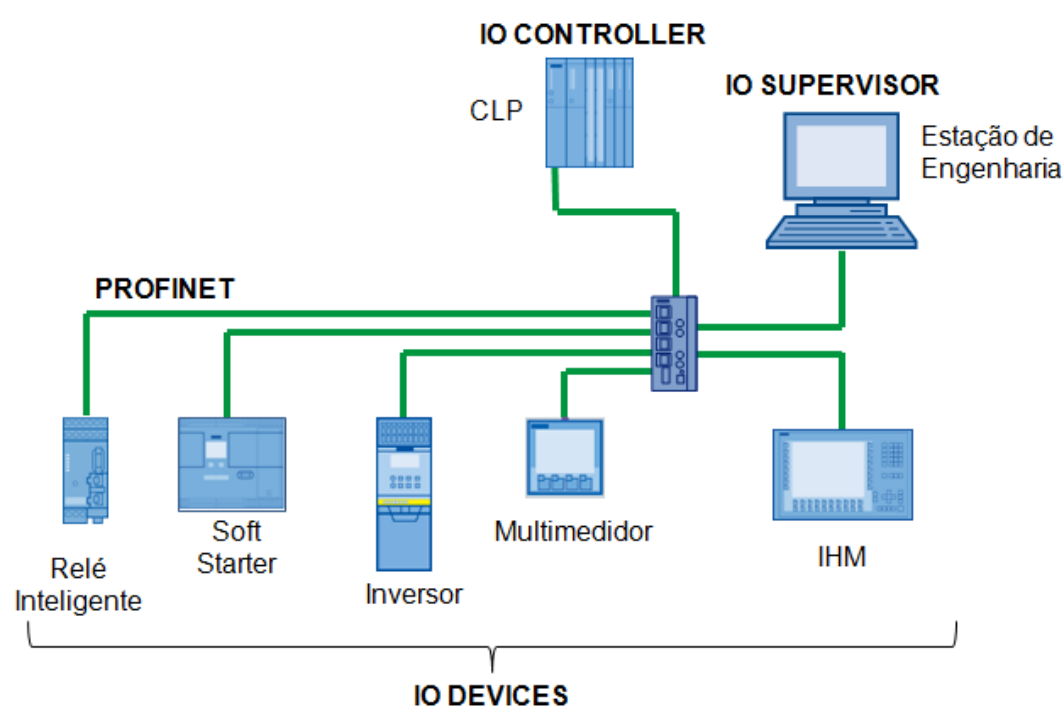

Figura 27 - Topologia Profinet em estrela para acionamentos de motores elétricos

A topologia em árvore é alcançada através de combinações de várias redes na topologia estrela interconectas via outro(s) switch(es). Normalmente são utilizadas para interconectar diversas áreas de automação (PROFINET..., 2010). 


\subsubsection{Topologia em Barramento ou Linha}

Diversos equipamentos Profinet possuem um switch integrado (comumente duas portas elétricas RJ45) que pode ser utilizado para implementação de uma topologia em linha, assim switches adicionais não são necessários e normalmente se utiliza menor quantidade de cabo para interconectar dispositivos. Nesta topologia o mesmo barramento é utilizado para interconectar todas as estações, ou seja, o cabo acessa duas portas elétricas da estação que é interconectada pela estação vizinha. Caso o cabo rompa ou um dispositivo falhe, perde-se a comunicação de parte da rede.

A Figura 28 mostra um exemplo de topologia em linha interconectando dispositivos de acionamentos elétricos.

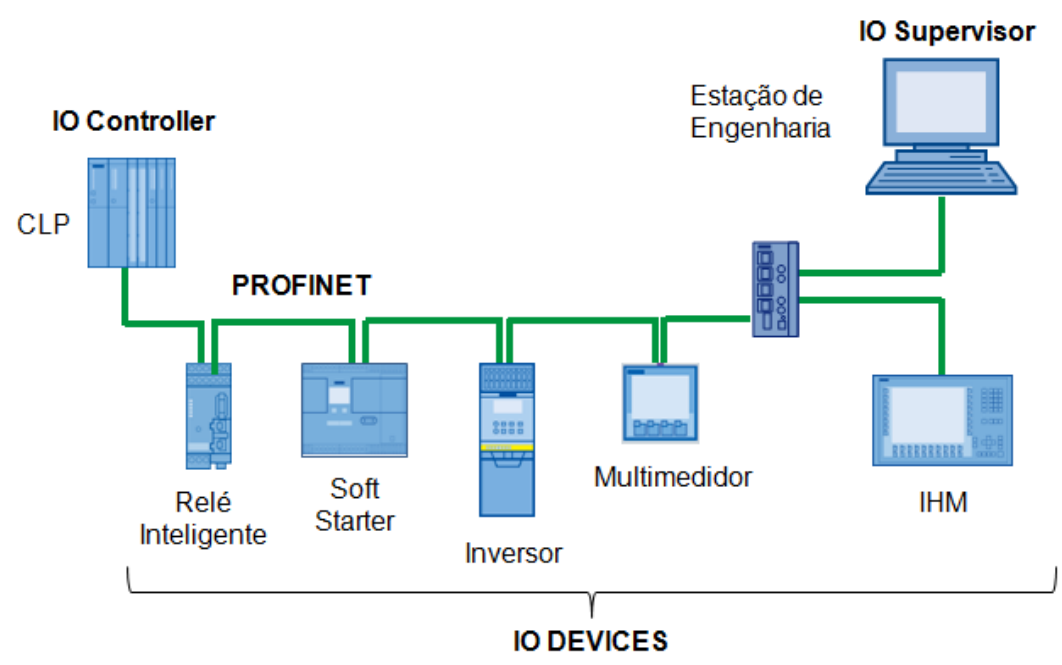

Figura 28 - Topologia Profinet em Barramento/Linha para acionamentos de motores elétricos

\subsubsection{Topologia em Anel}

A rede Profinet possibilita a implementação de uma rede em anel, onde as estações são interconectadas através de seus switches internos fechando um anel, neste caso o Profinet utiliza o protocolo de redundância Media Redundancy Protocol (MRP).

Para possibilitar a utilização de redes em anel, as estações Profinet são definidas como MRP Manager e MRP Client. O MRP Manager é o elemento que une as duas extremidades do barramento para formar o anel. Ele monitora o link de todos os nós conectados e controla o tráfego na rede (PROFINET..., 
2010 e GIORGETTI et al., 2013). Caso haja uma falha no cabeamento ou em um nó, o MRP Manager atua de maneira a não haver perda de comunicação, assim uma estrutura em anel aumenta a disponibilidade da rede de comunicação.

A Figura 29 apresenta um exemplo de rede Profinet em anel para aplicação de acionamentos de motores elétricos. Neste caso a estação de engenharia e IHM estão fora do anel.

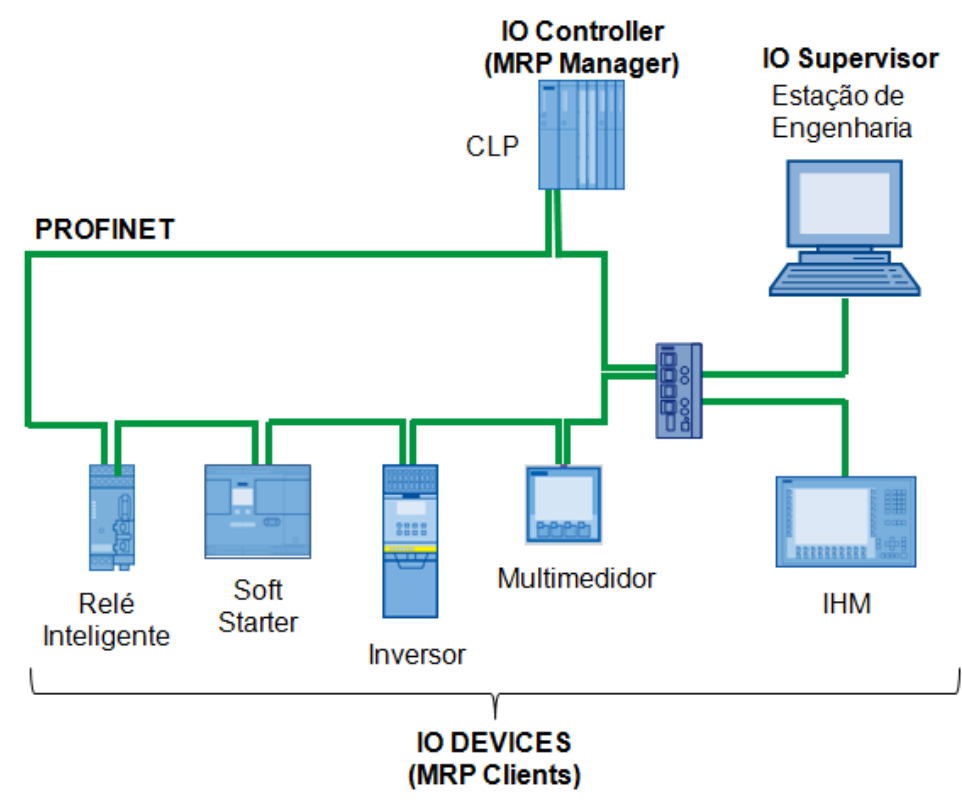

Figura 29 - Topologia em anel Profinet para acionamentos de motores elétricos

\subsection{Considerações finais sobre conceitos dos protocolos}

Este capítulo apresentou conceitos importantes sobre os protocolos Profibus DP e Profinet que serão estudados para aplicações de integração de acionamentos elétricos com sistema de automação. Estes conceitos serão utilizados para fundamentar teoricamente a implementação de experimentos, análise dos resultados e conclusões no desenvolvimento deste trabalho de pesquisa.

Em relação às especificações técnicas das tecnologias, através de dados de normas, documentos de organizações e manuais de fabricantes, foi elaborada uma comparação exibida na Tabela 8. 
Tabela 8 - Comparação de especificações técnicas Profibus DP e Profinet para acionamentos de motores elétricos

\begin{tabular}{|l|l|l|}
\hline Característica & \multicolumn{1}{|c|}{ PROFIBUS DP } & \multicolumn{1}{|c|}{ PROFINET } \\
\hline Meio Físico & $\begin{array}{l}\text { Par traçado } \\
\text { Fibra ótica }\end{array}$ & $\begin{array}{l}\text { Par trançado } \\
\text { Fibra ótica } \\
\text { Sem fio } \\
\text { Coaxial }\end{array}$ \\
\hline Número de estações por mestre & 126 & 256 \\
\hline Volume de Dados por dispositivo & 244 bytes & 1440 bytes \\
\hline Serviços de TI & Não & Sim \\
\hline Topologia & $\begin{array}{l}\text { Barramento (típica para } \\
\text { meio físico par trançado) }\end{array}$ & $\begin{array}{l}\text { Barramento, } \\
\text { estrela, anel e } \\
\text { topologias mistas }\end{array}$ \\
\hline Taxa de Transmissão (máximo) & 12Mbps & 100Mbps \\
\hline Tipo de Transmissão & Half Duplex & Full Duplex \\
\hline Terminadores & Necessário & Não necessário \\
\hline
\end{tabular}

Verifica-se na tabela algumas funcionalidades adicionais para rede Profinet, como possibilidade de utilização de mais estações por IO-Controller em relação ao mestre classe 1 , maior flexibilidade na implementação física da rede devido a mais possibilidades de topologias e maior capacidade para troca de dados. Adicionalmente possui funcionalidade de serviços de tecnologia da informação (TI), como opção de Web Browser de dispositivos que podem facilitar informações de diagnósticos dos CCMis aos operadores do sistema.

Para análise do desempenho dessas redes através de implementações práticas, a próxima seção apresenta indicadores de desempenho de redes de comunicação industrial em pesquisas correlatas no meio acadêmico. 


\section{INDICADORES DE DESEMPENHO}

Este capítulo apresenta indicadores de desempenho de redes de comunicação industrial, inicialmente expõe-se os indicadores da norma IEC 61784-2 e posteriormente pesquisas correlatas na literatura são apresentadas com objetivo de verificar desempenho de uma rede de comunicação industrial. A partir deste ponto são definidos os indicadores a serem utilizados na comparação de desempenho de redes de comunicação do escopo deste trabalho.

\subsection{Indicadores de desempenho da norma IEC 61784-2}

Para a análise de desempenho de redes de comunicação, alguns parâmetros devem ser considerados de acordo com sua relevância em determinadas aplicações. A norma IEC61784-2 apresenta indicadores de desempenho para redes de comunicação industrial baseado em Ethernet (RTE), como o protocolo Profinet. Esses indicadores verificam:

- recursos de um dispositivo RTE

- recursos de uma rede RTE

- requisitos de uma aplicação

Os indicadores de desempenho segundo esta norma são:

- Delivery time: tempo necessário para envio de um pacote de dados de um dispositivo fonte até o dispositivo de destino.

- Número de estações RTE: número máximo de estações em uma rede de comunicação RTE, switches não são considerados para este número.

- Basic Network Topology: topologias que são suportados por um protocolo RTE. As topologias básicas são: estrela, anel e barramento, podendo haver também uma combinação das topologias básicas.

- Number of switches between end stations: número de switches entre duas estações que se comunicam.

- Throughput RTE: total de dados de tempo real trafegando em um ponto específico da rede por segundo.

- Non-RTE bandwidth: porcentagem de banda utilizada para comunicação de dados de não tempo real trafegando em um ponto específico da rede. 
- Time synchronization accuracy: indica o desvio máximo de clock entre duas estações.

- Non-time based synchronization accuracy: indica o jitter máximo do comportamento cíclico de duas estações.

- Redudancy recovery time: indica o tempo máximo necessário colocar a rede em plena operação após uma falha.

Dos indicadores apresentados, no que diz respeito a uma aplicação de CCMi, o número de estações se mostra importante, pois existem plantas industriais com número de motores por CCM bastante alta, como em indústrias de processo (indústria química, petroquímica, açúcar e etanol) que chegam a mais de $\mathbf{2 0 0}$ motores elétricos. Adicionalmente, apesar da dispersão geográfica dos equipamentos em um CCMi ser relativamente pequena, a variedade de topologias afeta diretamente a flexibilidade de rede, por exemplo na inserção de novos dispositivos, disponibilidade, entre outros aspectos e se torna também um indicador importante.

\subsection{Pesquisas correlatas sobre indicadores de desempenho na literatura}

Os indicadores de desempenho também são abordados em Felser (2005) que adicionalmente apresenta mais detalhes relativos ao indicador Delivery Time, mostrando uma possível classificação como classe de baixa velocidade com delivery time em torno de $100 \mathrm{~ms}$, a segunda classe para controle de processo com delivery time abaixo de $10 \mathrm{~ms}$ e finalmente, a terceira e mais restrita classe para aplicações de motion control com tempo de ciclo menores que $1 \mathrm{~ms}$.

Marsal et al. (2006) e Ferrari et al. (2007a) analisam desempenho em redes baseadas em Ethernet através do tempo de resposta (response time), que também pode ter a nomenclatura de tempo de reação de evento (Event Reaction Time) como sendo o tempo requerido para produzir uma saída a partir de uma mudança na entrada.

Ferrari et al. (2007a), ainda sobre o indicador tempo de reação ao evento, analisa o jitter e refresh time em aplicações de redes RTE. Segundo a (INTERNATIONAL TELECOMMUNICATION UNION, 1993), jitter é definido como variações de pequenas durações não acumulativas nos instantes significativos de um sinal digital da sua posição ideal no tempo. 
Assim, Ferrari et al.(2006) apresenta uma abordagem para estimar o jitter de redes Profinet através de modelos matemáticos. Posteriormente ele apresenta uma metodologia experimental através de uma estrutura de rede Profinet para medir estes valores e comparar resultados do modelo matemáticos e reais desta rede. Os resultados mostram que o modelo matemático apresentado no artigo é válido. A Figura 30 mostra o esquemático do experimento utilizada no artigo científico.
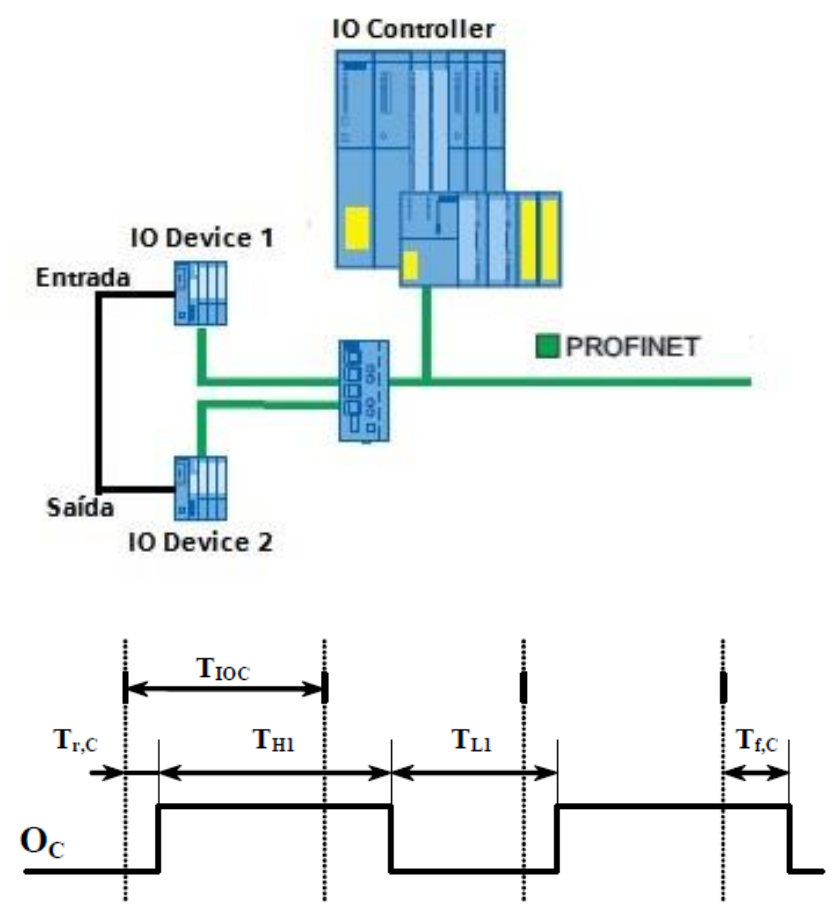

Figura 30 - Modelo apresentado por Ferrari et al. (2006) para medição do tempo de reação de evento e jitter

Kleines et al. (2008) estuda desempenho de redes Profinet, analisando a possibilidade de utilização desta tecnologia em substituição da tecnologia Profibus DP. Os indicadores utilizado são latência e o jitter. Para medições reais, um sistema piloto foi implementado similarmente ao apresentado acima por Ferrari et al. (2006), com mais dispositivos na rede e mantendo comunicação RT Classe 1. Os resultados exibidos mostraram valores de jitter maiores quando comparados ao Profibus DPV2.

Jasperneite, Schumacher e Weber (2007), Schumacher e Weber (2008) e Prytz (2008) comparam o desempenho de redes Profinet IRT e redes EtherCAT em aplicações que exigem comportamento em tempo real restrito. $O$ 
estudo é baseado em cálculos e simulações considerando implementação de ambas as redes em sua estrutura ótima. O principal indicador de desempenho utilizado foi o tempo de ciclo (cycle time), ou seja o cálculo do mínimo tempo de ciclo alcançado pelas tecnologias em função do número de dispositivos na rede em alguns cenários distintos (topologias, volume de dados, velocidade de transmissão). Outros indicadores ainda são citados como jitter, disponibilidade de funcionalidades nos protocolos, custo de implementação entre outros. Prytz (2008) apresenta melhores desempenho com EtherCAT enquanto Schumacher (2008) apresenta uma abordagem baseada na topologia para melhorar o desempenho da tecnologia Profinet.

Depari et al. (2008) apresenta um instrumento de baixo custo para medição de desempenho em redes RTE, este é capaz de associar uma estampa de tempo com resolução menor que 100ns nos frames RTE e enviar para um software convencional de análise dos dados off-line. Adicionalmente o instrumento de medição não introduz atrasos no funcionamento do trecho de rede analisado. O autor compara dados coletados pelo protótipo em um hardware de alto custo que usa duplicação de sinal na camada física do protocolo, verificando sua eficácia. Essa dissertação utiliza fundamentos deste trabalho na elaboração do sistema de coleta de dados tanto na tecnologia Profibus DP como na tecnologia Profinet.

Ferrari et al. (2008) também apresenta um instrumento de baixo custo, que adicionalmente é implementado de forma distribuída em uma rede RTE qualquer. Ele utiliza o protocolo Profinet Class 3 (PN IRT) para realizações do protótipo, que alcança tempos de ciclo de $100 \mu \mathrm{s}$ e jitter de $1 \mu \mathrm{s}$, verificando atrasos ponto a ponto, sincronismos entre estações, etc. $\mathrm{O}$ instrumento mede diversos pontos da rede simultaneamente e utiliza uma estação de monitoramento (utilizando software "WireShark") que armazena os dados para análise posterior. Esta dissertação também utiliza o software "WireShark" para armazenamento dos dados, e posterior análise.

Podemos concluir que o jitter e o tempo de ciclo são indicadores importantes utilizados na literatura, principalmente em relação a aplicações de tempo real restritas como em posicionamento e controle de velocidade de motores elétricos, onde o tempo de ciclo pode chegar a $1 \mathrm{~ms}$. Adicionalmente a inserção de grande quantidade de equipamentos em uma rede, no caso de um 
CCMi com muitos acionamentos elétricos, pode influenciar neste indicador. Por estes motivos, estes indicadores são utilizados para verificação de desempenho das tecnologias estudadas.

Em Ferrari et al. (2011) é analisado o comportamento de uma de rede Profinet com diversos dispositivos (127 IO-Devices). Através da coleta de pacotes no ramal do IO-Controller que foram enviados pelos diversos nós, são verificados parâmetros de tempo como jitter, tempo médio de troca de dados, além da utilização de banda. Desta maneira, este artigo é de grande importância para o escopo deste trabalho. Será utilizada uma adaptação da metodologia para coleta de dados utilizado por Ferrari et al. (2011) para redes Profinet e Profibus DP em aplicações de acionamento de motores elétricos, que similarmente ao cenário deste estudo, normalmente são compostas por um grande número de dispositivos.

Em outro estudo Domingues-Jaimes, Wisniewski e Trsek (2010) analisam o tráfego de dados na rede, introduzindo uma metodologia para identificar dados RTE dos protocolos Profinet RT, EtherNet/IP and Modbus TCP/IP.

Assim, se observa que o indicador ocupação de largura de banda pode ser utilizado na comparação entre as redes estudadas em uma aplicação com vários dispositivos, pois a partir dele conclusões podem ser tomadas em relação a capacidade de transmissão de dados da rede.

Sestito et al. (2013), compara redes Profibus DP e Profinet em uma aplicação com apenas um mestre / IO-Controller e um Escravo / IO-Device. Ele utiliza equipamentos para captura das mensagens Profibus DP e Profinet e alcança valores de ocupação de banda, tempo de ciclo e jitter. A metodologia deste estudo é baseada na utilização destes equipamentos e foi adaptada para este trabalho. 


\section{METODOLOGIA}

Este capítulo descreve a metodologia empregada na análise e comparação de desempenho de tecnologias de redes de automação industrial (Profibus DP e Profinet) na integração de acionamentos de motores elétricos trifásicos ao sistema de automação.

Define-se três indicadores de desempenho do ponto de vista de aspectos da rede, e outro para verificação de desempenho do ponto de vista físico da aplicação considerada. No que diz respeito a aspectos da rede, os indicadores utilizados foram: tempo de ciclo, jitter e ocupação de banda; e para verificação de desempenho físico, a aplicação estudada foi controle de posicionamento simples de motor elétrico, através do indicador tempo de acomodação do sistema.

A partir destes indicadores, a metodologia é implementada através de coleta e análise de dados de experimentos práticos, assim este trabalho se trata de uma pesquisa experimental com abordagem quantitativa.

$\mathrm{Na}$ coleta de dados, os pacotes trocados pela rede em diversos tempos de ciclo são coletados durante um período determinado, através de um sistema de medição que será descrito posteriormente.

Os dados de todos os $(n)$ ciclos são tratados para se obter a lista de valores dos tempos de ciclo (tc) e os respectivos números de bytes transmitidos em cada ciclo (volume de dados).

Em relação ao tempo de ciclo, é analisado seu valor médio e desvio padrão em relação ao configurado no CLP. O objetivo é verificar a exatidão e precisão dos valores para comparar a tecnologia em relação ao seu determinismo, através de distribuição normal dos dados coletados.

Segundo o Instituto Nacional de Metrologia, Qualidade e Tecnologia (2012), exatidão é o grau de concordância entre um valor medido e um valor verdadeiro, enquanto precisão é o grau de concordância entre valores medidos, obtidos por medições repetidas. A Figura 31 mostra um exemplo de distribuição normal para análise do tempo de ciclo. 


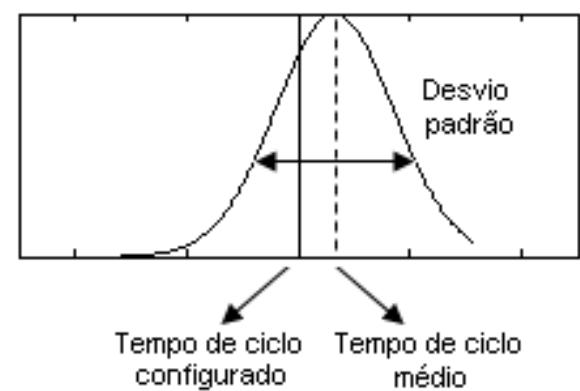

Figura 31 - Curva de distribuição normal para tempo de ciclo

Quanto menor a diferença entre média do tempo de ciclo e valor configurado mais exato é o valor. Quanto menor o valor do desvio padrão, maior a precisão. Em conjunto esta análise verifica o determinismo da rede.

Nesta dissertação considera-se como taxa de transmissão média, o valor obtido pela equação 5 , e ocupação de banda o resultado calculado a partir da equação 6 .

Taxa de transmissão média $[$ bits $/ s]=\frac{\sum_{1}^{n} \frac{\text { volume de dados } n}{t c_{n}}}{n}$

Ocupação de banda média[\%] $=\frac{\text { taxa de transmissão média }}{\text { taxa de transmissão configurada }}$

Para a tecnologia Profinet, utilizada em $100 \mathrm{Mbps}$, foi considerada apenas parcela de $60 \%$ deste valor, destinada a tráfego de dados de processo em tempo real. Isto foi considerado, pois sua especificação requer que $40 \%$ de sua largura de banda seja deixado livre para utilização de comunicação de non-real time, para funções de diagnóstico e configuração por exemplo (FERRARI et al., 2011). Assim está parcela não deve ser considerada no cálculo da equação 6 , com objetivo de deixar as tecnologias em condições similares. A tecnologia Profibus DP não cita nenhuma recomendação em relação a ocupação de largura de banda, assim foi considerada $100 \%$ do valor parametrizado. 


\subsection{Experimentos para coleta de dados}

Dois cenários típicos de acionamentos de motores elétricos foram utilizados para verificar o comportamento de redes de automação industrial aplicada no escopo deste trabalho. Em ambas situações, procurou-se garantir, mesma configuração de equipamentos para ambos protocolos, de maneira a garantir condições similares de operação para a coleta de dados. Neste contexto, os seguintes aspectos são considerados:

- O controlador lógico programável (CPU 317-2 DP/PN) do sistema possui incorporado capacidade de comunicação de Mestre Classe 1 para Profibus DP e IO-Controller para Profinet no mesmo hardware;

- o multimedidor de grandezas elétricas (PAC3200) troca mesma quantidade de dados de processo e disponibiliza comunicação de ambas tecnologias através de módulos de comunicação, utilizado como acessório;

- para simulação de partida direta e reversora foi utilizado o relé inteligente (Simocode Pro V), parametrizado de maneira a realizar troca de mesma quantidade de dados de processo, através de equipamentos distintos que suportam ambas tecnologias;

- para estação remota de coleta de entradas e saídas, digitais e analógicas foi utilizado o equipamento ET200S, com mesma configuração de entradas e saídas, alterando apenas a unidade de comunicação para cada tecnologia, que possuem especificações técnicas equivalentes;

- finalmente, para inversor de frequência foi utilizado configuração com mesmo pacote de troca de dados de processo, motor elétrico e módulo de potência, alterando apenas a unidade de controle para cada tecnologia, que apresentam especificações técnicas similares. Adicionalmente, no cenário de controle de posição, a mesma configuração de parâmetros de controle foi utilizada.

O software de programação do CLP utilizado para implementação das redes dos experimentos foi o SIMATIC STEP7 Version $5.5+$ SP2 + HF1 da Siemens. Adicionalmente foi utilizado o software SCOUT V4.3.1.12 para parametrização do inversores de frequência $\mathrm{S} 110$ do mesmo fabricante. 
No escopo deste trabalho não foram utilizados partidas com soft starters e disjuntores de alimentação. Os experimentos foram realizados no Laboratório de Automação Industrial da Escola de Engenharia de São Carlos que disponibiliza infraestrutura necessária.

\subsubsection{Cenário 1 - Capacidade de transmissão de dados na rede}

O "Cenário 1" se baseia em uma aplicação de CCMi representativa de indústrias de processo, onde a malha de controle exige tempo real, porém para valores não restritos de tempo, e geralmente são compostas por grande quantidades de dispositivos na rede.

Nestas condições serão verificadas ocupação de banda de ambas tecnologias verificando sua capacidade de transmissão de dados, e adicionalmente verifica-se variações de tempo de ciclo e jitter alcançados pela rede.

Os equipamentos utilizados para experimento com rede Profibus DP são listados na Tabela 9.

Tabela 9 - Equipamentos utilizados para experimento Profibus DP - Cenário 1

\begin{tabular}{|l|l|l|c|c|l|}
\hline Item & Equipamento & Descrição & $\begin{array}{l}\text { Bytes de } \\
\text { Entrada }\end{array}$ & $\begin{array}{l}\text { Bytes de } \\
\text { Saída }\end{array}$ & Função \\
\hline 1 & CPU 317-2 DP/PN & Controlador & - & - & $\begin{array}{l}\text { Mestre } \\
\text { Classe 1 }\end{array}$ \\
\hline 2 & PAC3200 & Multimedidor & 112 & 2 & Escravo DP \\
\hline 3 & Simocode Pro V & Partida Direta & 10 & 4 & Escravo DP \\
\hline 4 & ET200S & Sinais digitais/analógicos & 7 & 4 & Escravo DP \\
\hline 5 & Sinamics S110 & Inversor de frequência & 24 & 24 & Escravo DP \\
\hline 6 & ProfiTrace 2 & Analisador de rede & - & - & $\begin{array}{l}\text { Mestre } \\
\text { Classe 2 }\end{array}$ \\
\hline
\end{tabular}

Para a configuração descrita, serão coletados dados nas velocidades de $500 \mathrm{kbps}, 1.5 \mathrm{Mbps}$, 3Mbps, $6 \mathrm{Mbps}$ e 12Mbps em modo DPV0.Também analisase a rede Profibus DPV0 com parametrização de tempo de ciclo fixo, onde se mantém a taxa de transmissão em 12Mbps, e os tempos de ciclo parametrizados são de $1 \mathrm{~ms}, 2 \mathrm{~ms}$, $4 \mathrm{~ms}$ e $8 \mathrm{~ms}$.

Através do analisador de redes Profibus DP é possível a coleta de todos pacotes que trafegam pela rede. $\mathrm{O}$ analisador adiciona estampa de tempo nos pacotes, que são coletados através do software específico da ferramenta ProfiTrace 2. Os dados são tratados em uma rotina implementada em uma 
planilha do Microsoft Excel, especialmente desenvolvida para este trabalho. A macro gera os valores dos indicadores de desempenho utilizados na análise e comparação das redes.

O sistema de medição utiliza um analisador de rede que afere dados intrínsecos ao barramento conferindo qualidade aos dados coletados. $O$ ProfiTrace 2 é transparente aos pacotes em ambas as direções, e sua estampa de tempo possui resolução de 100ns. O analisador é ligado a rede através de um Tap Connector, que é desenvolvido de maneira a não causar distúrbios na rede. Este equipamento suporta mensagens Profibus nas versões DPV0, DPV1 e DPV2.

A Figura 32 apresenta o esquemático de rede Profibus DP para experimento do Cenário 1.

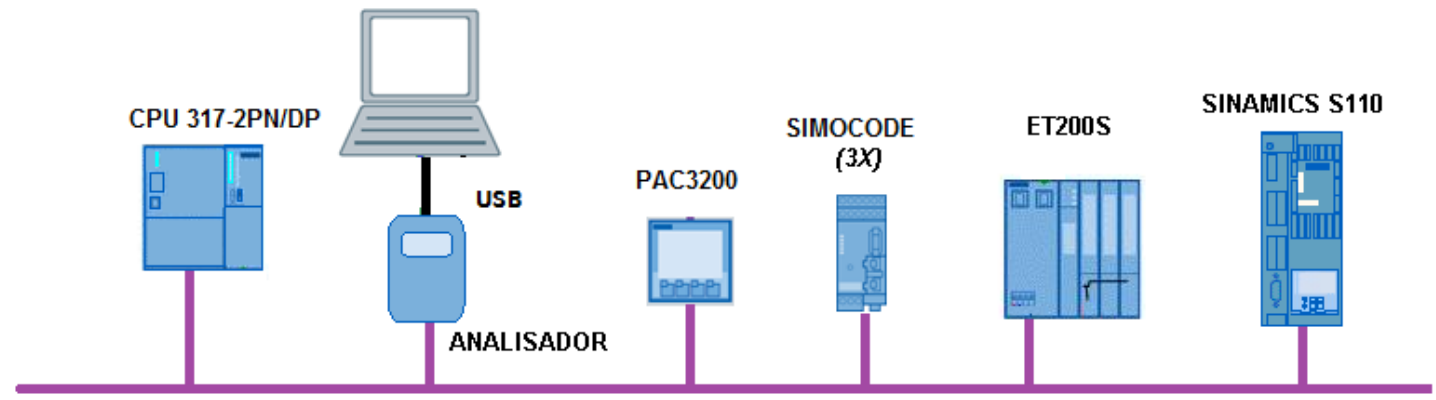

PROFIBUS DP

Figura 32 - Experimento Profibus DP - Cenário 1

Resumidamente, as redes apresentadas na

Tabela 10 foram implementadas para a tecnologia Profibus DP no Cenário 1.

Tabela 10 - Especificação das redes Profibus DP do Cenário 1

\begin{tabular}{|c|c|c|}
\hline Rede & $\begin{array}{c}\text { Taxa de } \\
\text { Transmissão }\end{array}$ & $\begin{array}{c}\text { Tempo de } \\
\text { Ciclo }\end{array}$ \\
\hline 1 & $500 \mathrm{kbps}$ & - \\
\hline 2 & $1.5 \mathrm{Mbps}$ & - \\
\hline 3 & $3 \mathrm{Mbps}$ & - \\
\hline 4 & $6 \mathrm{Mbps}$ & - \\
\hline 5 & $12 \mathrm{Mbps}$ & - \\
\hline 6 & $12 \mathrm{Mbps}$ & $1 \mathrm{~ms}$ \\
\hline 7 & $12 \mathrm{Mbps}$ & $2 \mathrm{~ms}$ \\
\hline 8 & $12 \mathrm{Mbps}$ & $4 \mathrm{~ms}$ \\
\hline 9 & $12 \mathrm{Mbps}$ & $8 \mathrm{~ms}$ \\
\hline
\end{tabular}


Realiza-se coleta em torno de 70 mil pacotes para cada rede acima, adicionando equipamentos gradativamente conforme mostra a Tabela 11. Totaliza-se para rede Profibus DP, 54 experimentos no Cenário 1. A rede sugerida com taxa de transmissão de $12 \mathrm{Mbps}$ e tempo de ciclo de $0.5 \mathrm{~ms}$ não é possível ser implementada devido a restrições técnicas dos equipamentos utilizados.

Tabela 11 - Adição de equipamentos nos experimentos do Cenário 1

\begin{tabular}{|c|c|c|c|c|c|}
\hline \multirow[t]{2}{*}{ Rede } & \multicolumn{4}{|c|}{ Quantidade de Escravos / IO-Devices } & \multirow{2}{*}{$\begin{array}{c}\text { Total de } \\
\text { Escravos/ } \\
\text { IO-Devices }\end{array}$} \\
\hline & PAC3200 & Simocode & ET200S & S110 & \\
\hline $\mathrm{x} .1$ & 1 & 0 & 0 & 0 & 1 \\
\hline$x .2$ & 1 & 1 & 0 & 0 & 2 \\
\hline$x .3$ & 1 & 2 & 0 & 0 & 3 \\
\hline $\mathrm{x.4}$ & 1 & 3 & 0 & 0 & 4 \\
\hline x. 5 & 1 & 3 & 1 & 0 & 5 \\
\hline$x .6$ & 1 & 3 & 1 & 1 & 6 \\
\hline
\end{tabular}

Para a tecnologia Profinet, os equipamentos utilizados para experimento são listados na Tabela 12. Nesta configuração, são coletados dados com tempo de ciclo de $0.5 \mathrm{~ms}, 1 \mathrm{~ms}, 2 \mathrm{~ms}$ e $4 \mathrm{~ms}$, no modo de operação RT (Class 1 ), utilizando-se as topologias estrela (com utilização de um switch externo) e barramento (sem utilização de switch externo, ou seja utiliza-se apenas switches integrados aos IO-Devices).

Tabela 12 - Equipamentos utilizados para experimento Profinet - Cenário 1

\begin{tabular}{|l|l|l|c|c|l|}
\hline Item & Equipamento & Descrição & $\begin{array}{l}\text { Bytes de } \\
\text { Entrada }\end{array}$ & $\begin{array}{l}\text { Bytes de } \\
\text { Saída }\end{array}$ & Função \\
\hline 1 & CPU 317-2 DP/PN & Controlador & - & - & IO-Controller \\
\hline 2 & PAC3200 & Multimedidor & 112 & 2 & IO-Device \\
\hline 3 & Simocode Pro V & Partida Direta & 10 & 4 & IO-Device \\
\hline 4 & ET200S & Sinais digitais/analógicos & 7 & 4 & IO-Device \\
\hline 5 & Sinamics S110 & Inversor de frequência & 24 & 24 & IO-Device \\
\hline 6 & TAP Kunbus & $\begin{array}{l}\text { Analisador de rede } \\
\text { Ethernet Data Sniffer }\end{array}$ & - & - & $\begin{array}{l}\text { IO- } \\
\text { Supervisor }\end{array}$ \\
\hline 7 & Scalance X208 & Switch & - & - & - \\
\hline
\end{tabular}


Através do software Wireshark 1.12.1 e do TAP de Ethernet industrial TAP EDS 2100 do fabricante Kunbus, pode-se visualizar o tráfego da rede, e realizar coleta de pacotes trocados no IO-Controller com estampa de tempo. A Figura 33 mostra dados coletados pelo software Wireshark.

Da mesma maneira que na tecnologia anterior, o TAP Kunbus é praticamente transparente aos pacotes que trafegam na rede, e não interfere no desempenho da rede testada já que insere tempo de atraso na ordem de 1ns. Possui resolução de estampa de tempo de 10ns, e é denominado como Ethernet Data Sniffer. Sniffers também são utilizados em outros trabalhos acadêmicos, como em Depari et al. (2008) e Ferrari et al. (2008) .

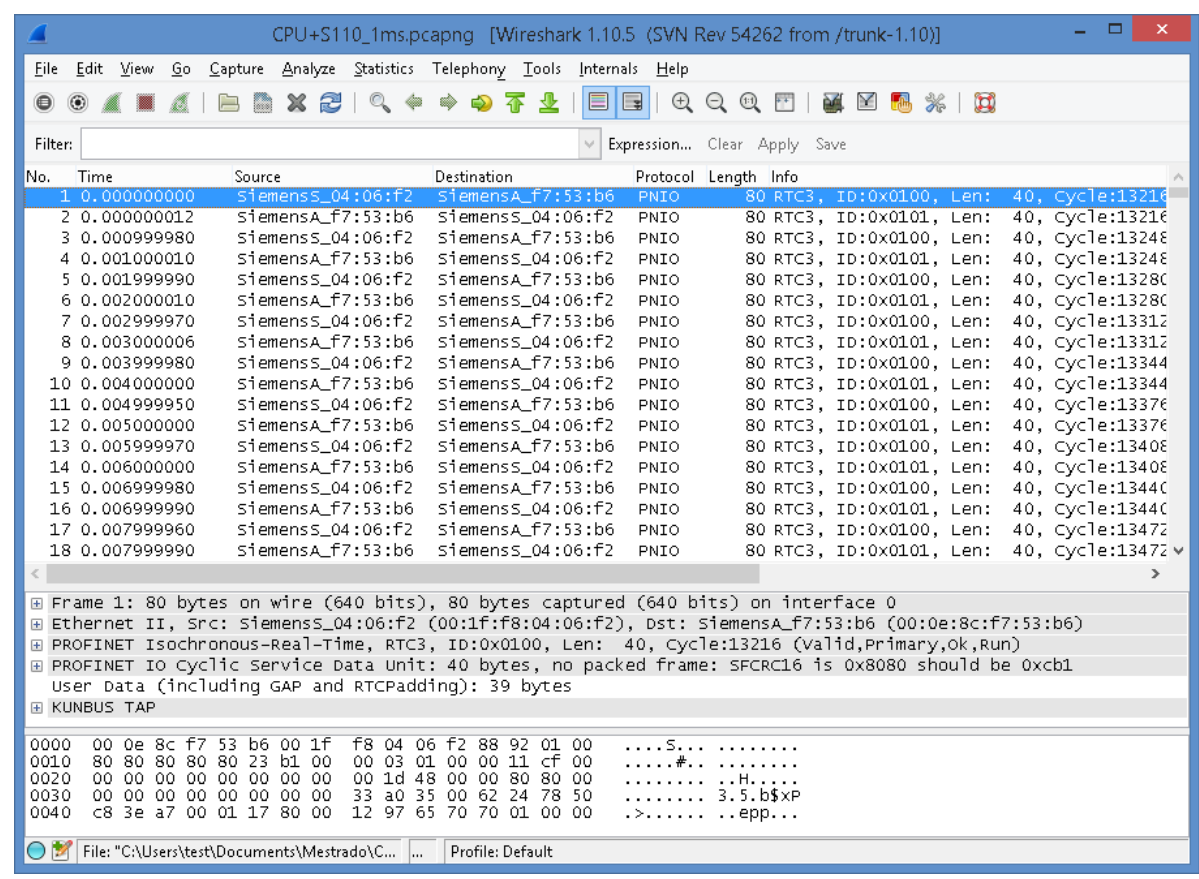

Figura 33 - Dados coletados pelo software Wireshark em conjunto com TAP Kunbus

Depari et al. (2008) apresenta a utilização de sniffers com estampa de tempo para estimar tempo de ciclo e jitter de redes RTE, acrescenta também que a utilização destes instrumentos são úteis em plantas industriais para análise da rede, porém não são indicados para utilização contínua devido a sua complexidade e alto custo.

O sniffer (no caso o TAP Kunbus) coleta os pacotes de um segmento de rede para outro segmento, que trafega pelas portas $X .1$ e X.2, conforme mostra esquema da Figura 34. Os pacotes que chegam na porta X.1 por exemplo, são 
duplicados sendo um deles dirigido diretamente a porta X.2 (com tempo de atraso desprezível) e para o outro é inserido a estampa de tempo. Em seguida este pacote é enviado via Ethernet para um software de análise, como o Wireshark.

A Figura 34 mostra duas maneiras possíveis de inserir estampa de tempo em um pacote de dados.

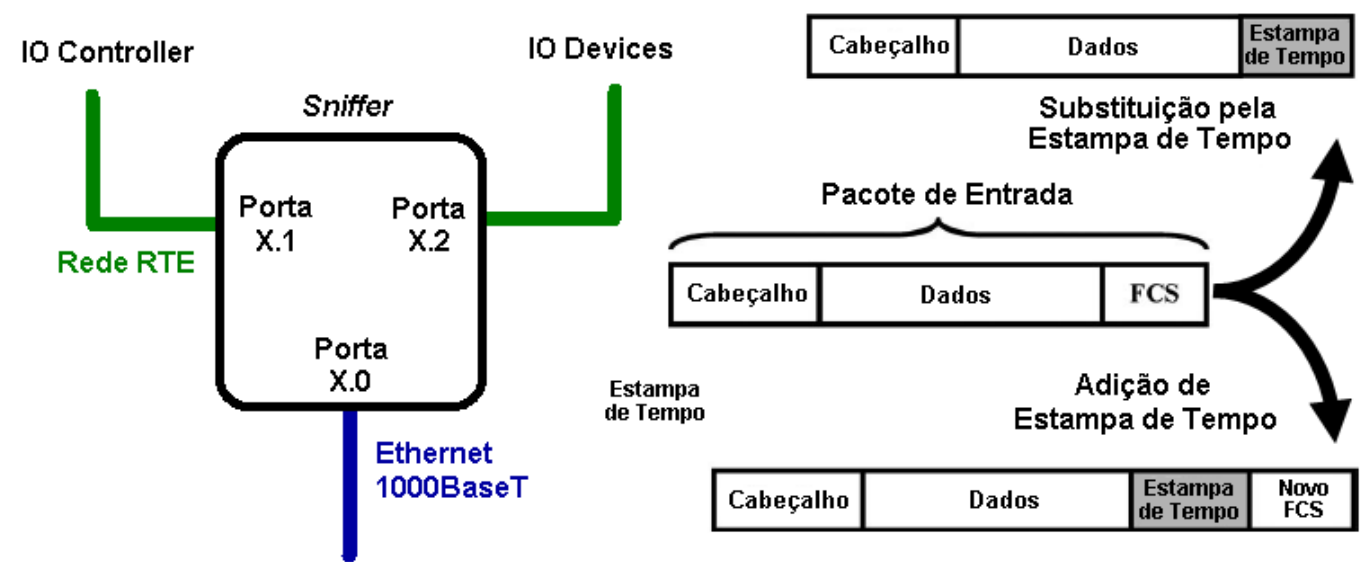

Figura 34 - Utilização de estampa de tempo. Adaptado de: Depari et al. (2008)

A Figura 35 apresenta o esquemático de rede Profinet utilizando topologia estrela no experimento do Cenário 1.

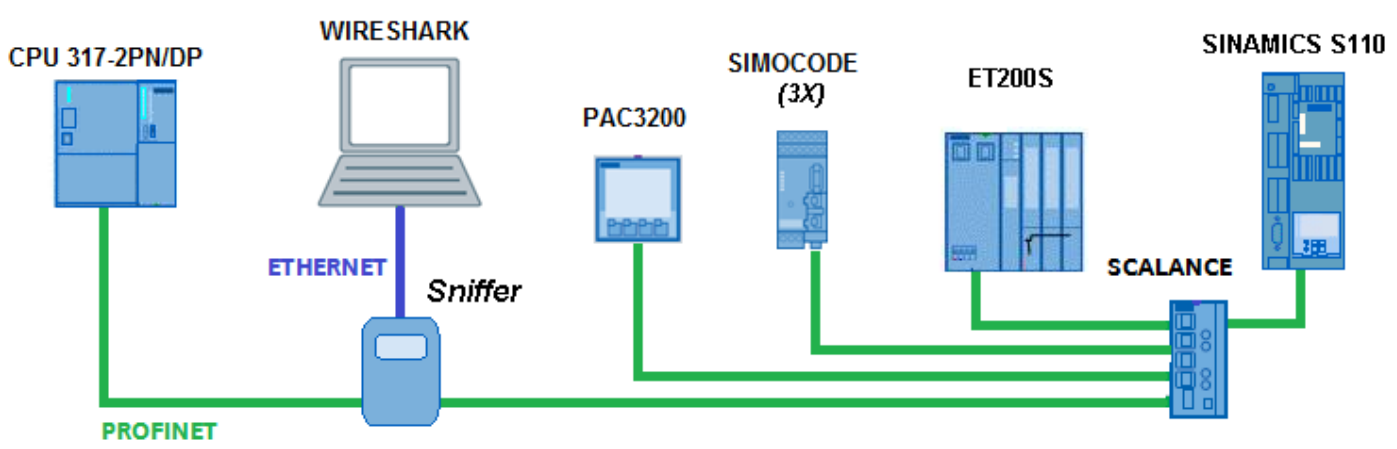

Figura 35 - Experimento Profinet topologia estrela - Cenário 1

Adicionalmente para o Cenário 1, são implementadas redes Profinet utilizando topologia barramento, ou seja utilizando apenas os switches integrados de cada equipamento. A Figura 36 apresenta o esquemático. 


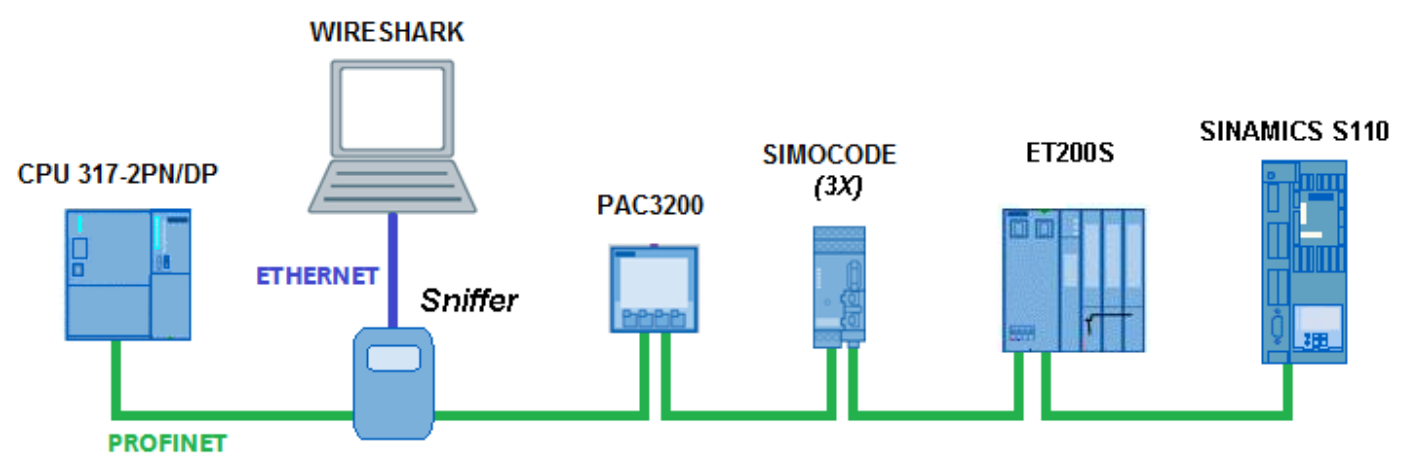

Figura 36 - Experimento Profinet topologia barramento - Cenário 1

Coleta-se por volta de 70 mil pacotes para cada rede implementada conforme mostra Tabela 13, adicionando equipamentos gradativamente conforme Tabela 11. Totaliza-se para a rede Profinet, 60 experimentos no Cenário 1.

Tabela 13 - Especificação das redes Profinet do Cenário 1

\begin{tabular}{|c|c|c|}
\hline Rede & Topologia & $\begin{array}{c}\text { Tempo de } \\
\text { Ciclo }\end{array}$ \\
\hline 10 & Estrela & $0.5 \mathrm{~ms}$ \\
\hline 11 & Estrela & $1 \mathrm{~ms}$ \\
\hline 12 & Estrela & $2 \mathrm{~ms}$ \\
\hline 13 & Estrela & $4 \mathrm{~ms}$ \\
\hline 14 & Estrela & $8 \mathrm{~ms}$ \\
\hline 15 & Barramento & $0.5 \mathrm{~ms}$ \\
\hline 16 & Barramento & $1 \mathrm{~ms}$ \\
\hline 17 & Barramento & $2 \mathrm{~ms}$ \\
\hline 18 & Barramento & $4 \mathrm{~ms}$ \\
\hline 19 & Barramento & $8 \mathrm{~ms}$ \\
\hline
\end{tabular}

Da mesma maneira, os dados são tratados através de uma macro baseada em planilha de Microsoft Excel, que gera resultados de tempo de ciclo médio e seu desvio padrão, jitter médio, e finalmente ocupação de banda. Estes resultados são apresentados resumidamente no capítulo de discussão dos resultados.

\subsubsection{Cenário 2 - Aplicações de Controle de posição}

Este cenário se baseia em uma aplicação comum para indústrias de manufatura, que é o controle de posição de motor elétrico trifásico, onde a malha de controle exige tempo real com valores restritos. Nestas condições 
são verificados como foco principal os indicadores tempo de ciclo, seu respectivo desvio padrão e jitter.

Adicionalmente aos indicadores de desempenho da rede, é importante também mensurar o desempenho do ponto de vista de aplicação do sistema de controle, ou seja do ponto de vista físico da aplicação onde a rede é parte integrante. Assim, para este cenário é considerado adicionalmente um indicador de desempenho de sistemas de controle denominado tempo de acomodação.

Segundo Franklin (2002) o tempo de acomodação é um importante parâmetro para analisar respostas transientes no tempo. Ele é definido como o tempo necessário para a saída do sistema alcançar e permanecer dentro de uma faixa em torno do valor em regime estacionário. Usualmente se utiliza os valores de $5 \%$ ou $2 \%$. Neste cenário foi utilizado faixa em torno de $5 \%$.

Os equipamentos utilizados para experimento com rede Profibus DP e Profinet são listados na Tabela 14.

Tabela 14 - Equipamentos utilizados para Cenário 2

\begin{tabular}{|l|l|l|c|c|l|}
\hline Item & Equipamento & Descrição & $\begin{array}{l}\text { Bytes de } \\
\text { Entrada }\end{array}$ & $\begin{array}{l}\text { Bytes de } \\
\text { Saída }\end{array}$ & Função \\
\hline 1 & CPU 317-2 DP/PN & Controlador & - & - & $\begin{array}{l}\text { Mestre Classe 1 } \\
\text { IO-Controller }\end{array}$ \\
\hline 2 & Sinamics S110 & Inversor de frequência & 24 & 24 & $\begin{array}{l}\text { Escravo } \\
\text { IO-Device }\end{array}$ \\
\hline 3 & ProfiTrace2 & Analisador de rede & - & - & Mestre Classe 2 \\
\hline 4 & TAP Kunbus & Analisador de rede & - & - & IO-Supervisor \\
\hline
\end{tabular}

A Tabela 15 mostras as redes implementadas para coleta de dados deste cenário. 
Tabela 15 - Especificação das redes para Cenário 2

\begin{tabular}{|c|c|c|c|c|c|}
\hline & $\begin{array}{c}\text { Taxa de } \\
\text { Transmissão }\end{array}$ & $\begin{array}{c}\text { Tempo de } \\
\text { Ciclo }\end{array}$ & & $\begin{array}{c}\text { Taxa de } \\
\text { Transmissão }\end{array}$ & $\begin{array}{c}\text { Tempo de } \\
\text { Ciclo }\end{array}$ \\
\hline \multirow{5}{*}{ 号 } & 12Mbps & - & \multirow{4}{*}{ 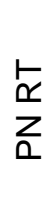 } & 100Mbps & $0.5 \mathrm{~ms}$ \\
\hline & 6Mbps & - & & 100Mbps & $1 \mathrm{~ms}$ \\
\hline & 3Mbps & - & & $100 \mathrm{Mbps}$ & $2 \mathrm{~ms}$ \\
\hline & 1.5Mbps & - & & 100Mbps & $4 \mathrm{~ms}$ \\
\hline & $500 \mathrm{kbps}$ & - & \multirow{4}{*}{ 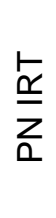 } & 100Mbps & $0.75 \mathrm{~ms}$ \\
\hline \multirow{9}{*}{ \} $&{12 \mathrm{Mbps}} &{1.5 \mathrm{~ms}} &{ } &{\text { 100Mbps }} &{1 \mathrm{~ms}} \\
{\hline} &{\text { 12Mbps }} &{2 \mathrm{~ms}} &{ } &{\text { 100Mbps }} &{2 \mathrm{~ms}} \\
{\hline} &{\text { 6Mbps }} &{2 \mathrm{~ms}} &{ } &{\text { 100Mbps }} &{4 \mathrm{~ms}} \\
{\hline} &{\text { 3Mbps }} &{2 \mathrm{~ms}} &{ } &{ } &{ } \\
{\hline} &{1.5 \mathrm{Mbps}} &{2 \mathrm{~ms}} &{ } &{ } &{ } \\
{\hline} &{\text { 12Mbps }} &{4 \mathrm{~ms}} &{ } &{ } &{ } \\
{\hline} &{\text { 6Mbps }} &{4 \mathrm{~ms}} &{ } &{ } &{ } \\
{\hline} &{\text { 3Mbps }} &{4 \mathrm{~ms}} &{ } &{ } &{ } \\
{\hline} &{\text { 1.5Mbps }} &{4 \mathrm{~ms}} &{ } &{ } &{ } \\
$\hline}
\end{tabular}

A configuração da rede DPV2 em $0.5 \mathrm{~ms}$ e $1 \mathrm{~ms}$ não foi possível devido a restrições técnicas dos equipamentos utilizados por esta tecnologia nesta configuração. Adicionalmente, não foi possível utilizar a versão IRT do Profinet configurado com tempo de ciclo a $0.5 \mathrm{~ms}$ pelo mesmo motivo.

A Figura 37 mostra o esquemático do experimento utilizando Profibus DP e Profinet para o Cenário 2. 

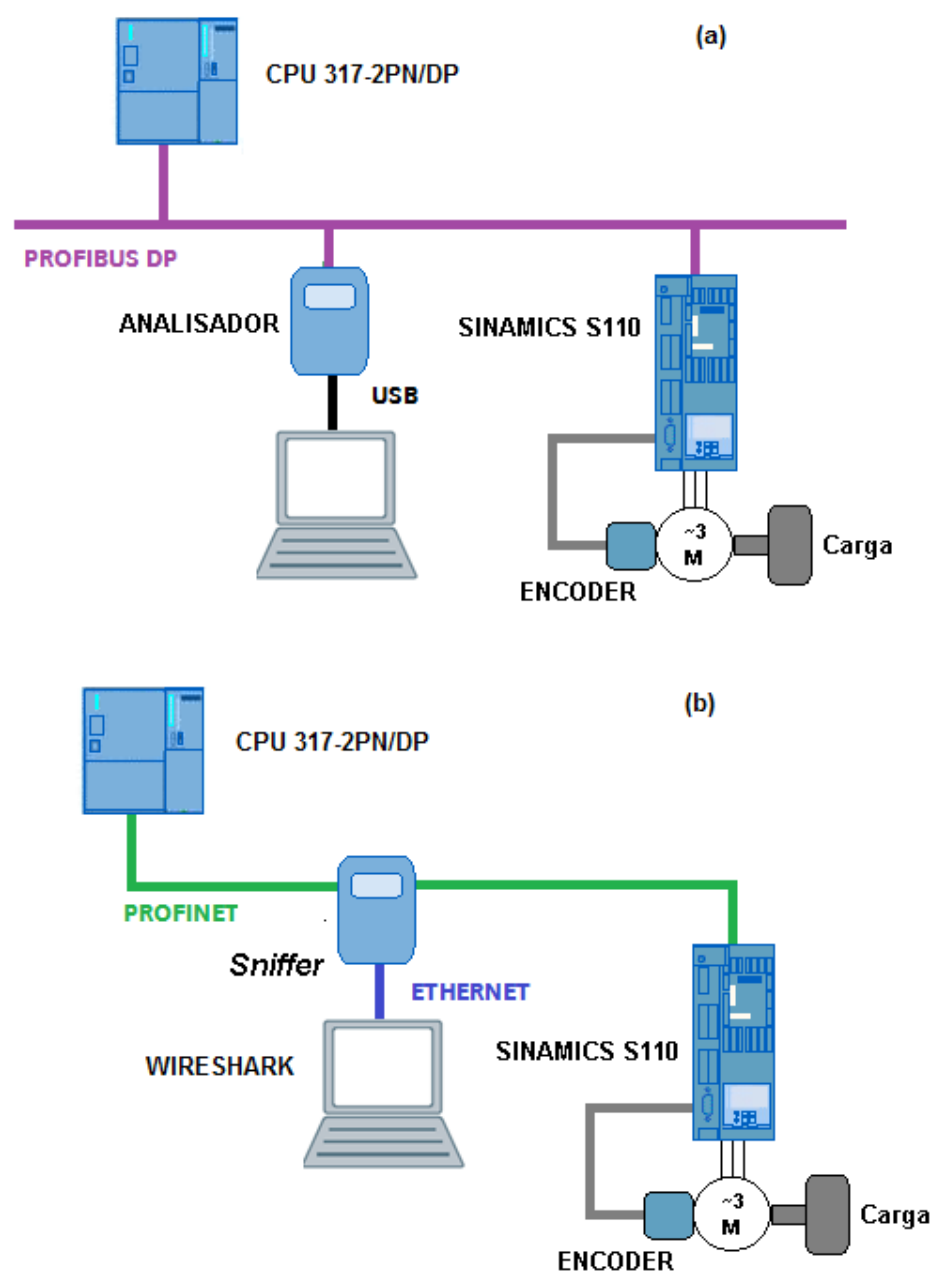

Figura 37 - Experimentos - Cenário 2 (a) Profibus DP (b) Profinet

O inversor de frequência $\mathrm{S} 110$ é indicado para aplicações de posicionamento simples e possui malha de controle PID integrada. No experimento foi utilizado mesmos parâmetros em ambas tecnologias controlando um motor trifásico com pequena carga instalada em seu eixo de rotação (inércia da carga até 5 vezes a inércia do eixo do motor). $O$ motor é equipado com um encoder incremental para fechamento do loop de controle. Mais detalhes sobre o hardware utilizado encontram-se na Tabela 16. 
Tabela 16 - Lista de equipamentos e parâmetros para acionamento do motor no controle de posição - Cenário 2

\begin{tabular}{|c|c|c|c|c|c|}
\hline Item & Equipamento & $\begin{array}{c}\text { Referência / } \\
\text { Parâmetro }\end{array}$ & Item & Equipamento & Parâmetro \\
\hline \multirow[t]{7}{*}{1} & \multicolumn{2}{|c|}{ Inversor S110 } & \multirow[t]{7}{*}{2} & \multicolumn{2}{|c|}{ Motor } \\
\hline & $\begin{array}{l}\text { Unidade de } \\
\text { Controle }\end{array}$ & $\begin{array}{l}\text { 6SL3040-0JA00 (DP) } \\
\text { 6SL3040-0JA01 (PN) }\end{array}$ & & Referência & 1LA7060-4AB10 \\
\hline & $\begin{array}{l}\text { Unidade de } \\
\text { Potência }\end{array}$ & 6SL3210-1SB14-0UA0 & & Tensão & $230 \mathrm{Vac}$ \\
\hline & $\begin{array}{l}\text { Painel de } \\
\text { Operação }\end{array}$ & 6SL3055-0AA00-4BA0 & & Corrente & $0.73 \mathrm{~A}$ \\
\hline & $\begin{array}{c}\text { Tempo de } \\
\text { atualização de } \\
\text { posição via rede }\end{array}$ & $4000.0 \mu \mathrm{s}$ & & Rotação & 1350rpm \\
\hline & $\begin{array}{l}\text { Tempo para } \\
\text { fechamento de } \\
\text { malha de } \\
\text { corrente/velocidade }\end{array}$ & $250.0 \mu \mathrm{s}$ & & Fator de Potência & 0,75 \\
\hline & $\begin{array}{c}\text { Tempo para } \\
\text { fechamento de } \\
\text { controle de posição }\end{array}$ & $1000.0 \mu \mathrm{s}$ & & Frequência & $50 \mathrm{~Hz}$ \\
\hline & & & 3 & Encc & der \\
\hline & & & & Tipo & Incremental HTL \\
\hline & & & & $\begin{array}{l}\text { Pulsos por } \\
\text { revolução }\end{array}$ & 1024 \\
\hline
\end{tabular}

Para verificação do desempenho do sistema de controle de posição, o controlador do sistema (CPU 317-2PN/DP) envia a posição de referência via rede de comunicação para o inversor de frequência que através do controle PID executa o posicionamento do motor. Paralelamente o controlador coleta e grava em sua memória com periodicidade de $1 \mathrm{~ms}$ a posição atual do inversor, enviada ciclicamente através da mesma rede de comunicação. Para este propósito, utiliza-se um bloco com interrupção cíclica de $1 \mathrm{~ms}$ no controlador, considera-se desprezível o atraso em sua execução em relação ao tempo de atualização da posição atual do motor no inversor de frequência.

A Figura 38 representa o mecanismo de coleta de dados para o controle de posição deste cenário. 


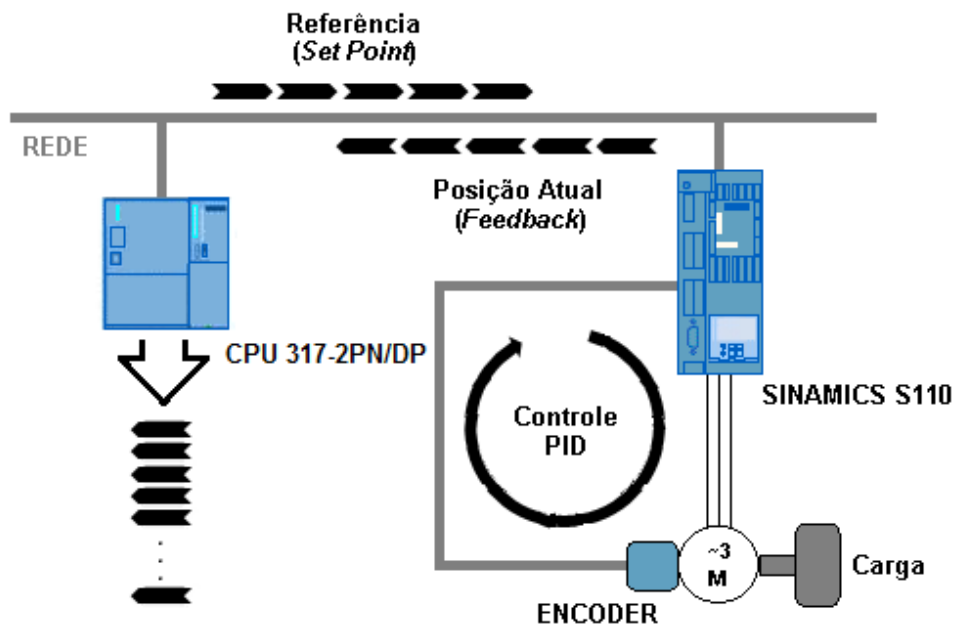

Figura 38 - Mecanismo de coleta de dados para o controle de posição - Cenário 2

O posicionamento é realizado 20 vezes para cada rede configurada da Tabela 15, e o pior caso (maior valor do tempo de acomodação) é considerado para análise dos resultados.

A metodologia deste experimento tem forte relação com o indicador tempo de reação ao evento descrito por Ferrari et al. (2007a), já que em seu trabalho, são mensurados valores do ponto de vista físico da aplicação (entradas e saídas digitais do controlador), e não apenas da rede de comunicação. Adicionalmente ao experimento de Ferrai et al. (2007a), este experimento leva em consideração valores de inércia do sistema de controle (motor e carga instalada), o que representa mais adequadamente aplicações reais de motion control. Neste trabalho, não é abordado sincronismo de eixos.

A partir da coleta dos dados dos cenários apresentados, pode-se analisar e comparar o desempenho entre as tecnologias estudadas. Apresentase os resultados, discussões e conclusões no próximo capítulo. 


\section{RESULTADOS E DISCUSSÃO}

Este capítulo apresenta os resultados obtidos através da metodologia utilizado na coleta de dados dos dois cenários estudados no escopo deste trabalho.

\subsection{Cenário 1}

A coleta de dados teve o objetivo de analisar o tempo de ciclo, jitter e ocupação de banda em uma aplicação com até sete dispositivos na rede, utilizando-se as redes Profibus DPV0 convencional e com tempo de ciclo fixo, Profinet RT com e sem switch externo adicional, ou seja na topologia estrela e barramento respectivamente.

\subsubsection{Profibus DPV0}

A Figura 39 apresenta os resultados obtidos para o Profibus DPV0 convencional, ou seja, com tempo de ciclo auto ajustado pelo mestre.
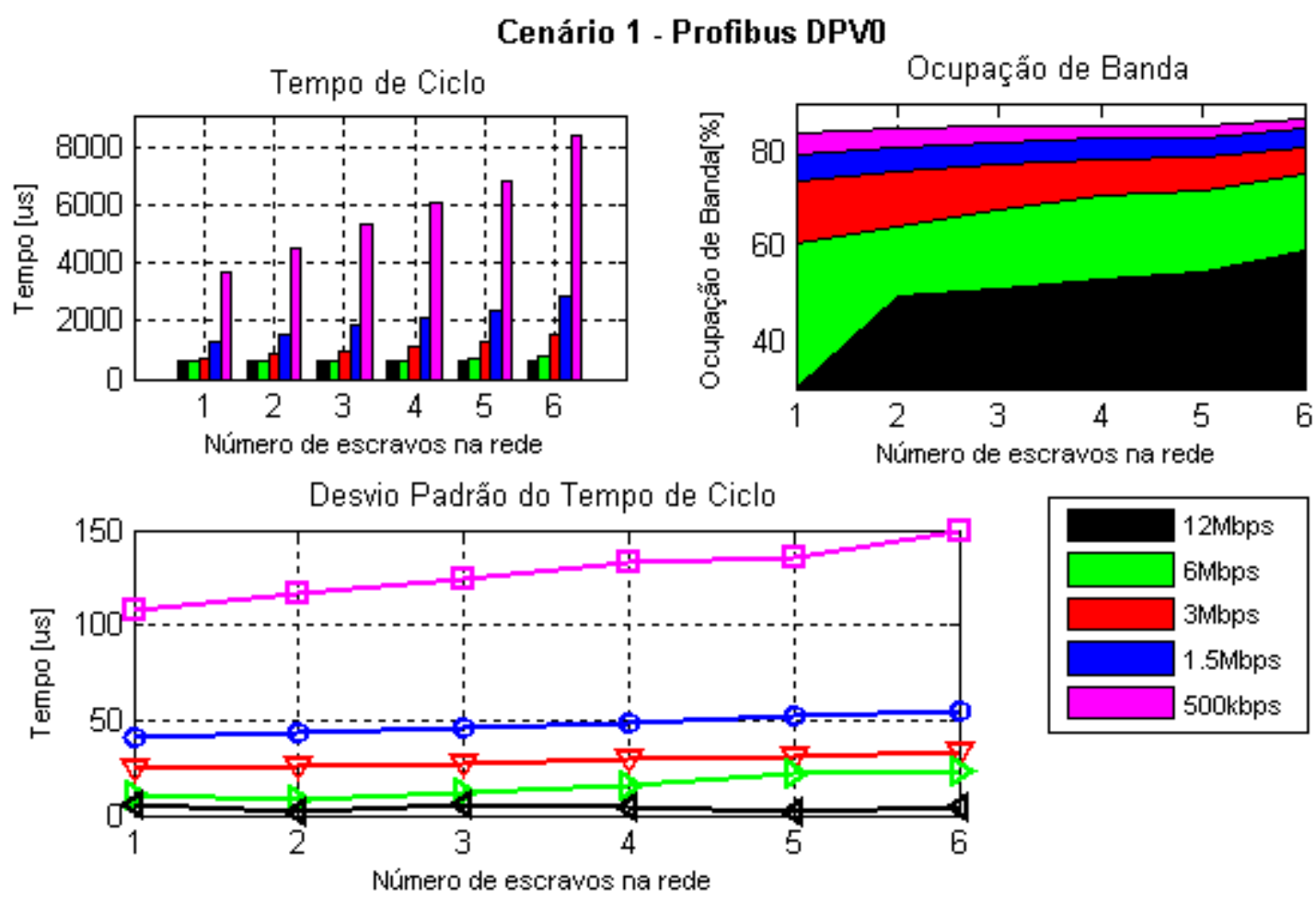

Figura 39 - Experimentos - Resultados do cenário 1 - DPV0

Verifica-se que fixando a taxa de transmissão da rede, conforme há aumento do número de escravos, há aumento do tempo de ciclo. Este incremento é um valor praticamente constante que depende de cada tipo de 
escravo novo inserido (bytes de processo a serem enviados e recebidos), quantidade e taxa de transmissão configurada.

Fixando o número de escravos da rede, verifica-se que há um incremento no valor do tempo de ciclo conforme diminuição da taxa de transmissão configurada da rede.

O tempo de ciclo fica limitado em um valor próximo a $600 \mu \mathrm{s}$, devido a limitação técnica de um ou mais equipamentos presentes na rede. Neste caso, o equipamento é o PAC3200 onde o Target Rotation Time típico $\left(T_{\text {tr }}\right)$ se limita a $7200 t_{\text {bit, }}$ que em 12Mbps resulta em 0.6ms. Assim, antes de início de novo ciclo, o mestre Profibus envia pacotes de passagem de token para si mesmo, até que os equipamentos estejam aptos a enviar novamente um novo pacote com seus dados de processo atualizados. Este pacote é do tipo "Isochrone spare" e possui 6 bytes.

A análise do desvio padrão do tempo de ciclo oferece subsídios para verificação do determinismo da rede. Assim, observa-se quanto maior o número de escravos e menor o taxa de transmissão, a rede passa a apresentar maiores valores absolutos de desvio padrão de tempo de ciclo, o que resulta em redes menos determinísticas. Esta tendência não ocorre quando o tempo de ciclo fica limitado a capacidades de atualização de dados de processo dos equipamentos de campo, ou seja quando surgem pacotes onde o mestre passa o token para ele mesmo. Esta condição ocorreu em todas as redes com configuração em 12Mbps, e para redes com 1, 2 e 3 escravos na configuração com 6Mbps (tempo de ciclo em torno de $600 \mu \mathrm{s}$ ). A Tabela 17 apresenta os valores obtidos. 
Tabela 17 - Tempo de ciclo e desvio da rede DPV0 - Cenário 1

\begin{tabular}{|c|c|c|c|c|c|c|}
\hline & \multicolumn{6}{|c|}{ Escravos } \\
\hline $\begin{array}{c}\text { Taxa de } \\
\text { transmissão } \\
\text { [Mbps] }\end{array}$ & 1 & 2 & 3 & 4 & 5 & 6 \\
\hline & \multicolumn{6}{|c|}{ Tempo de ciclo [ $\mu \mathrm{s}]$} \\
\hline 0.5 & 3686.7 & 4489.2 & 5291.8 & 6093.7 & 6839.3 & 8390.9 \\
\hline 1.5 & 1298.8 & 1565.7 & 1832.6 & 2099.4 & 2347.5 & 2864.1 \\
\hline 3 & 701.1 & 837.9 & 974.7 & 1111.6 & 1239.1 & 1500.6 \\
\hline 6 & 600.2 & 600.2 & 600.2 & 614.3 & 677.3 & 809.8115 \\
\hline \multirow[t]{2}{*}{12} & 600.1 & 600.1 & 600.1 & 600.1 & 600.1 & 600.0959 \\
\hline & \multicolumn{6}{|c|}{ Desvio Padrão [ $\mu \mathrm{s}]$} \\
\hline 0.5 & 107.32 & 116.04 & 124.63 & 132.48 & 135.65 & 149.14 \\
\hline 1.5 & 40.94 & 43.80 & 46.63 & 48.69 & 51.71 & 54.69 \\
\hline 3 & 24.17 & 25.85 & 27.60 & 29.31 & 30.60 & 32.92 \\
\hline 6 & 10.41 & 8.29 & 11.57 & 15.93 & 22.43 & 23.45 \\
\hline 12 & 5.89 & 1.83 & 6.00 & 4.31 & 2.17 & 4.51 \\
\hline
\end{tabular}

Como o experimento com tecnologia Profibus DPV0 não fixa em sua parametrização o tempo de ciclo da rede, não utilizou-se análise do jitter neste caso.

O indicador de desempenho ocupação de banda é pouco explorado na literatura envolvendo a tecnologia Profibus DP, porém sua análise se mostrou interessante. Foi considerada a ocupação de banda média conforme equação 6.

Verifica-se que a rede Profibus DPV0 tende a realizar a máxima ocupação de banda possível com objetivo de realizar o menor tempo de ciclo, ou seja, o(s) mestre(s) realizam a troca de dados com todos os escravos e imediatamente em seguida iniciam novo ciclo, alcançando níveis de ocupação de banda de $88 \%$. Há uma diminuição expressiva da ocupação como pode ser verificado na Figura 39, quando existe a limitação de tempo de atualização de dados por parte dos escravos, onde o mestre envia pacotes de passagem de token para si mesmo, ficando na ordem de $50 \%$ para as configurações de $12 \mathrm{Mbps}$, alcançando até $30 \%$ na taxa de transmissão de $12 \mathrm{Mbps}$ com um escravo na rede. 


\subsubsection{Profibus DPV0 com tempo de ciclo fixo}

Para a rede DPVo com tempo de ciclo fixo, os resultados são apresentados na Figura 40.
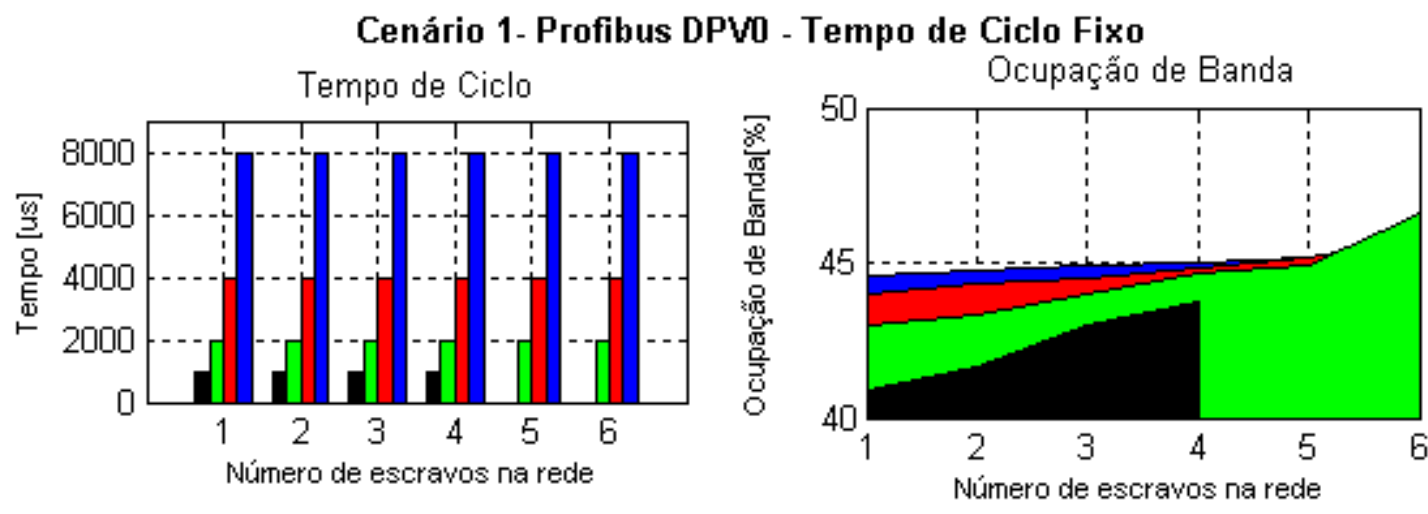

Desvio Padrẫo do Tempo de Ciclo
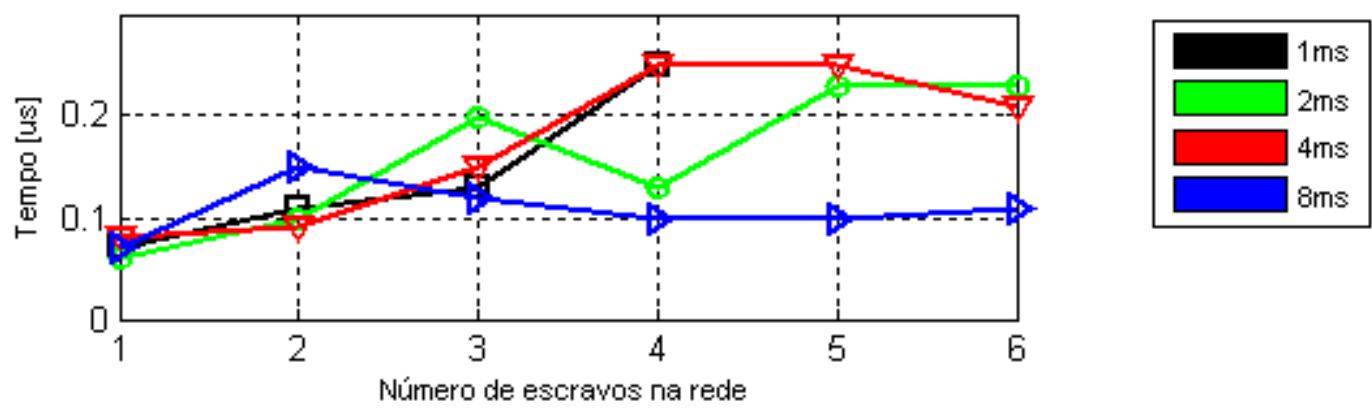

Figura 40 - Experimentos - Resultados do cenário 1 - DPV0 com tempo de ciclo fixo

O tempo de ciclo é pré-determinado, sendo configurado via STEP7 com multiplicidade do parâmetro "Time Base" que possui valores múltiplos de até $0.001 \mathrm{~ms}$. Neste contexto apenas a taxa de transmissão de 12Mbps foi utilizada, porém é possível utilização de outros taxas de transmissão. Os tempos de ciclo configurados foram de $1 \mathrm{~ms}, 2 \mathrm{~ms}, 4 \mathrm{~ms}$ e $8 \mathrm{~ms}$ por motivo de comparação com a rede Profinet a ser apresentada posteriormente.

Em decorrência de limitação de configuração devido a características técnicas e da quantidade de escravos na rede, o tempo de ciclo de $0.5 \mathrm{~ms}$ e adicionalmente a configuração com tempo de ciclo de $1 \mathrm{~ms}$ com 5 e 6 escravos não foram possíveis nesta tecnologia.

Assim, verifica-se com estas condições que o tempo de ciclo é sempre igual ou superior ao DPVO convencional para a mesma configuração de rede, 
já que o tempo de ciclo deve ser configurado igual ou acima do Target Rotation Time suportado pela rede em questão. A Tabela 18 apresenta os resultados.

Tabela 18 - Tempo de ciclo e desvio da rede DPV0 com tempo de ciclo fixo - Cenário 1

\begin{tabular}{|c|c|c|c|c|c|c|}
\hline & \multicolumn{6}{|c|}{ Quantidade de Escravos } \\
\hline $\begin{array}{c}\text { Tempo de } \\
\text { ciclo } \\
\text { [ms] }\end{array}$ & 1 & 2 & 3 & 4 & 5 & 6 \\
\hline & \multicolumn{6}{|c|}{ Média do Tempo de Ciclo [us] } \\
\hline 1 & 1000.0 & 1000.0 & 1000.0 & 1000.0 & - & - \\
\hline 2 & 2000.0 & 2000.0 & 2000.0 & 2000.0 & 2000.0 & 2000.0 \\
\hline 4 & 4000.0 & 4000.0 & 4000.0 & 4000.0 & 4000.0 & 4000.0 \\
\hline \multirow[t]{2}{*}{8} & 8000.0 & 8000.0 & 8000.0 & 8000.0 & 8000.0 & 8000.0 \\
\hline & \multicolumn{6}{|c|}{ Desvio Padrão [ $\mu \mathrm{s}]$} \\
\hline 1 & 0.07 & 0.11 & 0.13 & 0.25 & - & - \\
\hline 2 & 0.06 & 0.10 & 0.20 & 0.13 & 0.23 & 0.23 \\
\hline 4 & 0.08 & 0.09 & 0.15 & 0.25 & 0.25 & 0.21 \\
\hline 8 & 0.07 & 0.15 & 0.12 & 0.10 & 0.10 & 0.11 \\
\hline
\end{tabular}

Porém, quando se trata do determinismo da rede a partir do desvio padrão do tempo de ciclo, verifica-se que nesta versão a tecnologia alcança valores 1000 vezes menores em relação ao DPV0 convencional. Os valores ficam abaixo de 0.3us para todas as configurações. Verifica-se também que existe uma tendência no aumento do desvio padrão com o aumento do número de escravos na rede, assim pode-se concluir que quanto mais escravos na rede Profibus DPV0 com tempo de ciclo fixo, menor é a precisão do valor médio o que resulta em uma rede menos determinística.

Também é possível verificar o jiiter médio nesta configuração, os resultados são exibidos na Tabela 19.

Tabela 19 - Jitter da rede DPV0 com tempo de ciclo fixo - Cenário 1

\begin{tabular}{|c|c|c|c|c|c|c|}
\hline & \multicolumn{6}{|c|}{ Quantidade de Escravos } \\
\hline $\begin{array}{c}\text { Tempo de } \\
\text { ciclo } \\
\text { [ms] }\end{array}$ & 1 & 2 & 3 & 4 & 5 & 6 \\
\hline & \multicolumn{6}{|c|}{ Desvio Padrão [ $\mu \mathrm{s}]$} \\
\hline 1 & 0.05 & 0.07 & 0.09 & 0.12 & & \\
\hline 2 & 0.05 & 0.07 & 0.12 & 0.10 & 0.11 & 0.12 \\
\hline 4 & 0.06 & 0.07 & 0.08 & 0.11 & 0.10 & 0.10 \\
\hline 8 & 0.05 & 0.10 & 0.09 & 0.08 & 0.08 & 0.08 \\
\hline
\end{tabular}


O valor médio do jitter das configurações implementadas são inferiores a $0.2 \mu \mathrm{s}$, e verifica-se tendência de aumento do jitter a medida que a quantidade de dispositivos na rede aumenta.

Sobre a ocupação de banda, verifica-se que a tecnologia DPV0 com tempo de ciclo fixo manteve dentro da faixa de 40 a $50 \%$, ou seja, inferior ao DPV0 testado anteriormente. Um dos motivos pode ser explicado no que tange a reserva de banda desta tecnologia para garantir que haja a troca de todos os dados entre mestre e escravos. Novamente o mestre envia um pacote de passagem de token para si mesmo, aguardando o inicio do próximo ciclo parametrizado, e assim alcança maior precisão

Desta maneira, conclui-se que a tecnologia DPV0 convencional alcança menores tempos de ciclo, porém com menos determinismo que a rede em DPV0 com tempo de ciclo fixo.

\subsubsection{Profinet RT com topologia estrela}

Para a tecnologia Profinet elaborada na topologia estrela com utilização de um swtich externo, e utilizando-se a mesma configuração de dispositivos (IO-Devices) na rede, os resultados são exibidos na Figura 41.

\section{Cenário 1 - Profinet RT - Topologia Estrela}
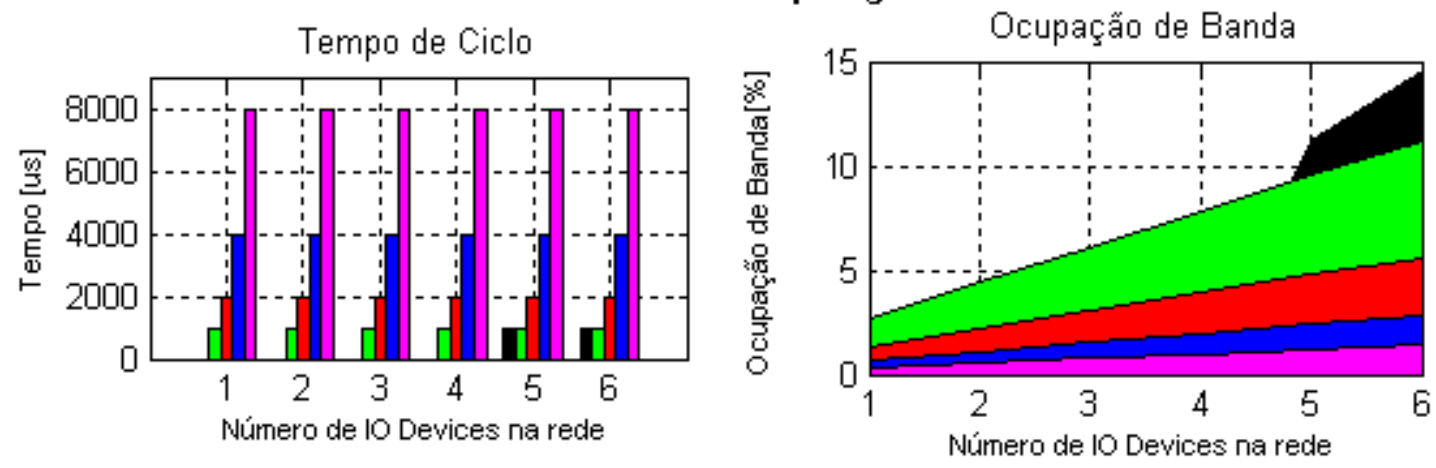

Desvio Padrẫo do Tempo de Ciclo
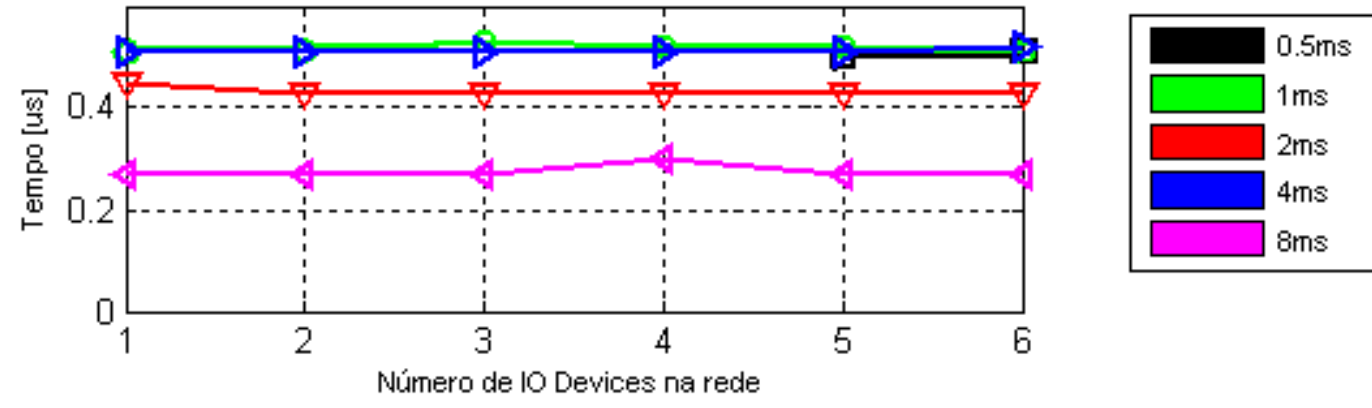

Figura 41 - Resultados do cenário 1 - Profinet RT topologia estrela 
Verifica-se que para rede configurada com tempo de ciclo de $0.5 \mathrm{~ms}$, as configurações de um a quatro IO-Devices não foram possíveis devido a restrições de parâmetros técnicos dos dispositivos, o tempo mínimo de atualização (Update Time) do PAC3200 e Simocode é de $1 \mathrm{~ms}$. Para as redes com cinco e seis IO-Devices apesar da possibilidade de parametrização destes últimos dispositivos (ET200S e inversor de frequência S110), existe ainda a limitação dos dispositivos supracitados, assim o tempo de ciclo alcançado fica $0.5 \mathrm{~ms}$ apenas em relação a esses dois últimos dispositivos. Como foi considerado no trabalho tempo de ciclo como sendo o tempo para troca de dados de todos os dispositivos da rede, o valor final continua sendo $1 \mathrm{~ms}$, devido a limitações do PAC3200 e Simocode pro.

Os valores obtidos do tempo de ciclo médio e desvio padrão na topologia estrela são mostrados na Tabela 20.

\section{Tabela 20 - Tempo de ciclo médio - Cenário 1 - Profinet RT Topologia Estrela}

\begin{tabular}{|c|c|c|c|c|c|c|}
\hline \multirow{2}{*}{$\begin{array}{c}\text { Tempo } \\
\text { Ciclo } \\
\text { (ms) }\end{array}$} & \multicolumn{6}{|c|}{ Quantidade de IO-Devices } \\
\hline & 1 & 2 & 3 & 4 & 5 & 6 \\
\hline & \multicolumn{6}{|c|}{ Média do Tempo de Ciclo [ $\mu \mathrm{s}]$} \\
\hline 0.5 & - & - & - & - & 1000.0 & 1000.0 \\
\hline 1 & 1000.0 & 1000.0 & 1000.0 & 1000.0 & 1000.0 & 1000.0 \\
\hline 2 & 2000.1 & 2000.1 & 2000.1 & 2000.1 & 2000.1 & 2000.1 \\
\hline 4 & 4000.2 & 4000.2 & 4000.2 & 4000.2 & 4000.2 & 4000.2 \\
\hline \multirow[t]{2}{*}{8} & 8000.4 & 8000.4 & 8000.4 & 8000.4 & 8000.4 & 8000.4 \\
\hline & \multicolumn{6}{|c|}{ Desvio Padrão [ $\mu \mathrm{s}]$} \\
\hline 0.5 & & & & & 0.50 & 0.51 \\
\hline 1 & 0.51 & 0.51 & 0.53 & 0.52 & 0.52 & 0.51 \\
\hline 2 & 0.45 & 0.43 & 0.43 & 0.43 & 0.43 & 0.43 \\
\hline 4 & 0.51 & 0.51 & 0.51 & 0.51 & 0.51 & 0.52 \\
\hline 8 & 0.27 & 0.27 & 0.27 & 0.30 & 0.27 & 0.27 \\
\hline
\end{tabular}

Quando analisa-se o desvio padrão do tempo de ciclo, verifica-se que o menor valor de seu desvio padrão é para rede configurada em $8 \mathrm{~ms}$, e permanece praticamente constante em valores absolutos para todas composições de dispositivos (de um a seis IO-Devices). Verifica-se também, que não existe uma tendência de diminuição do desvio padrão do tempo de ciclo com aumento do tempo de ciclo configurado, já que os valores apresentados pela rede em $2 \mathrm{~ms}$ foi inferior a rede em $4 \mathrm{~ms}$. Os valores 
alcançados, foram superiores aos apresentados com utilização da rede Profibus DPV0 com tempo de ciclo fixo configurada a $12 \mathrm{Mbps}$, mostrando que esta última é mais precisa no atingimento do tempo de ciclo configurado.

Adicionalmente, verifica-se o jitter médio da configuração Profinet na topologia estrela na Tabela 21 .

Tabela 21 - Jitter da rede PNRT Topologia Estrela - Cenário 1

\begin{tabular}{|c|c|c|c|c|c|c|}
\hline & \multicolumn{6}{|c|}{ IO-Devices } \\
\hline $\begin{array}{c}\text { Tempo de } \\
\text { ciclo } \\
{[\mathrm{ms}]}\end{array}$ & 1 & 2 & 3 & 4 & 5 & 6 \\
\hline & \multicolumn{7}{|c|}{ Média do Jiiter $[\mu \mathrm{s}]$} \\
\hline 0.5 & & & & & 0.49 & 0.49 \\
\hline 1 & 0.49 & 0.49 & 0.49 & 0.49 & 0.49 & 0.49 \\
\hline 2 & 0.30 & 0.30 & 0.30 & 0.31 & 0.30 & 0.31 \\
\hline 4 & 0.49 & 0.49 & 0.49 & 0.49 & 0.49 & 0.49 \\
\hline 8 & 0.47 & 0.47 & 0.47 & 0.47 & 0.47 & 0.47 \\
\hline
\end{tabular}

$\mathrm{Na}$ análise do jitter, verifica-se que existe defasagem em relação ao tempo de ciclo parametrizado, alcançando valor de jiiter de quase $0.5 \mu$ s, valores até quase 10 vezes superiores a tecnologia DPV0 com tempo de ciclo fixo, ou seja, esta última é mais exata.

Em relação a ocupação de banda, verifica-se um aumento linear da ocupação com o aumento do número de dispositivos da rede. Há também aumento da ocupação de banda a medida que o tempo de ciclo configurado diminui, ambos resultados já esperados na tecnologia Profinet. A ocupação de banda na tecnologia Profinet se apresentou muito inferior a tecnologia Profibus DPV0, os valores chegam a ser mais de 30 vezes menor (comparação com tempo de ciclo a 8ms entre DPV0 e PN RT topologia estrela). Esta condição mostra que a rede Profinet possui maior capacidade de inserir dispositivos na rede quando comparada a tecnologia Profibus DP, mantendo-se o tempo de ciclo. 


\subsubsection{Profinet RT topologia barramento/linha}

Para a tecnologia Profinet utilizando-se a mesma configuração de dispositivos (IO-Devices) na rede, elaborada na topologia barramento, sem utilização de switches adicionais aos já incorporados nos dispositivos da rede, os resultados são exibidos na Figura 42.

Cenário 1 - Profinet RT - Topologia Barramento/Linha
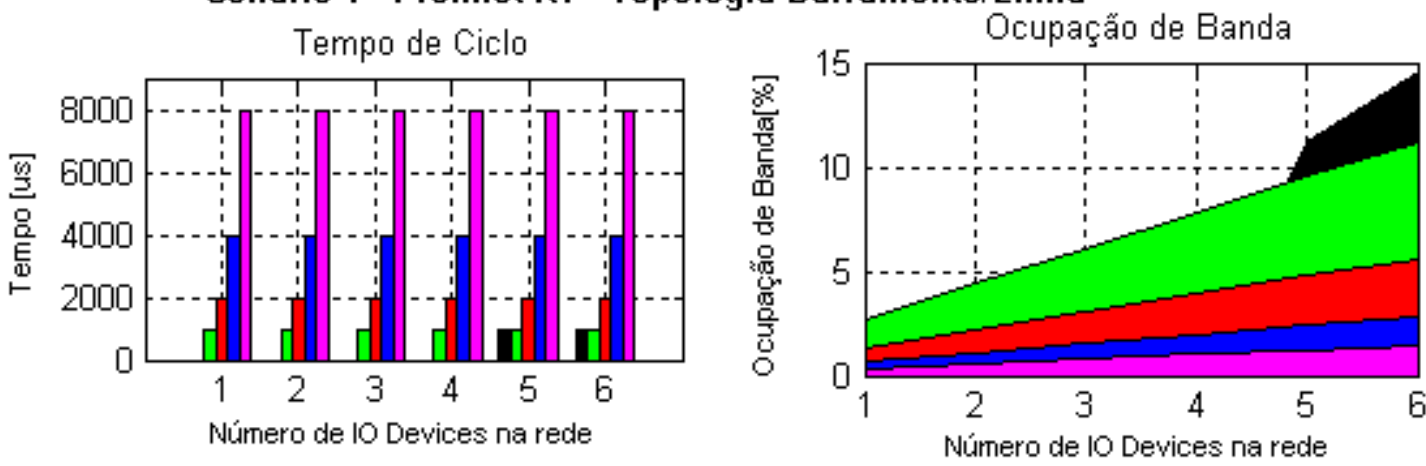

Desvio Padrẫo do Tempo de Ciclo
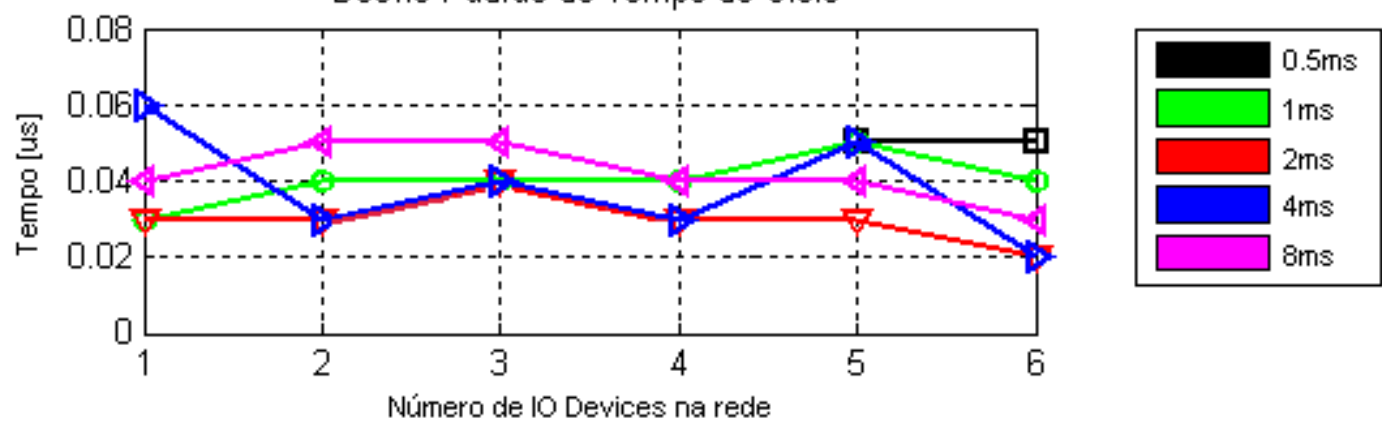

Figura 42 - Resultados do cenário 1 - Profinet RT topologia barramento

Assim como na rede na topologia estrela, para tempo de ciclo de $0.5 \mathrm{~ms}$, as configurações com de um a quatro IO-Devices não foram possíveis devido a restrições de parâmetros técnicos dos dispositivos PAC3200 e Simocode pro, e para 5 e 6 IO-Devices apesar da possibilidade de parametrização, existe ainda a limitação dos dispositivos supracitados. Adicionalmente os mesmos valores de tempo de ciclo médio aumenta a medida que se aumenta o tempo de ciclo configurado. A Tabela 22 apresenta os valores obtidos. 
Tabela 22 - Tempo de Ciclo da rede PN RT Topologia Barramento/Linha - Cenário 1

\begin{tabular}{|c|c|c|c|c|c|c|}
\hline & \multicolumn{6}{|c|}{ 1O-Devices } \\
\hline $\begin{array}{c}\text { Tempo de } \\
\text { ciclo } \\
\text { [ms] }\end{array}$ & 1 & 2 & 3 & 4 & 5 & 6 \\
\hline & \multicolumn{6}{|c|}{ Média do Tempo de Ciclo [us] } \\
\hline 0.5 & & & & & 1000.0 & 1000.0 \\
\hline 1 & 1000.0 & 1000.0 & 1000.0 & 1000.0 & 1000.0 & 1000.0 \\
\hline 2 & 2000.1 & 2000.1 & 2000.1 & 2000.1 & 2000.1 & 2000.1 \\
\hline 4 & 4000.2 & 4000.2 & 4000.2 & 4000.2 & 4000.2 & 4000.2 \\
\hline \multirow[t]{2}{*}{8} & 8000.4 & 8000.4 & 8000.4 & 8000.4 & 8000.4 & 8000.4 \\
\hline & \multicolumn{6}{|c|}{ Desvio Padrão [ $\mu \mathrm{s}]$} \\
\hline 0.5 & & & & & 0.05 & 0.05 \\
\hline 1 & 0.03 & 0.04 & 0.04 & 0.04 & 0.05 & 0.04 \\
\hline 2 & 0.03 & 0.03 & 0.04 & 0.03 & 0.03 & 0.02 \\
\hline 4 & 0.06 & 0.03 & 0.04 & 0.03 & 0.05 & 0.02 \\
\hline 8 & 0.04 & 0.05 & 0.05 & 0.04 & 0.04 & 0.03 \\
\hline
\end{tabular}

Em relação ao desvio padrão do tempo de ciclo para a rede Profinet RT topologia em barramento, não se verifica a tendência de variação com alteração no número de dispositivos na rede ou tempo de ciclo configurado, e nota-se valores inferiores quando comparados com a topologia estrela, chegando a ter desvio 20 vezes inferior para configuração com tempo de ciclo de $4 \mathrm{~ms}$, com seis IO-Devices, ou seja o tempo de ciclo é mais preciso.

Quando comparado a rede Profibus DPV0 com tempo de ciclo fixo, a rede Profinet topologia barramento também mostrou valores de desvio padrão do tempo de ciclo de até 10 vezes inferior (configuração de $4 \mathrm{~ms}$ de tempo de ciclo com 6 dispositivos na rede), mostrando-se que nesta configuração se torna mais precisa na execução do tempo de ciclo.

Uma razão encontrada para explicar o fato do baixo valor de desvio padrão do tempo de ciclo, é que para todos os dispositivos utilizados, o switch incorporado pode ser utilizado em redes Profinet IRT, ou seja, os switches são do tipo cut through e não do tipo store and foward, como é o switch externo utilizado na topologia em estrela (equipamento SCALANCE X208), que não pode ser utilizado em Profinet IRT. 
Em relação ao jitter, a rede Profinet em barramento apresentou uma tendência de aumento do seu valor com o aumento do tempo de ciclo parametrizado, assim como acontece no tempo de ciclo médio.

O valor do jitter médio da tecnologia Profinet RT topologia barramento é sempre inferior a topologia estrela, chegando a valores quase 10 vezes menor.

Quando comparado a Profibus DPV0 com tempo de ciclo fixo, verifica-se que para tempo de ciclo parametrizado até $2 \mathrm{~ms}$, com mais de dois dispositivos a rede Profinet é mais exata, porém para tempo de ciclo superiores a $4 \mathrm{~ms}$, o Profibus DPV0 com tempo de ciclo fixo passa a ser mais exata.

Ressalta-se, que com o aumento do número de dispositivos, a rede DPV0 piora sua exatidão enquanto o Profinet mantém, ou seja para redes com grande quantidades de dispositivos o Profinet topologia em barramento tende a ser mais determinística.

A Tabela 23 apresenta os valores de jitter da rede Profinet RT topologia barramento.

Tabela 23 - Jitter da rede PN RT Topologia Barramento/Linha - Cenário 1

\begin{tabular}{|c|c|c|c|c|c|c|}
\hline & \multicolumn{6}{|c|}{ IO-Devices } \\
\hline $\begin{array}{c}\text { Tempo de } \\
\text { ciclo } \\
{[\mathrm{ms}]}\end{array}$ & 1 & 2 & 3 & 4 & 5 & 6 \\
\hline & \multicolumn{5}{|c|}{ Média do Jiiter $[\mu \mathrm{s}]$} \\
\hline 0.5 & & & & & 0.05 & 0.05 \\
\hline 1 & 0.05 & 0.05 & 0.05 & 0.05 & 0.05 & 0.05 \\
\hline 2 & 0.10 & 0.10 & 0.10 & 0.10 & 0.10 & 0.10 \\
\hline 4 & 0.20 & 0.20 & 0.20 & 0.20 & 0.20 & 0.20 \\
\hline 8 & 0.39 & 0.39 & 0.39 & 0.40 & 0.40 & 0.41 \\
\hline
\end{tabular}

A ocupação de banda apresenta mesmo comportamento da rede utilizando topologia estrela, com aumento linear conforme o aumento do número de dispositivos da rede e de diminuição do tempo de ciclo configurado, resultados já esperados na tecnologia Profinet e mostrando assim maior capacidade de inserção de dispositivos quando comparados ao Profibus DP. 


\subsubsection{Conclusões para Cenário 1}

Após análise dos resultados pode-se chegar a algumas conclusões importantes para o Cenário 1. Inicialmente, verifica-se a maior capacidade de troca de dados e utilização de dispositivos na tecnologia Profinet em relação a tecnologia Profibus DP, que pode ser verificada a partir do indicador ocupação de banda em conjunto com tempo de ciclo. Assim, para aplicações em CCMi onde exista necessidade de grande quantidade de dispositivos, principalmente quando se requere a menores valores de tempo de ciclo, a tecnologia Profinet se mostra mais adequada.

Uma extrapolação dos resultados obtidos para maiores quantidades de dispositivos pode ser feita, e verificados pelo software de programação STEP7. Os valores apresentados na Tabela 24.

Tabela 24 - Extrapolação de quantidade de dispositivos na rede e tempo de ciclo

\begin{tabular}{|c|c|c|c|c|c|c|}
\hline \multirow[b]{2}{*}{ Tecnologia } & \multirow[b]{2}{*}{$\begin{array}{l}\text { Temp Ciclo } \\
\text { Exigido }\end{array}$} & \multicolumn{5}{|c|}{ Quantidades } \\
\hline & & $\begin{array}{l}\text { Multi- } \\
\text { medidor }\end{array}$ & $\begin{array}{l}\text { Partida Direta } \\
\text { /Reversora }\end{array}$ & $\begin{array}{l}\text { Remotas } \\
\text { de Sinais }\end{array}$ & Inversores & TOTAL \\
\hline \multirow{3}{*}{$\begin{array}{c}\text { DPV0 } \\
(1.5 \mathrm{Mbps})\end{array}$} & $1 \mathrm{~ms}$ & 0 & 0 & 0 & 0 & 0 \\
\hline & $8 \mathrm{~ms}$ & 1 & 15 & 5 & 5 & 26 \\
\hline & $32 \mathrm{~ms}$ & 1 & 60 & 20 & 20 & 101 \\
\hline \multirow{3}{*}{$\begin{array}{c}\text { DPV0 } \\
\text { (12Mbps) }\end{array}$} & $1 \mathrm{~ms}$ & 1 & 5 & 1 & 1 & 8 \\
\hline & $8 \mathrm{~ms}$ & 1 & 51 & 17 & 17 & 86 \\
\hline & $32 \mathrm{~ms}$ & 1 & 75 & 24 & 24 & $125^{\star}$ \\
\hline \multirow[b]{2}{*}{ PN RT } & $1 \mathrm{~ms}$ & 1 & 33 & 11 & 11 & 56 \\
\hline & $8 \mathrm{~ms}$ & 1 & 153 & 51 & 51 & $256^{\star \star}$ \\
\hline
\end{tabular}

* limite de escravos da tecnologia Profibus DP **limite de IO-Devices da CPU em Profinet

A Figura 43 apresenta o posicionamento das tecnologias estudadas para o cenário 1 relacionando quantidade de dispositivos possíveis para alguns tempos de ciclo. 


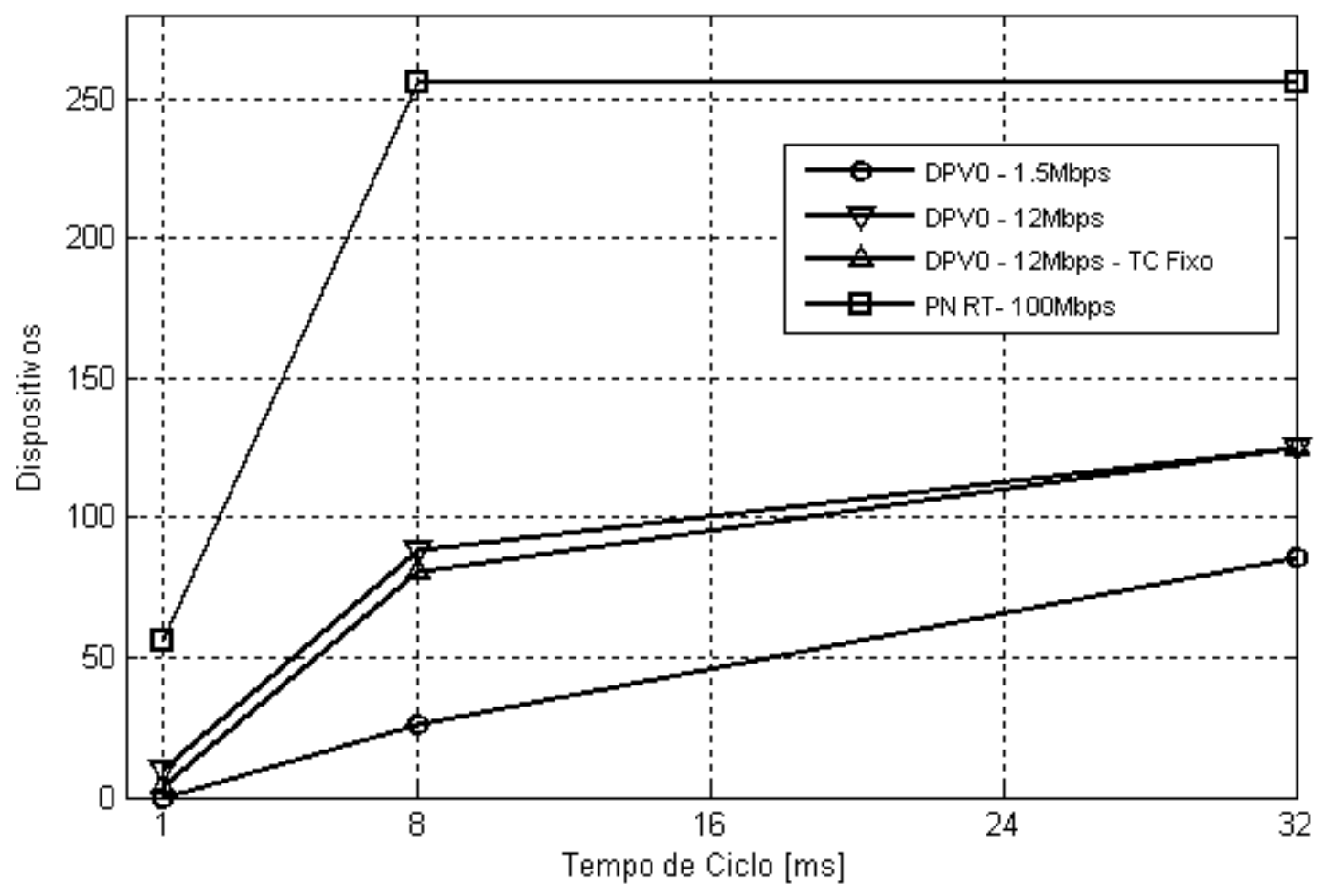

Figura 43 - Comparativo qualitativo - Cenário 1

Em relação ao determinismo, verifica-se que o Profibus DPV0 convencional não é tão precisa quanto as outras tecnologias, já o DPV0 com tempo de ciclo fixo se mostrou mais determinística que a Profinet topologia em estrela.

O Profinet RT topologia barramento se mostrou mais precisa, porém menos exata no atingimento do tempo de ciclo em comparação com o protocolo Profibus DPV0 com tempo de ciclo fixo, porém os valores não comprometem aplicações corriqueiras de CCMi em indústrias de controle de processo. 


\subsection{Cenário 2}

A coleta de dados teve o objetivo de analisar o tempo de ciclo, jitter e o tempo de acomodação em uma aplicação de controle de posição de motor elétrico trifásico, utilizando-se as redes Profibus DPV0, Profibus DPV2, Profinet RT e Profinet IRT.

\subsubsection{Profibus DPV0}

Com a utilização da tecnologia Profibus DPV0 no cenário 2, se obteve os resultados apresentados na Tabela 25 e 26. Verifica-se conforme esperado que com aumento da taxa de transmissão, ocorre diminuição do tempo de ciclo. O valor atinge $193 \mu$ s para rede configurada a $12 \mathrm{Mbps}$. Diferentemente do ocorrido no cenário 1 , não existe limitação do tempo de ciclo da rede devido a características técnicas dos equipamentos.

Assim como no cenário anterior, o indicador jitter não é utilizado, sendo analisado apenas desvio padrão do tempo de ciclo para questões de determinismo da rede. A Tabela 25 apresenta a curva normal dos pacotes trocados na rede estudada durante o experimento, onde o centro dos gráficos (referência zero), representa o tempo de ciclo configurado. Assim, somente para rede DPV0, o resultado induz a existência de uma rede exata, porém isto não pode ser concluído já que o tempo de ciclo médio foi considerado como valor configurado. 
Tabela 25 - Gráficos de curva normal da tecnologia Profibus DPV0- Cenário 2

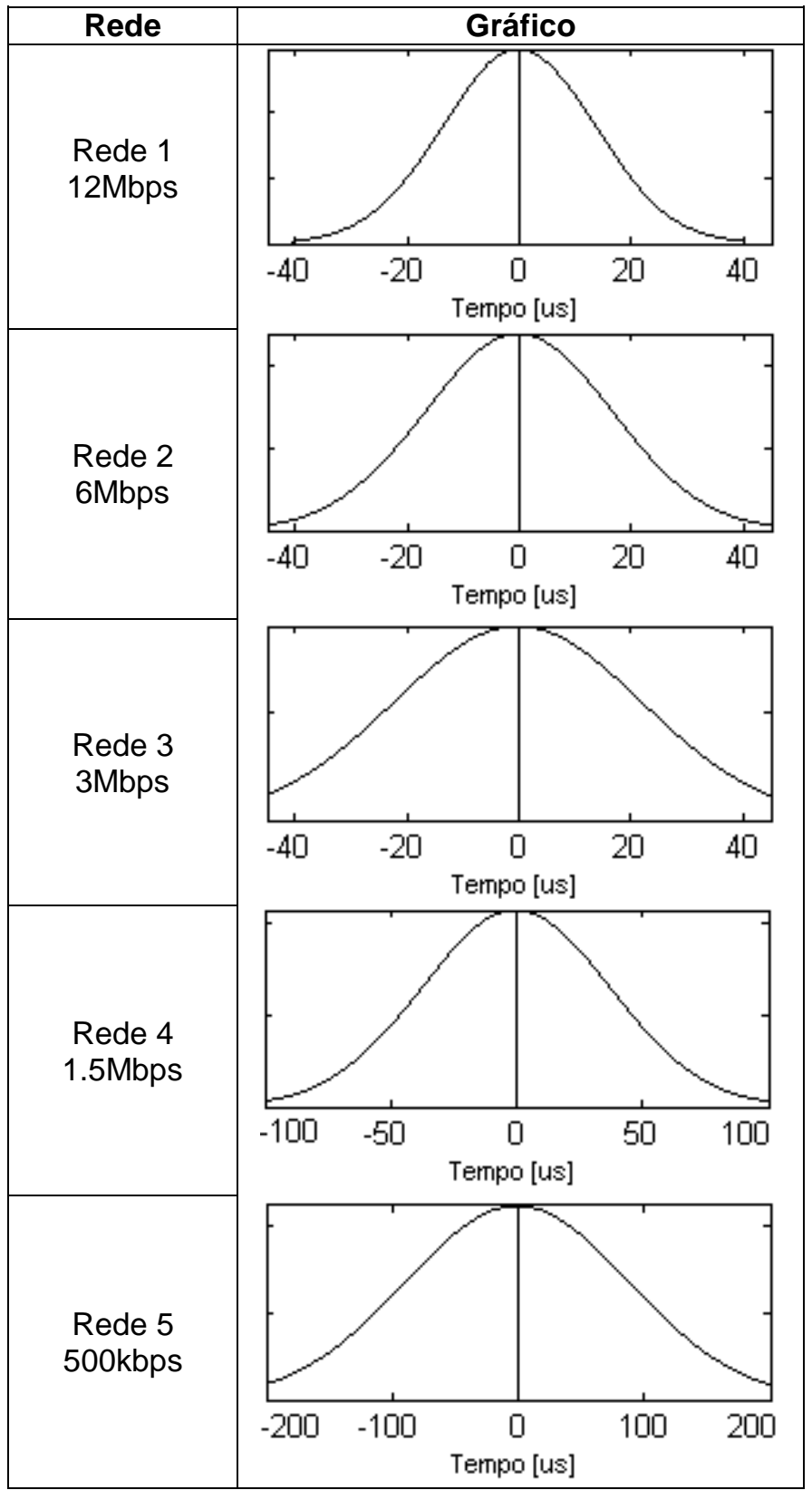

Verifica-se uma tendência de com o aumento da taxa de transmissão, o tempo de ciclo e seu respectivo valor de desvio padrão diminuem. O tempo de ciclo alcançado pela rede DPVO é o menor entre todas as configurações analisadas por este trabalho, porém o valor absoluto do desvio padrão foi maior quando comparado as demais redes, ou seja a rede não se mostrou precisa.

Em relação ao outro objetivo do cenário 2, que é identificar alterações no desempenho da aplicação de posicionamento de motor elétrico, onde foi utilizado o indicador tempo de acomodação do sistema de controle, a Tabela 26 mostra os valores obtidos. 
Tabela 26 - Tempo de acomodação, tempo de ciclo e desvio padrão para rede DPV0 Cenário 2

\begin{tabular}{|c|c|c|c|c|c|}
\hline Rede & $\begin{array}{c}\text { Taxa de } \\
\text { transmissão }\end{array}$ & $\begin{array}{c}\text { Tempo } \\
\text { Ciclo } \\
(\boldsymbol{\mu s})\end{array}$ & $\begin{array}{c}\text { Desvio } \\
\text { padrão } \\
(\boldsymbol{\mu s})\end{array}$ & $\begin{array}{c}\text { Acomodação } \\
(\mathbf{m s})\end{array}$ & $\begin{array}{c}\text { Variação' } \\
(\mathbf{\%})\end{array}$ \\
\hline Rede 1 & $12 \mathrm{Mbps}$ & 193 & 13.58 & 649 & $0.00 \%$ \\
\hline Rede 2 & $6 \mathrm{Mbps}$ & 280 & 16.67 & 650 & $0.15 \%$ \\
\hline Rede 3 & $3 \mathrm{Mbps}$ & 459 & 22.22 & 650 & $0.15 \%$ \\
\hline Rede 4 & $1.5 \mathrm{Mbps}$ & 814 & 37.35 & 651 & $0.31 \%$ \\
\hline Rede 5 & $500 \mathrm{kbps}$ & 2231 & 88.87 & 654 & $0.77 \%$ \\
\hline \multicolumn{6}{|c|}{1 - variação em relação ao melhor tempo de acomodação alcançado na tecnologia }
\end{tabular}

Verifica-se que com menores tempos de ciclo, o tempo de acomodação do sistema tende a diminuir, ou seja o sistema de controle tende a responder mais rapidamente, porém a redução do tempo de acomodação não é significativa, já que a variação do valor atingido com rede configurada a $12 \mathrm{Mbps}$ e $500 \mathrm{kbps}$ é inferior a $1 \%$.

Outro ponto é que mesmo com a rede configurado a $500 \mathrm{kbps}$, o tempo de ciclo se manteve inferior ao tempo de atualização da posição atual do motor enviado pelo inversor de frequência, que é de $4 \mathrm{~ms}$, assim para redes com mais drives ou mesmo outros escravos, o tempo de ciclo aumentaria, podendo comprometer o desempenho no que diz respeito ao tempo de acomodação.

\subsubsection{Profibus DPV2}

Com a utilização da tecnologia Profibus DPV2 no cenário 2, se obteve os resultados apresentados na

Tabela 27 e Tabela 28. Não foi possível configuração desta rede com tempo de ciclo de $0.5 \mathrm{~ms}$ e $1 \mathrm{~ms}$ devido a limitações da própria tecnologia. 
Tabela 27 - Tempo de ciclo e desvio padrão do jitter para rede DPV2 - Cenário 2

\begin{tabular}{|c|c|c|c|c|}
\hline Rede & Descrição & $\begin{array}{c}\text { Tempo } \\
\text { Ciclo } \\
(\boldsymbol{\mu s})\end{array}$ & $\begin{array}{c}\text { Desvio } \\
\text { Padrão } \\
(\boldsymbol{\mu s})\end{array}$ & $\begin{array}{c}\text { Jitter } \\
\text { Médio } \\
(\boldsymbol{\mu s})\end{array}$ \\
\hline Rede 6 & $12 \mathrm{Mbps}$ & 1500.0 & 0.06 & 0.04 \\
\hline \multirow{4}{*}{ Rede 7 } & $1.5 \mathrm{Mbps}$ & 2000.0 & 0.22 & 0.07 \\
\cline { 2 - 5 } & $3 \mathrm{Mbps}$ & 2000.0 & 0.13 & 0.06 \\
\cline { 2 - 5 } & $6 \mathrm{Mbps}$ & 2000.0 & 0.08 & 0.05 \\
\cline { 2 - 5 } & $12 \mathrm{Mbps}$ & 2000.0 & 0.07 & 0.05 \\
\hline \multirow{4}{*}{ Rede 8 } & $1.5 \mathrm{Mbps}$ & 4000.0 & 0.29 & 0.13 \\
\cline { 2 - 5 } & $3 \mathrm{Mbps}$ & 4000.0 & 0.19 & 0.11 \\
\cline { 2 - 5 } & $6 \mathrm{Mbps}$ & 4000.0 & 0.13 & 0.09 \\
\cline { 2 - 5 } & $12 \mathrm{Mbps}$ & 4000.0 & 0.05 & 0.03 \\
\hline
\end{tabular}

A Tabela 28 mostra graficamente através de distribuição normal dos tempos de ciclo coletados na rede, verifica-se que para todas as redes, a exatidão se mantém constante, e verifica-se que quanto maior a taxa de transmissão configurada maior a precisão da rede. A configuração que apresenta melhor precisão é para tempo de ciclo de $4 \mathrm{~ms}$ com taxa de $12 \mathrm{Mbps}$. Referente ao jitter, verifica-se uma tendência equivalente, e os valores obtidos chegam a $0.03 \mu \mathrm{s}$. 
Tabela 28 - Gráficos de curva normal da tecnologia Profibus DPV2- Cenário 2

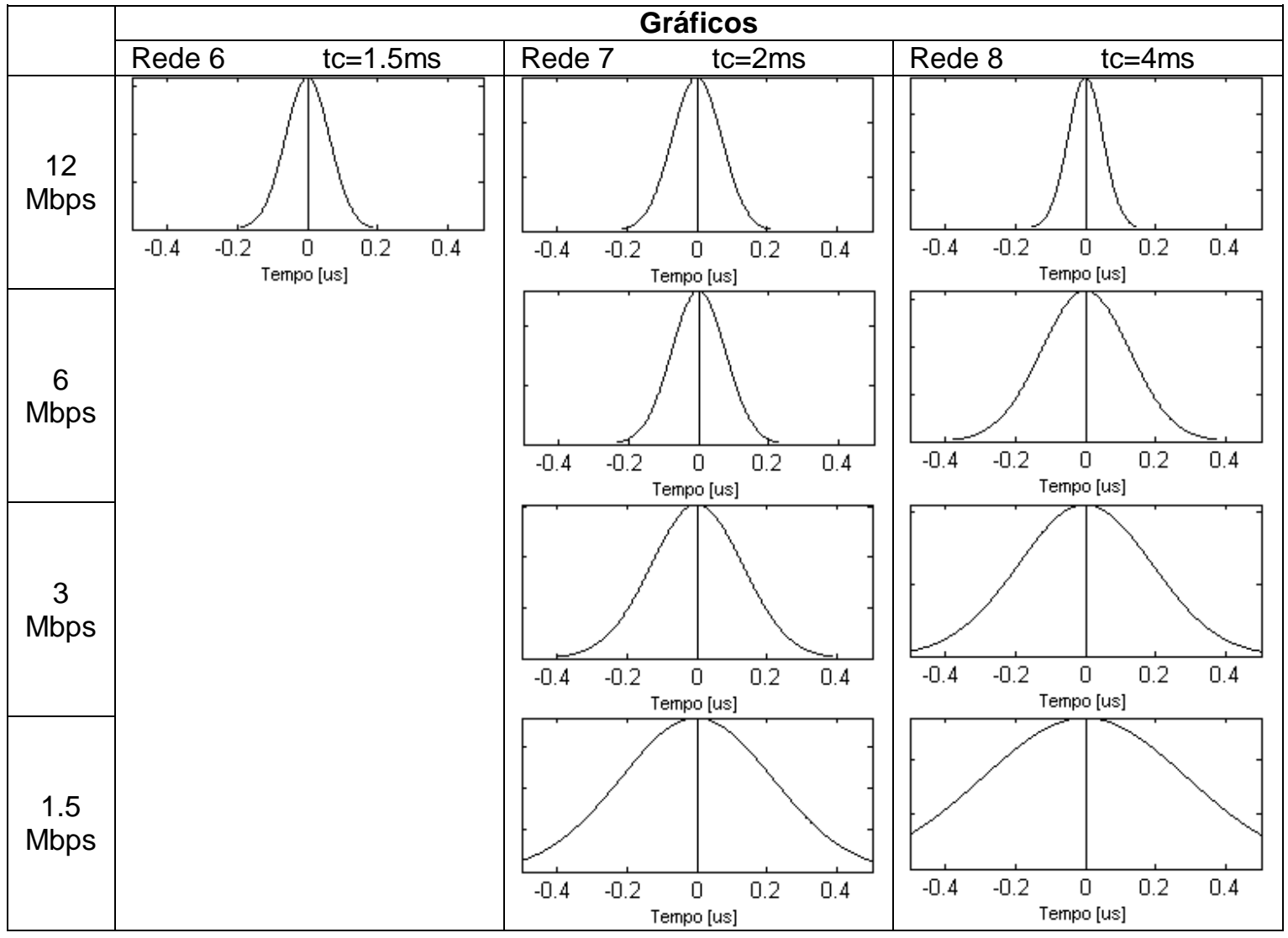

No que diz respeito ao tempo de acomodação do sistema de controle de posição do motor, foi considerado apenas os valores para taxa de transmissão de $12 \mathrm{Mbps}$, e adicionalmente foram realizados coleta de dados para os tempos de ciclo de $8 \mathrm{~ms}$ e $16 \mathrm{~ms}$. Os resultados obtidos são apresentados na Tabela 29.

Tabela 29 - Tempo de acomodação para rede DPV2 - Cenário 2

\begin{tabular}{|l|c|c|c|r|}
\hline Rede & $\begin{array}{c}\text { Taxa de } \\
\text { Transmissão }\end{array}$ & $\begin{array}{c}\text { Tempo } \\
\text { Ciclo }(\boldsymbol{\mu s})\end{array}$ & $\begin{array}{c}\text { Acomodação } \\
\text { (ms) }\end{array}$ & $\begin{array}{c}\text { Variação } \\
\text { (\%) }\end{array}$ \\
\hline Rede 6 & $12 \mathrm{Mbps}$ & 1500.0 & 651 & $0.00 \%$ \\
\hline Rede 7 & $12 \mathrm{Mbps}$ & 2000.0 & 652 & $0.15 \%$ \\
\hline Rede 8 & $12 \mathrm{Mbps}$ & 4000.0 & 653 & $0.31 \%$ \\
\hline Rede 9 & $12 \mathrm{Mbps}$ & 8000.0 & 657 & $0.92 \%$ \\
\hline Rede 10 & $12 \mathrm{Mbps}$ & 16000.0 & 669 & $2.76 \%$ \\
\hline
\end{tabular}

Verifica-se novamente uma tendência de que quanto menor o tempo de ciclo configurado/alcançado, menor o tempo de acomodação do sistema. Para configuração de rede até $4 \mathrm{~ms}$, o tempo de acomodação varia menos de $0.5 \%$, 
o que pode ser considerado um valor desprezível, que não influenciaria no desempenho do controle de posição. Já para os tempo de $8 \mathrm{~ms}$ e $16 \mathrm{~ms}$ a variação tende a aumentar a valores mais altos o que pode comprometer a aplicação.

\subsubsection{Profinet RT}

Para a tecnologia Profinet RT, os resultados em relação ao tempo de ciclo e jitter podem ser vistos na Tabela 30 e Tabela 31.

Tabela 30 - Tempo de ciclo e desvio padrão do jitter para rede PN RT - Cenário 2

\begin{tabular}{|c|c|c|c|c|}
\hline Rede & $\begin{array}{c}\text { Tempo de } \\
\text { Ciclo } \\
\text { (Configurado) }\end{array}$ & $\begin{array}{c}\text { Tempo } \\
\text { Ciclo } \\
(\boldsymbol{\mu s})\end{array}$ & $\begin{array}{c}\text { Desv. } \\
\text { Pad. } \\
\text { Tempo de } \\
\text { Ciclo }(\boldsymbol{\mu s})\end{array}$ & $\begin{array}{c}\text { Média } \\
\text { Jitter } \\
(\boldsymbol{\mu s})\end{array}$ \\
\hline Rede 11 & $0.5 \mathrm{~ms}$ & 500.0 & 0.05 & 0.04 \\
\hline Rede 12 & $1 \mathrm{~ms}$ & 1000.0 & 0.05 & 0.04 \\
\hline Rede 13 & $2 \mathrm{~ms}$ & 2000.0 & 0.05 & 0.04 \\
\hline Rede 14 & $4 \mathrm{~ms}$ & 4000.1 & 0.05 & 0.07 \\
\hline
\end{tabular}

A Tabela 31 mostra graficamente os resultados através de curva normal dos tempo de ciclo coletados na rede. Verifica-se que para a rede PN RT existe tendência de atraso entre o tempo de ciclo médio e o tempo de ciclo esperado, e adicionalmente existe aumento do valor jitter, ou seja há piora na exatidão da rede com o aumento do tempo de ciclo configurado. Esta tendência também foi encontrada no cenário 1 para esta tecnologia.

Em relação ao desvio padrão do tempo de ciclo, verifica-se que o valor fica praticamente constante em valores absolutos para todos os tempos de ciclo configurados, ou seja a rede mantém sua precisão para diferentes tempos de ciclo configurados. 
Tabela 31 - Gráficos de curva normal da tecnologia Profinet RT - Cenário 2

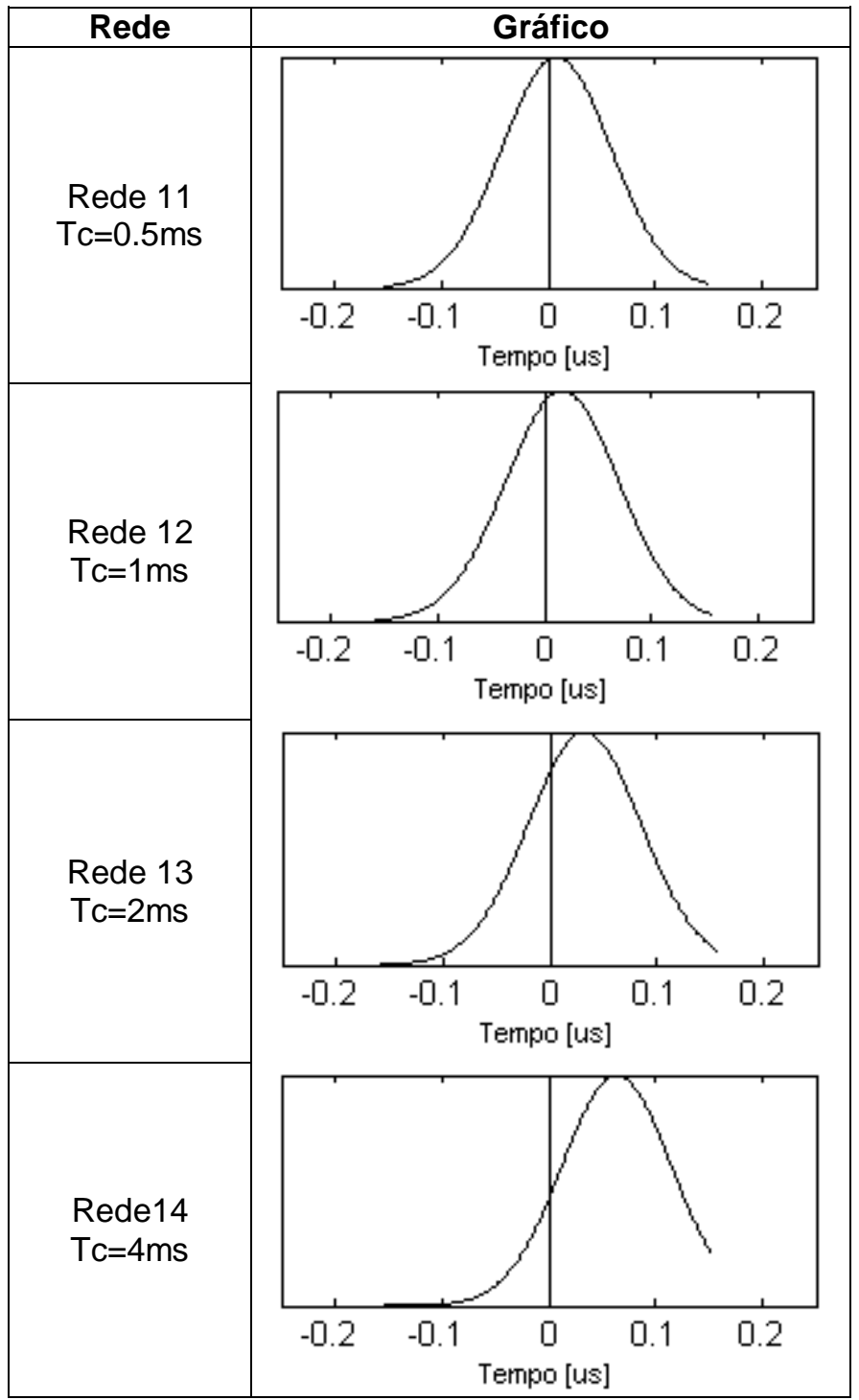

No que diz respeito ao tempo de acomodação, a tecnologia Profinet RT no cenário 2 proporcionou os resultados apresentados na Tabela 32.

Tabela 32 - Tempo de acomodação para rede PN RT - Cenário 2

\begin{tabular}{|c|c|c|c|}
\hline Rede & $\begin{array}{c}\text { Tempo } \\
\text { Ciclo }(\boldsymbol{\mu s})\end{array}$ & $\begin{array}{c}\text { Acomodação } \\
(\mathbf{m s})\end{array}$ & $\begin{array}{c}\text { Variação } \\
\text { (\%) }\end{array}$ \\
\hline Rede 11 & 500.0 & 651 & $0.00 \%$ \\
\hline Rede 12 & 1000.0 & 652 & $0.15 \%$ \\
\hline Rede 13 & 2000.0 & 653 & $0.31 \%$ \\
\hline Rede 14 & 4000.1 & 655 & $0.61 \%$ \\
\hline Rede 15 & 8000.2 & 659 & $1.23 \%$ \\
\hline Rede 16 & 16000.4 & 669 & $2.76 \%$ \\
\hline \multicolumn{4}{|c|}{ 1 - variação em relação ao melhor tempo de acomodação a } \\
\hline
\end{tabular}

1 - variação em relação ao melhor tempo de acomodação alcançado na tecnologia 
Verifica-se que com utilização de tempo de ciclo até $4 \mathrm{~ms}$ a variação em relação ao melhor desempenho foi inferior a $1 \%$, ou seja valores que podem ser considerados desprezíveis. Novamente, a partir de ciclo configurados em $8 \mathrm{~ms}$ e $16 \mathrm{~ms}$ o tempo de acomodação cresce alcançando valores superiores a $1 \%$.

\subsubsection{Profinet IRT}

Para o Profinet IRT não foi possível configurador a rede para $0.5 \mathrm{~ms}$ por limitações da própria tecnologia e equipamentos. Assim, foi utilizado o menor tempo de ciclo disponível que foi de $0.75 \mathrm{~ms}$. Valores superiores a $4 \mathrm{~ms}$ também não são disponíveis com o CLP utilizado na versão IRT, ou seja, este é o maior tempo de ciclo configurável para a rede implementada.

Os indicadores de desempenho no ponto de vista da rede podem ser vistos na Tabela 33 e Tabela 34.

Tabela 33 - Tempo de ciclo e desvio padrão do jitter para rede PN IRT - Cenário 2

\begin{tabular}{|c|c|c|c|c|}
\hline Rede & $\begin{array}{c}\text { Tempo de } \\
\text { Ciclo } \\
\text { (Configurado) }\end{array}$ & $\begin{array}{c}\text { Tempo } \\
\text { Ciclo } \\
(\boldsymbol{\mu} \mathbf{s})\end{array}$ & $\begin{array}{c}\text { Desv. } \\
\text { Pad. } \\
\text { Tempo de } \\
\text { Ciclo }(\boldsymbol{\mu s})\end{array}$ & $\begin{array}{c}\text { Média } \\
\text { Jitter } \\
(\boldsymbol{\mu s})\end{array}$ \\
\hline Rede 17 & $0.75 \mathrm{~ms}$ & 750.0 & 0.04 & 0.02 \\
\hline Rede 18 & $1 \mathrm{~ms}$ & 1000.0 & 0.04 & 0.02 \\
\hline Rede 19 & $2 \mathrm{~ms}$ & 2000.0 & 0.03 & 0.02 \\
\hline Rede 20 & $4 \mathrm{~ms}$ & 4000.0 & 0.03 & 0.02 \\
\hline
\end{tabular}

Verifica-se que para a rede PN IRT não existe atraso entre o tempo de ciclo alcançado e o tempo de ciclo configurado, com o valor médio de jitter desprezível, concluindo-se que se tem uma rede exata, com o melhor desempenho entre tecnologias neste aspecto.

Adicionalmente, se alcançou a melhor precisão entre as tecnologias estudadas através da análise do desvio padrão do tempo de ciclo. Verifica-se no entanto, que existe uma tendência de aumento do valor do desvio a medida que o tempo de ciclo configurado diminui, tendência distinta dos demais experimentos.

Tabela 34 - Gráficos de curva normal da tecnologia Profinet IRT - Cenário 2 


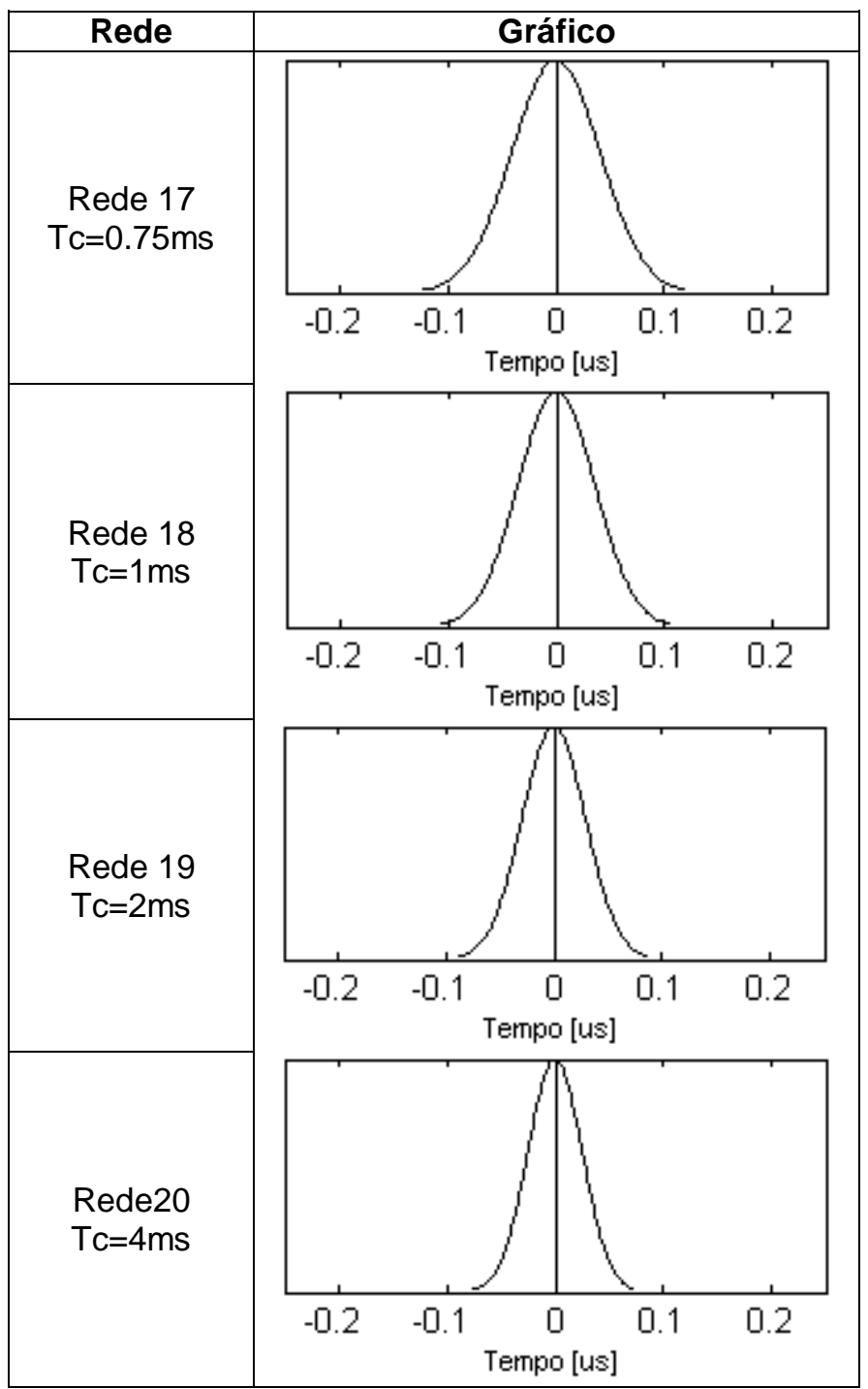

Já em relacão ao desempenho considerando tempo de acomodação, a tecnologia Profinet IRT no cenário 2 proporcionou os resultados apresentados na Tabela 35.

Tabela 35 - Tempo de acomodação para rede PN IRT

\begin{tabular}{|c|c|c|c|}
\hline Rede & $\begin{array}{c}\text { Tempo } \\
\text { Ciclo ( } \boldsymbol{\mu s )}\end{array}$ & $\begin{array}{c}\text { Acomodação } \\
(\mathbf{m s )}\end{array}$ & $\begin{array}{c}\text { Variação } \\
(\%)\end{array}$ \\
\hline Rede 17 & 750.0 & 651 & $0.00 \%$ \\
\hline Rede 18 & 1000.0 & 651 & $0.00 \%$ \\
\hline Rede 19 & 2000.0 & 651 & $0.00 \%$ \\
\hline Rede 20 & 4000.0 & 654 & $0.46 \%$ \\
\hline
\end{tabular}

Verifica-se que o tempo de acomodação apresentado são iguais para tempo de ciclo de $0.75 \mathrm{~ms}, 1 \mathrm{~ms}$ e $2 \mathrm{~ms}$, e para o tempo de $4 \mathrm{~ms}$ a variação em 
relação a este valor foi inferior a $1 \%$, ou seja valores baixos, que podem ser considerados desprezíveis na aplicação.

\subsubsection{Conclusões para o Cenário 2 - Controle de Posição}

O Cenário 2 proporcionou dados importantes na análise do desempenho das tecnologias Profibus DP nas versões DPV0 e DPV2, e Profinet nas versões RT e IRT.

Em relação a indicadores de rede, verificou-se a tecnologia DPV0 foi a que obteve menor tempo de ciclo, influenciado principalmente pela baixa quantidade de dispositivos na rede implementada, porém foi a que demonstrou pior precisão, se mostrando ser menos determinística, que em sua versão DPV2. Por sua vez, a versão DPV2 apresentou exatidão e precisão, mas 0 tempo de ciclo alcançado apresentou valor elevado, por exemplo sete vezes maior que o PN RT e duas vezes maior que o PN IRT.

Para o protocolo Profinet, a versão RT apresentou atraso em relação ao tempo de ciclo parametrizado, que não era esperado, mas alcançou excelente precisão. O Profinet IRT apresentou tempo de ciclo de $0.75 \mathrm{~ms}$, que apesar de ser superior ao PN RT, é inferior ao tempo de fechamento de malha de posição do inversor, que é de $1 \mathrm{~ms}$. Adicionalmente alcançou melhor exatidão e precisão para tempo de ciclo e menor valor de jitter médio em comparação as demais tecnologias, concluíndo-se ser a rede mais determinística estudada.

Em relação ao indicador utilizado para verificar o desempenho do controle de posição, que foi o tempo de acomodação, a Figura 44 apresenta os valores obtidos para todas tecnologias apresentadas no cenário 2. Para Profibus DPV2, foram plotados desempenho apenas para taxa de transmissão de $12 \mathrm{Mbps}$. 


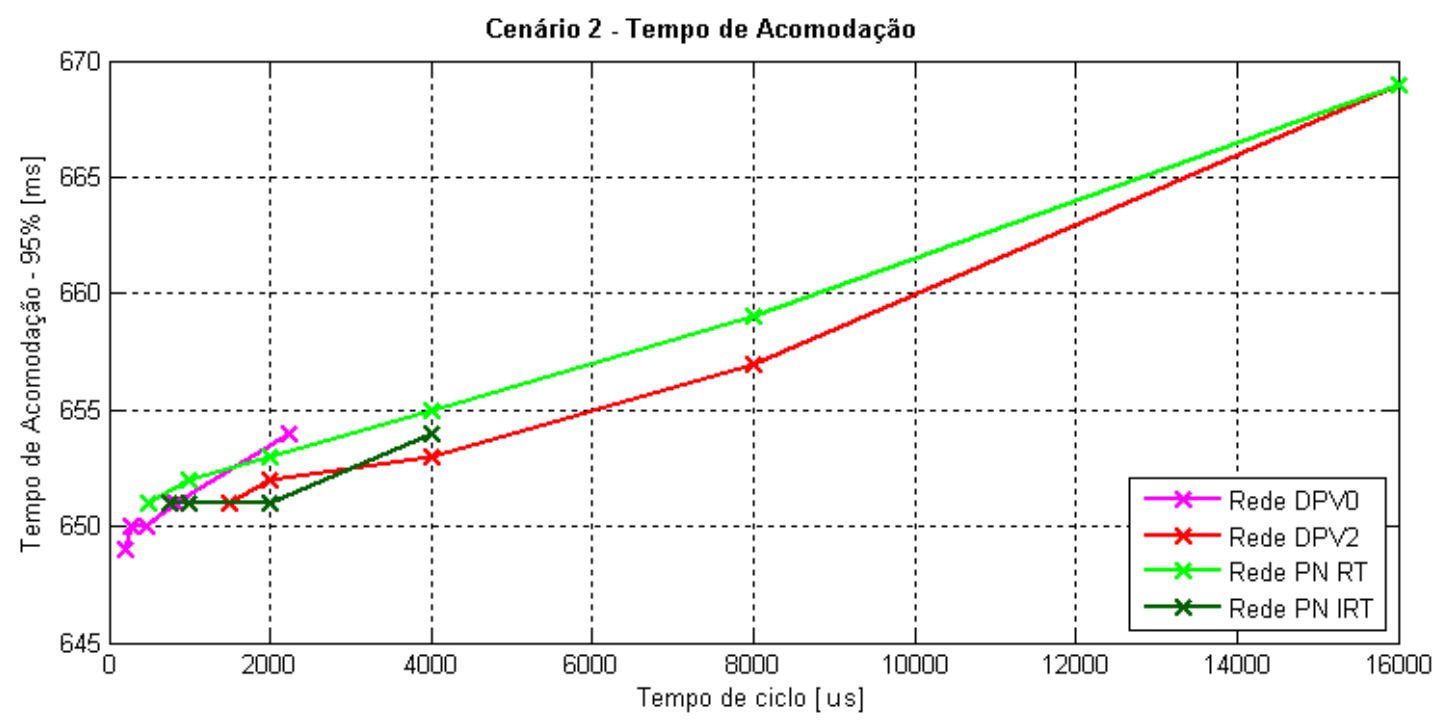

Figura 44 - Comparativo de tempo de acomodação para as tecnologias estudas no Cenário 2

Verifica-se uma variação muito pequena de desempenho para todas as tecnologias que alcançaram tempo de ciclo até $4 \mathrm{~ms}$, apresentando variação em torno de $1 \%$ em relação ao melhor desempenho obtido. Estes valores podem ser considerados desprezíveis, e concluí-se que ambas tecnologias poderiam ser utilizadas nas condições do experimento implementado, que é o posicionamento de motores trifásicos simples. 


\section{CONCLUSÕES FINAIS}

Através da análise bibliográfica sobre CCMi, verifica-se a importância da utilização de redes de comunicação industrial para integração de acionamentos de motores elétricos trifásicos ao sistema de automação, mostrando os benefícios de sua aplicação a nível de projeto, instalação, operação e manutenção.

Devido a tendência de introdução de tecnologias RTE em ambientes industriais torna-se importante a comparação desta tecnologia em relação as tecnologias fieldbus já consolidadas.

As conclusões descritas neste capítulo se baseiam especificamente neste tipo de aplicação, com os equipamentos utilizados nos experimentos, que foram escolhidos de maneira a representar o mais fielmente uma aplicação real. Assim, as conclusões não devem ser generalizadas às demais aplicações possíveis destas tecnologias, como comunicação a nível de supervisório, redes de instrumentação, entre outras.

No cenário onde as redes de comunicação em CCMi exigem grande número de acionamentos de motores, a rede Profinet mostrou possuir maior capacidade em relação a quantidade de dispositivos instalada, já que apresentou menores valores de ocupação de banda, mantendo valores baixos de tempo de ciclo, mesmo com o aumento do números de IO-Devices. Adicionalmente, o Profinet mostrou possuir determinismo suficiente para as necessidades, porém a rede Profibus DPVO com tempo de ciclo fixo apresentou melhor desempenho (exatidão e precisão no tempo de ciclo) em comparação a utilização de redes Profinet topologia estrela.

Complementarmente, deve-se pontuar algumas funcionalidades que 0 Profinet proporciona, como diagnóstico via Web Browser através de canais de comunicação que não exigem tempo real, podendo ser acessado facilmente sem necessidade de softwares de engenharia dedicado para cada equipamento de acionamento de motor; e também da possibilidade de utilização da mesma tecnologia e infraestrutura de rede para diferentes níveis na hierarquia de redes de comunicação em uma indústria, integrando desde os componentes em nível de campo, passando pelo nível de controle e produção chegando até a níveis de gerenciamento de produção. 
Para aplicação de motion control simples, comuns em indústria de manufatura, a tecnologia Profibus DPV0 alcançou menores valores de tempos de ciclo, principalmente por ter sido utilizado apenas um escravo na rede, porém apresentou valores altos de desvio padrão do tempo de ciclo, o que mostra ser menos determinística quando comparada com DPV2 e ambas versões do Profinet.

Estas características prejudicariam uma aplicação de motion control com sincronismo de eixos, por exemplo. Por outro lado, a rede Profinet IRT apesar de ter alcançado tempo de ciclo superior a DPV0, foi a mais determinística já que apresentou os menores valores de jitter, precisão e exatidão no tempo de ciclo.

Apesar destes diferentes resultados em indicadores de desempenho de rede, ambas tecnologias e suas respectivas versões alcançaram desempenho muito similares em relação ao tempo de acomodação do sistema de controle, para tempos de ciclo de até $4 \mathrm{~ms}$. Conclui-se que os desvios apresentados dos indicadores de desempenho do ponto de vista da rede podem ser considerados desprezíveis em relação as inércias presentes do sistema mecânico, para a aplicação estudada de controle de posição de um motor elétrico.

Cria-se um método de engenharia para análise de redes através de análise de dados offline, e também contribui para suportar usuários das tecnologias na tomada de decisões para definição da mais indicada para suas necessidades.

\subsection{Trabalhos Futuros}

Para continuidade desta linha de pesquisa se propõem estudos adicionais de redes de comunicação sendo utilizadas na integração de acionamentos de motores elétricos trifásicos ao sistema de automação. Alguns trabalhos sugeridos são:

- utilização de topologia Profinet em anel, utilizando maior número de dispositivos na rede, switches gerenciáveis e não-gerenciáveis em cascata, e introdução adicional de dados non Real Time; 
- comparação de diferentes protocolos de redes RTE, considerando além da tecnologia Profinet, outros protocolos como o Ethernet/IP, ModbusTCP, EtherCAT entre outros;

- análise de desempenho de redes de comunicação em aplicações de motion control com sincronismo de múltiplos eixos utilizando versão DPV2 e Profinet IRT;

Estes estudos poderão contribuir para análise destas redes do ponto de vista científico, e agregar informação aos usuários da tecnologia na escolha da opção mais indicada de acordo com suas necessidades. 


\section{REFERÊNCIAS BIBLIOGRÁFICAS}

AGUIAR, M. L. Modelos dinâmicos de máquinas elétricas. São Carlos: USP: 2012. cap. 2a, p. 1. Notas de aula, SEL 5738.

ASSOCIAÇÃO BRASILEIRA DE NORMAS TÉCNICAS. NBR IEC 60947-4-2: Dispositivos de manobra e comando de baixa tensão: Parte 4-2: Contatores e partida de motores - Controladores de partida de motores c.a. a semicondutores. Rio de Janeiro, 2011. 98 p.

BENZI, F.; BUJA, G. S.; FELSER, M. Communication Architectures for Electrical Drives. IEEE Transactions on Industrial Informatics, v.1, n. 1, p. 47-53, 2005.

DEPARI, A. et al. A New instrument for real-time ethernet performance measurement. IEEE Transactions on Instrumentation and Measurement, $v$. 57 , n. 1, p. 121-127, 2008.

DIAS, A. L.; BRANDÃO, D. Funcionalidades da integração de acionamentos elétricos ao sistema de automação. In: SIMPÓSIO BRASILEIRO DE AUTOMAÇÃO INTELIGENTE, 10., 2011, São João del-Rei. Anais.... São João del-Rei: SBAI, 2011. p. 1370-1375.

DOLEJS, O.; SMOLIK, P.; HANZALEK, Z. On the Ethernet use for real-time publish-subscribe based applications. In: IEEE INTERNATIONAL WORKSHOP ON FACTORY COMMUNICATION SYSTEMS, 5., 2004, Vienna. Proceedings... Piscataway: IEEE Operations Center, 2004. p. 39-44.

DOMINGUEZ-JAIMES, I.; WISNIEWSKI, L.; TRSEK, H. Identification of traffic flows in Ethernet-based industrial fieldbuses. In: EMERGING TECHNOLOGIES AND FACTORY AUTOMATION, 2010, Bilbao. Proceedings... Piscataway: IEEE, 2010. p.1-4.

EMPRESA DE PESQUISA ENERGÉTICA (EPE). Balanço energético nacional 2014: ano base 2013. Rio de Janeiro: EPE, 2014.

FALDELLA, E.; TUCCI, P. A Model-driven approach to automated diagnosis of industrial distributed $1 / O$ systems based on fieldbus technologies. In: INTERNATIONAL SYMPOSIUM ON INFORMATION, COMMUNICATION AND AUTOMATION TECHNOLOGIES, 22., 2009, Bosnia. Proceedings... Bosnia: IEEE, 2009. p 1-7.

FELSER, M. Real-time Ethernet-industry prospective. Proceedings of the IEEE, v. 93, n. 6, p. 1118-1129, 2005.

FERRARI, P. et al. Experimental analysis to estimate jitter in PROFINET IO Class 1 networks. In: EMERGING TECHNOLOGIES AND FACTORY AUTOMATION, 6., 2006, Prague. Proceedings... New York: IEEE, 2006. p. 429-432. 
FERRARI, P. et al. A Distributed instrument for performance analysis of realtime Ethernet networks. IEEE Transactions on Industrial Informatics, v. 4, n. 1, p. 16-25, 2008.

. et al. New simulation models to evaluate performance of PROFINET IO class 1 systems. In: IEEE INTERNATIONAL CONFERENCE ON INDUSTRIAL INFORMATICS, 5., 2007, Vienna. Proceedings... Piscataway: IEEE Service Center, 2007a. v. 1, p. 237-242.

. et al. Evaluation of timing characteristics of a prototype system based on PROFINET IO RT Class 3. In: IEEE CONFERENCE ON EMERGING TECHNOLOGIES AND FACTORY AUTOMATION, 12., 2007, Patras. Proceedings... Piscataway: IEEE Service Center, 2007b. p. 1254-1261.

. et al. Large PROFINET IO RT networks for factory automation: a case study. In: CONFERENCE ON EMERGING TECHNOLOGIES AND FACTORY AUTOMATION, 17., 2011, Toulouse. Proceedings... New York: IEEE, 2011. p. $1-4$.

et al. Mixing real time Ethernet traffic on the IEC 61850 process bus. In: IEEE INTERNATIONAL WORKSHOP ON FACTORY COMMUNICATION SYSTEMS, 9., 2012, Lemgo. Piscataway: IEEE, 2012. p. 153-156.

FRANCHI, C. M. Acionamentos elétricos. 4. ed. São Paulo: Érica, 2008. $250 p$.

FRANKLIN, G. F. Feedback control of dynamic systems. 4th ed. New Jersey: Prentice Hall, 2002. 877p.

GIORGETTI, A. et al. Performance analysis of media redundancy protocol (MRP). IEEE Transactions on Industrial Informatics, v. 9, n. 1, p. 218-227, 2013.

GOH, H. H.; LOOI , M. S.; KOK, B. C. Comparison between direct-on-line, stardelta and auto-transformer induction motor starting method in terms of power quality. In: INTERNATIONAL MULTICONFERENCE OF ENGINEERS AND COMPUTER SCIENTISTS, 2009, Hong Kong. Proceedings... Hong Kong: [s.n.], 2009. v. 2, p.1558-1563.

IMS RESEARCH. The EMEA market for industrial Ethernet. 2011.

INTERNATIONAL ELECTROTECHNICAL COMMISSION. IEC 61784-2 Ed. 2.0: industrial communication networks - profiles - part 2: additional fieldbus profiles for real-timenetworks based on ISO/IEC 8802-3. Geneva: IEC, 2010.

INSTITUTO NACIONAL DE METROLOGIA, QUALIDADE E TECNOLOGIA. Vocabulário internacional de metrologia: conceitos fundamentais e gerais $\mathrm{e}$ termos associados (VIM 2012). Rio de Janeiro: INMETRO, 2012 
INTERNATIONAL TELECOMMUNICATION UNION. General aspects of digital transmission systems - vocabulary of digital transmisison and multiplexing, and pulse code modulation (PCM) terms. Geneva: ITU-T, 1993.

JASPERNEITE, J.; SCHUMACHER, M.; WEBER, K. Limits of increasing the performance of industrial Ethernet protocols. In: IEEE CONFERENCE ON EMERGING TECHNOLOGIES AND FACTORY AUTOMATION, 12., 2007, Patras. Proceedings... Piscataway: IEEE Service Center, 2007. p. 17-24.

KLEINES, $\mathrm{H}$. et al. Performance aspects of PROFINET IO. IEEE Transactions on Nuclear Science, v. 55, n. 1, 2008.

LIU, Q.; LI, Y. Modbus/TCP based network control system for water process in the firepower plant. In: WORLD CONGRESS ON INTELLIGENT CONTROL AND AUTOMATION, 6., 2006, Dalian. Proceedings... Piscataway: IEEE, 2006. p. $432-435$.

MARSAL, G. et al. Evaluation of response time in Ethernet-based automation systems. In: EMERGING TECHNOLOGIES AND FACTORY AUTOMATION, 6. Prague. Proceedings... New York: IEEE, 2006. p. 380-387.

MOSSIN, E. A. Diagnóstico automático de redes Profibus. 2012. 219 f. Tese (Doutorado em Engenharia Elétrica) - Escola de Engenharia de São Carlos, Universidade de São Paulo, São Carlos, 2012.

POPP, M. Industrial communication with PROFINET. Karlsruhe: PROFIBUS Nutzerorganisation e.V., 2007.

PROFIBUS. Profibus basic slide set: technology, life cycle, management, organization/support, case studies. Karlsruhe: Profibus International, 2013.

PROFIBUS. Profibus system description: technology and application. Karlsruhe: PROFIBUS Nutzerorganisation e.V., 2010.

PROFINET design guideline. Karlsruhe: Profibus International, 2010

PROFINET System Description - Technology and Application. Karlsruhe: PROFIBUS Nutzerorganisation e.V. PNO, 2011.

PRYTZ, G. A performance analysis of EtherCAT and PROFINET IRT. IEEE INTERNATIONAL CONFERENCE ON EMERGING TECHNOLOGIES AND FACTORY AUTOMATION, 13., 2008, Hamburg. Proceedings... Piscataway; IEEE, 2008. p. 408-415.

SCHUMACHER, M.; WEBER, K. A New approach for increasing the performance of the industrial Ethernet system PROFINET. IEEE INTERNATIONAL WORKSHOP ON FACTORY COMMUNICATION SYSTEMS, 7., 2008, Dresden. Proceedings... Piscataway: IEEE, 2008. p. 159-167. 
SESTITO, G. S. et al. Análise comparativa de redes Profibus e Profinet. In: CONGRESSO INTERNACIONAL E EXPOSIÇÃO DE AUTOMAÇÃO, SISTEMAS E INSTRUMENTAÇÃO, 17., 2013, São Paulo. Anais... São Paulo: ISA, 2013.

SHAIKH, M. Optimizing energy consump-tion and improving operational efficiency through the use of smart MCCs in process automation systems. Alpharetta: Siemens Energy \& Automation, 2006.

SIEMENS. SIMATIC PDM - the process device manager. Nürnberg: Siemens, 2008. Technical brochure.

SIEMENS LTDA. Módulo 3S - Coordenação de Partidas de Motores Elétricos. São Paulo: Siemens Ltda: 2003. Seminários Técnicos 2003 - Engenheiros e Projetistas.

SOLVESON; M.G.; MIRAFZAL, B; DEMERDASH, N.A.O. Soft-Started Induction Motor Modeling and Heating Issues for Different Starting Profiles Using a Flux Linkage $A B C$ Frame of Reference. IEEE Transactions On Industry Applications, v. 42, n. 4, p. 973-982, 2006.

THOMESSE, J. P. Fieldbus technology in industrial automation. Proceedings of the IEEE, v. 93, n. 6, p. 1073-1101, 2005.

TORRES, R. V. Simulador de redes Profibus. 2013. 106 f. Dissertação (Mestrado em Engenharia Elétrica) - Escola de Engenharia de São Carlos, Universidade de São Paulo, São Carlos, 2013.

WARREN, J. C. Ethernet/IP applications for electrical industrial systems. IEEE INDUSTRY APPLICATIONS SOCIETY ANNUAL MEETING, 2009, Houston. Proceedings... Piscataway: IEEE, 2009. p. 1-5.

WEG Equipamentos Elétricos S.A. Motores Elétricos. Jaraguá do Sul: WEG: 2009 .

$\mathrm{YU}, \mathrm{P}$ et al. Design and implementation of Profibus-DP intelligent slave station controller. In: INTERNATIONAL CONFERENCE ON INSTRUMENTATION, MEASUREMENT, COMPUTER, COMMUNICATION AND CONTROL, 2., 2012, Harbin. Proceedings... Piscataway:IEEE, 2012. p. 133-138. 


\section{APÊNDICE A - CONFIGURAÇÃO DO CLP VIA STEP7}

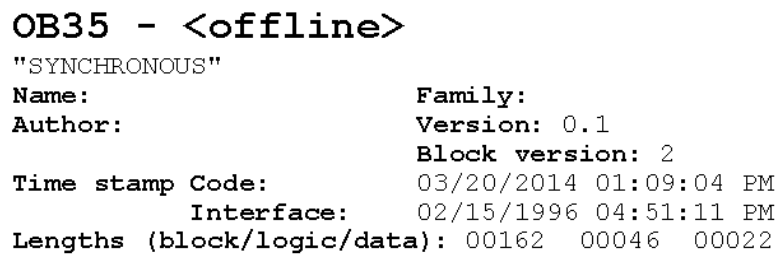

\begin{tabular}{|c|l|l|l|}
\hline Name & Data Type & Address & Comment \\
\hline TEMP & & 0.0 & \\
\hline OB35_EV_CLASS & Byte & 0.0 & $\begin{array}{l}\text { Bits 0-3 } \\
=1 \text { (Event class 1) }\end{array}$ \\
\hline OB35_STRT_INF & Byte & 1.0 & $16 \# 36$ (OB 35 has started) \\
\hline OB35_PRIORITY & Byte & 2.0 & Priority of OB Execution \\
\hline OB35_OB_NUMBR & Byte & 3.0 & 35 (Organization block 35, OB35) \\
\hline OB35_RESERVED_1 & Byte & 4.0 & Reserved for system \\
\hline OB35_RESERVED_2 & Byte & 5.0 & Reserved for system \\
\hline OB35_PHASE_OFFSET & Word & 6.0 & Phase offset (msec) \\
\hline OB35_RESERVED_3 & Int & 8.0 & Reserved for system \\
\hline OB35_EXC_EREQ & Int & 10.0 & Frequency of execution (msec) \\
\hline OB35_DATE_TIME & Date_And_Time & 12.0 & Date and time OB35 started \\
\hline
\end{tabular}

Block: OB35 "Cyclic Interrupt - 1ms"

\begin{tabular}{|l|l|}
\hline Network: 1 & Call FC100 \\
\hline Write set point for motion control \\
\hline
\end{tabular}

CALL "FC_AXIS_CTRL_STS" FC100

\begin{tabular}{|l|}
\hline Network: $2 \quad$ Call FC200 \\
\hline Read actual velocity of the motor \\
\hline
\end{tabular}

CALL "FC_READ_ACT_VELOCITY" FC200

\begin{tabular}{|l|}
\hline Network: $3 \quad$ Call FC300 \\
\hline Read actual position of the motor \\
\hline
\end{tabular}

CALL "FC_READ_ACT_POSITION" FC300 
FC100 - <offline>

"FC_AXIS_CTRL_STS"

Name:

Family:

Author:

Version: 0.1

Time stamp Code: 03/20/2014 11:32:32 AI

Block version: 2

Interface: 03/19/2014 08:29:40 PM

Lengths (block/logic/data): 002500015400014

\begin{tabular}{|l|l|l|l|}
\hline Name & Data Type & Address & Comment \\
\hline IN & 0.0 & \\
\hline OUT & 0.0 & \\
\hline IN_OUT & 0.0 & \\
\hline TEMP & 0.0 & \\
\hline RETURN & 0.0 & \\
\hline RET_VAL & 0.0 & \\
\hline
\end{tabular}

Block: FC100

Network: 1 Read drive status data

CALL "DPRD_DAT"

LADDR $:=W \# 16 \# 100$

SFC14 -- Read Consistent Data

RET VAL: $=$ MW10

RECORD: :="DB_AXIS_CTRL_STS_WORD". STATUS P\#DB100.DBX24.0

NOP $O$

Network: 2 Copy start movement from control word to digital output

Task $\quad$ "DB_AXIS_CTRL_STS_WORD".CONTROL.STW1.ActivateTraversing
$=\quad \mathrm{Q} \quad 0.0$

Network: 3 Write drive control data

CALL "DPWR_DAT"

LADDR $:=$ W\# $16 \# 100$

RECORD :="DB_AXIS_CTRL_STS_WORD".CONTROL P\#DB100.DBX0.0

RET_VAL: $=$ MW $2 \overline{0}$

NOP -0

SFC15

- Write Consistent Da

ta to a standard DP Slave 


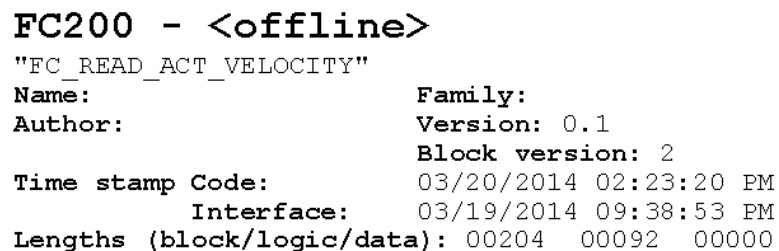

\begin{tabular}{|l|l|l|l|}
\hline Name & Data Type & Address & Comment \\
\hline IN & 0.0 & \\
\hline OUT & 0.0 & \\
\hline IN_OUT & 0.0 & \\
\hline TEMP & 0.0 & \\
\hline RETURN & 0.0 & \\
\hline RET_VAL & 0.0 & \\
\hline
\end{tabular}

Network: $1 \quad$ Reset actual DB position when starts movement

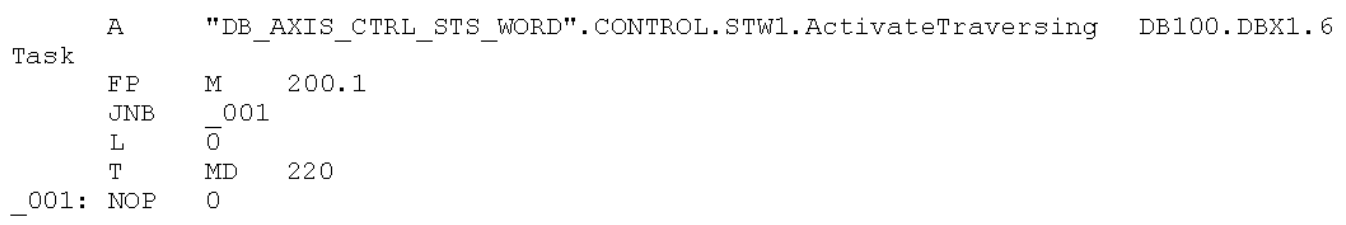


Network: $4 \quad$ Load M value and transfer to the desired DB postion

$\left.\begin{array}{lll}\text { L } & \text { MW } & 210 \\ \text { T } & \text { DBW } & {[M D} \\ & 22\end{array}\right]$

Network: 5 Increment DB poisition

A "DB_AXIS_CTRL_STS_WORD".CONTROL.STW1.ActivateTraversing DB100.DBX1.6

Task A $\quad$ M 200.0

JNB 003

L $\quad \bar{L} \# 16$

L $\quad$ MD 220

T MD 220

_-003: NOP 0

Network: 6 Compare the actual DB position to maximum DB position

2000 WORD $=32000$ bits

L MD 220

L L\#31984

$\begin{array}{lll}<=D & & \\ = & \text { M } & 200.0\end{array}$ 


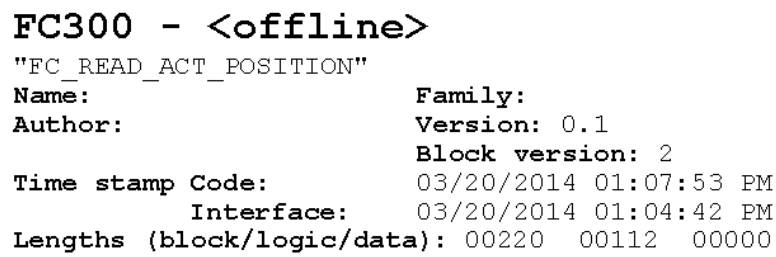

\begin{tabular}{|l|l|l|l|}
\hline Name & Data Type & Address & Comment \\
\hline IN & 0.0 & \\
\hline OUT & 0.0 & \\
\hline IN_OUT & 0.0 & \\
\hline TEMP & 0.0 & \\
\hline RETURN & 0.0 & \\
\hline RET_VAL & 0.0 & \\
\hline
\end{tabular}

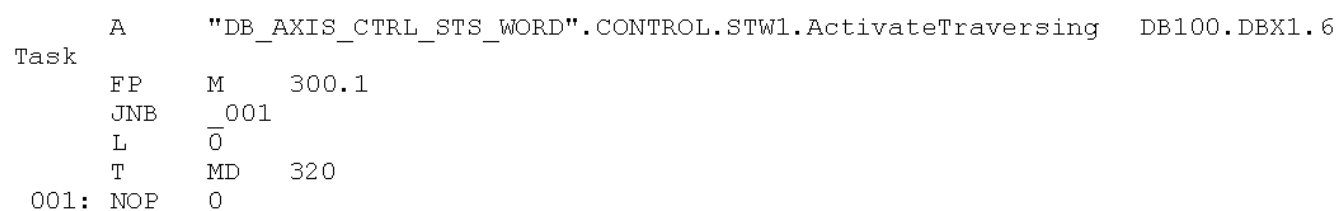

OPN "DB_ACTUAL_POSITION" DB 300 


\begin{tabular}{cll|}
\hline Network: & 4 & Load M value and transfer to the desired DB postion \\
L & MD & 310 \\
T & DBD & {$[$ MD 320$]$} \\
& \\
Network: & 5 & Increment DB poisition \\
\hline
\end{tabular}

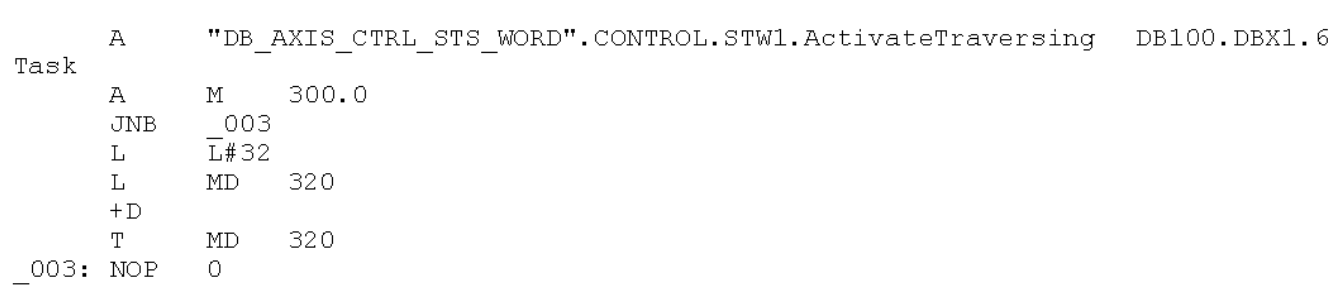

